\title{
A Topic Modeling Approach to Categorizing API Customer Value Propositions
}

\author{
by
}

Mohamed Amin

A thesis submitted to the Faculty of Graduate and Postdoctoral Affairs in partial fulfillment of the requirements for the degree of

Master of Applied Science

in

Technology Innovation Management

Carleton University

Ottawa, Ontario

Copyright (C 2016, Mohamed Amin 


\section{Abstract}

Companies increasingly use Application Programming Interfaces (APIs) to create new value propositions in the digital world. However, there is little knowledge about the type of value propositions that public APIs enable companies to provide. Thus, this study analyzes data from 13,829 API descriptions published in programmableweb.com to: (i) identify and categorize current and emerging API customer value propositions, (ii) analyze the evolution of API customer value propositions, and (iii) showcase Topic Modeling as a feasible technique to study API customer value propositions. This research contributes towards API service systems research by: (i) identifying six categories of API customer value propositions, and (ii) revealing a long tail distribution of API customer value propositions that is flattening. 


\section{Acknowledgements}

I would like to start by thanking my Supervisor, Professor Mika Westerlund, for his guidance, tolerance, and open mind for new ideas and methods. I would also like to thank the TIM faculty: Professor Tony Bailetti, for teaching me what a Customer Value Proposition in the real world means, Professor Michael Weiss, for giving me the fundamental idea behind this research, and Professor Steven Muegge, for teaching me meticulousness in research and writing. Although I may have not met their standards yet, I know I am headed in the right direction.

I would like to thank my parents for their support and encouragement throughout my TIM journey and their willingness to do everything to help me complete this degree. I would also like to thank my in-laws for the numerous times they had to babysit my kids as my wife and I are engulfed in grad school.

Super special thanks, appreciation and love to my wife, Maha, for everything she did to help me complete this degree. This includes, but by no means limited to: taking full care of every aspect of the house, bearing the number of nights I did not make it home for dinner, patiently responding to my complaints about research methods, and literature reviews, her unconditional support, and most importantly for saying "NO" every single time I mentioned I am going to quit the program. 


\section{Table of Contents}

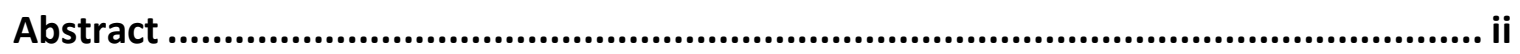

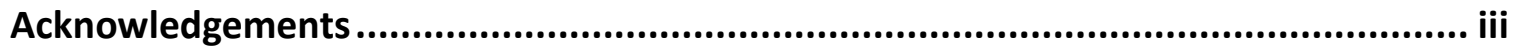

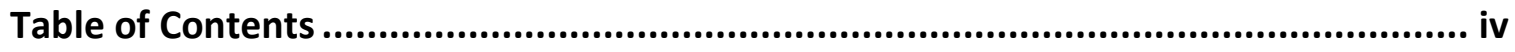

List of figures........................................................................................... vii

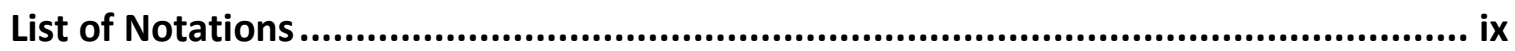

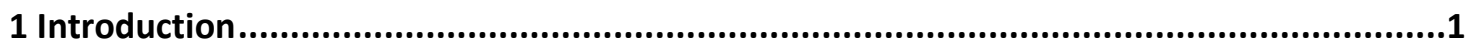

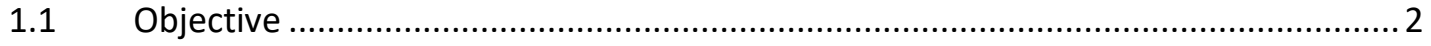

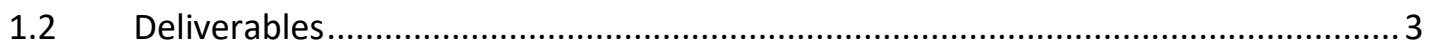

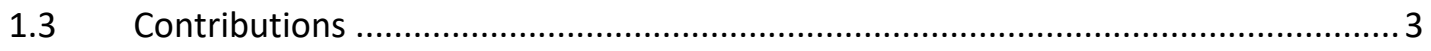

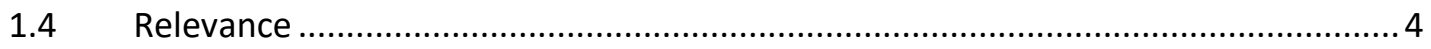

1.5 Overview of the method and expected results.................................................. 4

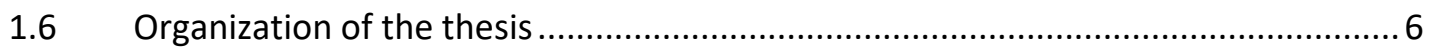

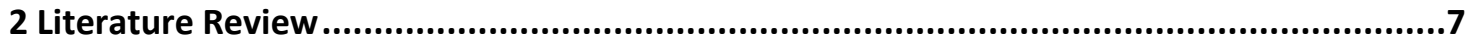

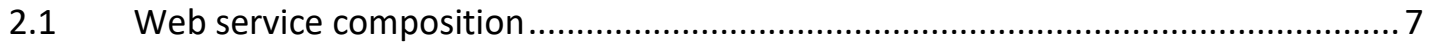

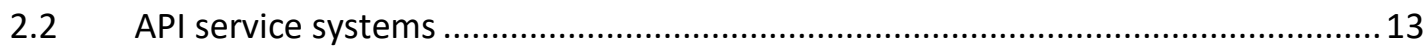

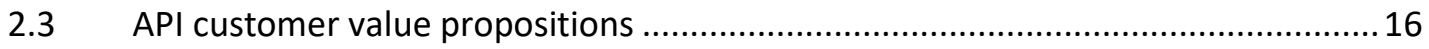

2.4 Summary and synthesis of key findings from the literature ...................................19

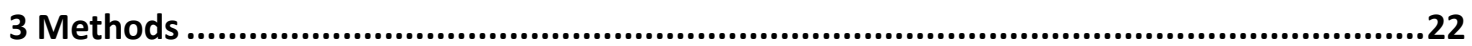

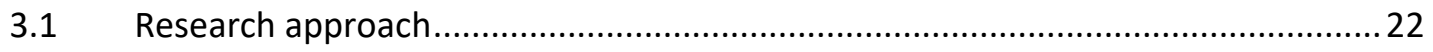

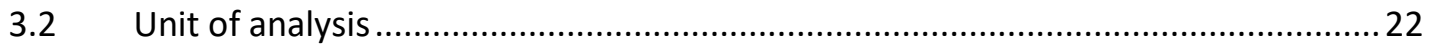

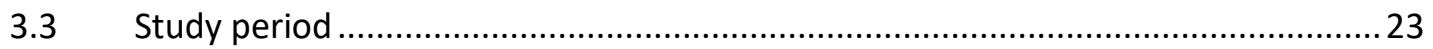




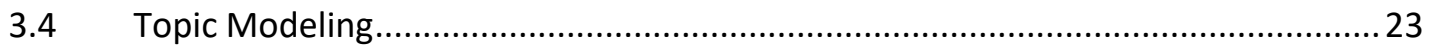

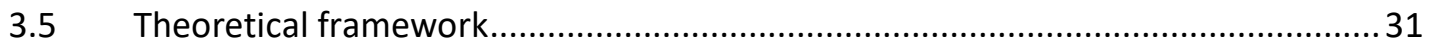

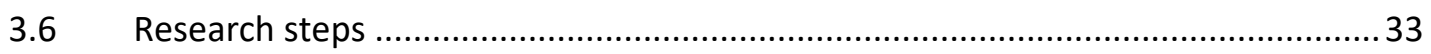

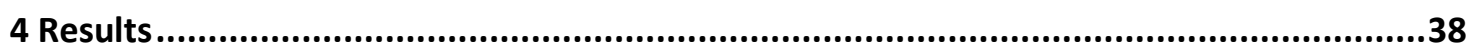

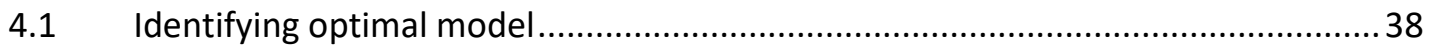

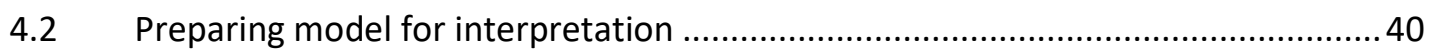

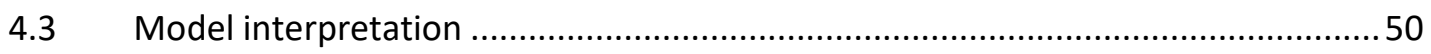

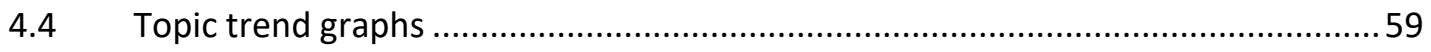

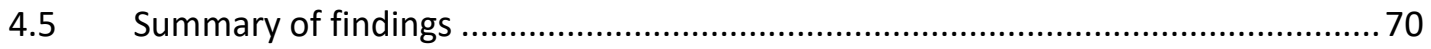

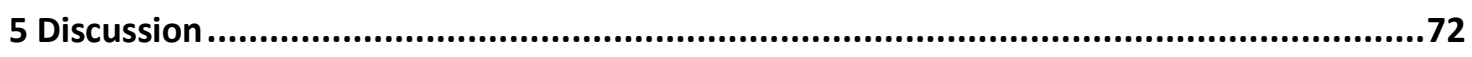

5.1 Categorization Model of Customer Value Propositions in the API Service system .72

$5.2 \quad$ The long tail of customer value propositions...................................................... 77

5.3 Connecting supply and demand in the API economy ....................................... 79

5.4 API service systems from aggregators to filters ............................................... 80

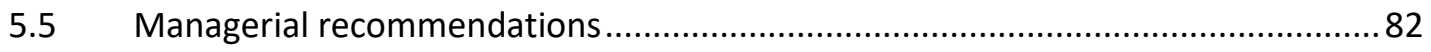

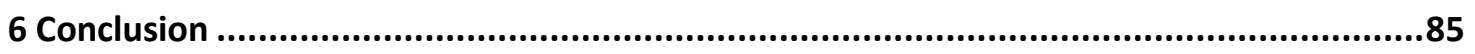

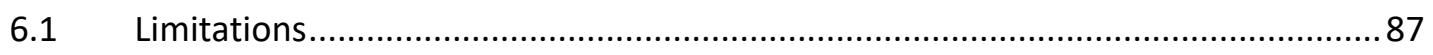

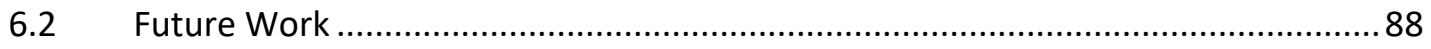

7 References

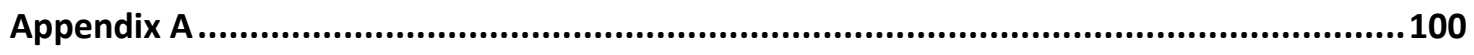

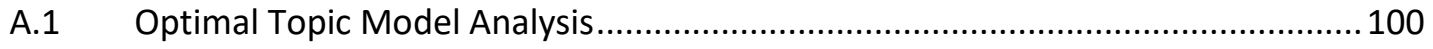

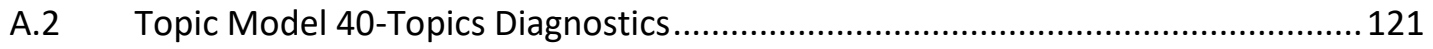

A.3 Sample from output-doc-topic file for 40-topics .............................................. 122

A.4 Example API description documents for each topic ........................................124 


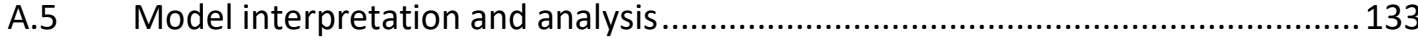




\section{List of figures}

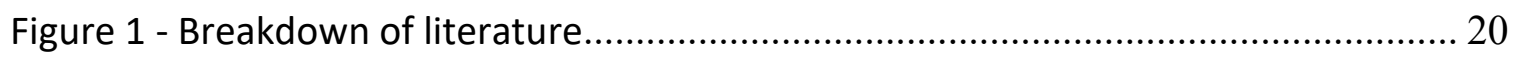

Figure 2 - An example of API description from programmableweb.com ....................... 22

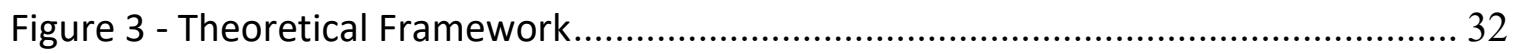

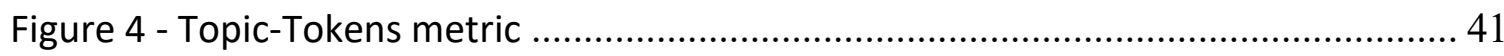

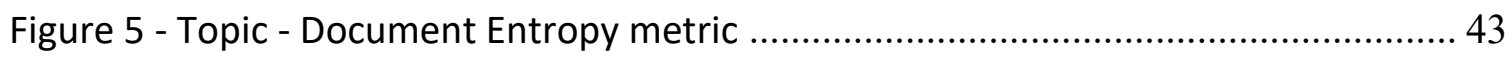

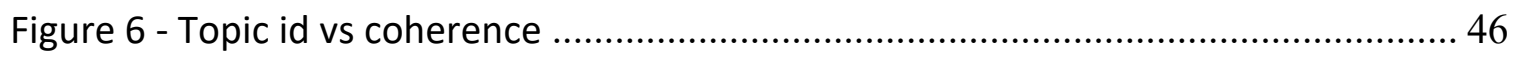

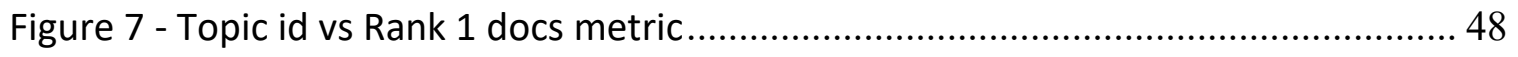

Figure 8 - Aggregate topic trend graphs for all categories ..................................... 60

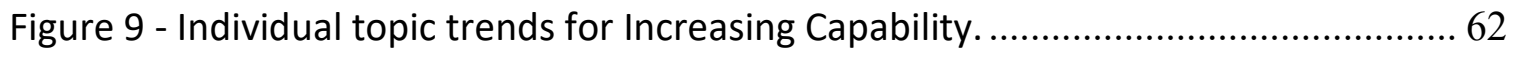

Figure 10 - Individual topic trend graphs for Increasing Information Resources............ 63

Figure 11 - Individual topic trends for Personalization and Interoperability. ................. 64

Figure 12 - Individual topic trend graphs for Linking Services and Linking Data ............. 65

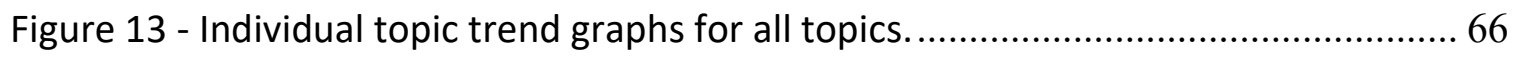

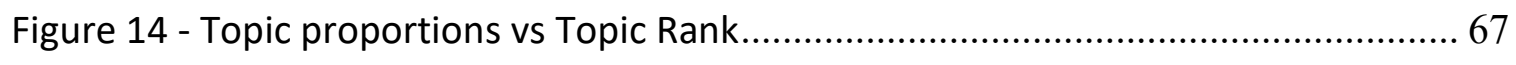

Figure 15 - Customer value propositions categorization model ................................. 73 


\section{List of tables}

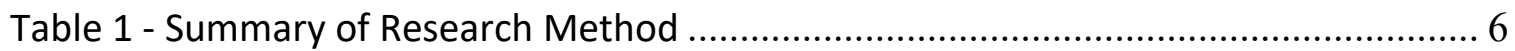

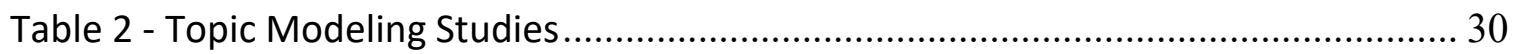

Table 3 - Topic Modeling implementations ............................................................ 31

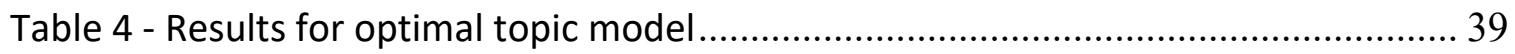

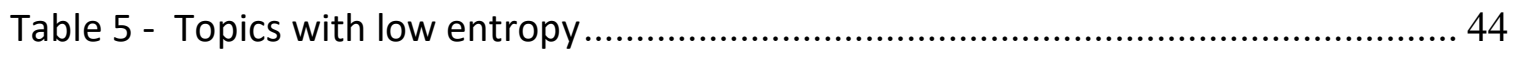

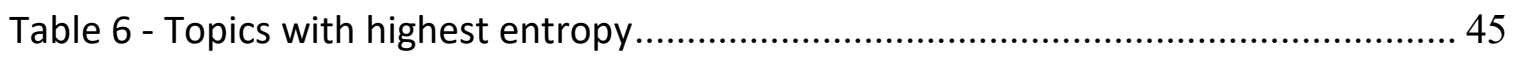

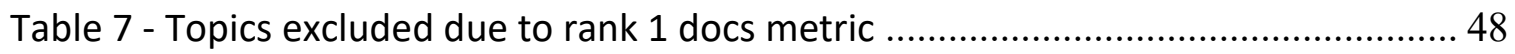

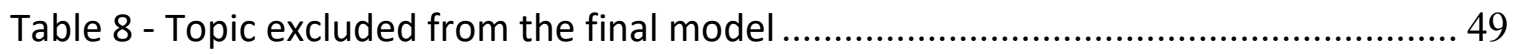

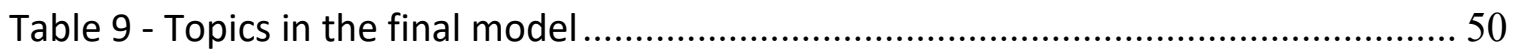

Table 10 - Model interpretation and categorization summary ................................... 59

Table 11 - Topic categories vs topic proportions in the long tail curve of June $2009 \ldots . . .69$

Table 12 - Topic categories vs topic proportions in the long tail curve of Jan 2016 ....... 70 


\section{List of Notations}

\begin{tabular}{|c|c|}
\hline API & Application Programming Interface \\
\hline CTM & Correlated Topic Models \\
\hline DTM & Dynamic Topic Models \\
\hline HTTP & Hyper Text Transfer Protocol \\
\hline JSON & JavaScript Object Notation \\
\hline LDA & Latent Dirichlet Allocation \\
\hline LSA & Latent Semantic Analysis \\
\hline LSI & Latent Semantic Indexing \\
\hline PLSA & Probabilistic Latent Semantic Analysis \\
\hline PLSI & Probabilistic Latent Semantic Indexing \\
\hline RAML & RESTful API Modeling Language \\
\hline RDF & Resource Description Framework \\
\hline REST & Representational State Transfer \\
\hline RPC & Remote Procedural Call \\
\hline RSS & Rich Site Summary \\
\hline RTM & Relational Topic Models \\
\hline sLDA & Supervised Latent Dirich \\
\hline
\end{tabular}


SOAP Simple Object Access Protocol

URL Uniform Resource Locator

WADL Web Application Description Language

WSDL Web Service Definition Language

XML Extensible Markup Language 


\section{Introduction}

API service systems are collections of APIs - technical interfaces that provide programmatic access to a company's data or service - whose combination and procurement by API consumers result in novel applications such as Mashups (Barros \& Dumas, 2006). Directories such as programmableweb.com represent service systems by aggregating, presenting, and allowing the discovery of collections of APIs and Mashups. Today, programmableweb.com is the largest repository of APIs and reports having 15,816 APIs in its directory. This research uses API service systems and programmableweb.com interchangeably.

The study of the API service systems is of high value (Lyu et al., 2014). Several studies have taken an empirical look at API service systems, in particular programmableweb.com, using network science techniques (Endres-Niggemeyer, 2013; Huang et al., 2012; Lyu et al., 2014; Yu \& Woodard, 2008; Weiss \& Gangadharan, 2010; Wiess \& Sari, 2010; Weiss et al., 2013; Rosenblum, 2011). These studies use the links between Mashups and APIs as a focal point for their study.

In 2010, the number of Mashups was reported to be 5,028 and the number of APIs was reported to be 2,084 (Weiss \& Sari, 2010). In 2016, the number of Mashups reported by programmableweb.com is 7,827 , and the number of APIs reported is 15,816 . These numbers show that while Mashup listings have seen a slow growth over the past six years, API listings have skyrocketed indicating that APIs are still ripe for exponential growth. This calls for the need of using different techniques and methods to study APIs to reveal new insights. 
Researchers are urged to use practical approaches to solve real-life problems in the API economy (Tan et al., 2016). One practical problem that API service providers frequently face is figuring out how to create and communicate value using their APIs (Woods et al., 2011). Thus, customer value propositions are an important aspect of a company's API strategy, and little is known about this area.

Customer value propositions can be conceptualized as a communication practice (Ballantyne et al., 2011). In programmableweb.com, API providers use API descriptions to communicate customer value propositions to potential API consumers. By analyzing API descriptions, API customer value propositions can be identified and categorized.

This study uses Topic Modeling as a text mining technique to study how API providers present their customer value propositions to API consumers in programmableweb.com. Topic Modeling has emerged as a strong natural language processing technique for characterizing "topics" in a large corpus of text (Blei, 2012). By applying Topic Modeling to a dataset of API descriptions from programmableweb.com, we can empirically identify and categorize API provider's representation of customer value propositions and how these representations evolved over time revealing new insights and managerial implications.

\subsection{Objective}

The objective of this research is to apply Topic Modeling on a corpus of API descriptions from programmableweb.com to identify and categorize API customer value propositions. 


\subsection{Deliverables}

This thesis has 5 deliverables.

- A categorization model of API customer value propositions.

- Topic trend graphs showing how topics evolved over the period from 2006 to 2016 revealing a long tail distribution that is flattening out.

- A showcase for using Topic Modeling to study API service systems.

- Recommendations for how API service providers, API service systems, and entrepreneurs can fill the industry gap.

\subsection{Contributions}

This research makes two types of contributions, contributions to the general body of scholarship and contributions to practice.

\subsubsection{Contributions to scholarship}

This research contributes towards scholarly knowledge by:

- Applying Topic Modeling as a research approach to studying service systems.

- Serving as a basis for further developing customer value propositions research in service systems by creating value maps and value networks.

- Revealing insights about the evolution of customer value propositions in service systems.

\subsubsection{Contributions to practice}

This research contributes towards practice by: 
- The identification of an industry gap, where API service systems are falling short from acting as filters to connect demand and supply in the API economy.

- Allowing API service providers to categorize their APIs based on the new categorization model.

\subsection{Relevance}

The deliverables of this research would:

- Allow entrepreneurs and existing API providers to differentiate themselves by better articulating their customer value propositions

- Provide API service systems with a tool that allows them to study how value is created in their service systems and where the gaps are

- Provide API service systems with guidance as to how they can become filters closing the gap between supply and demand in the API service system.

- Provide researchers with an example of how Topic Modeling can be applied to study service systems.

\subsection{Overview of the method and expected results}

This is an inductive theory building research where descriptive theory is the ultimate goal of the study (Carlile \& Christensen, 2004). Table 1 summarizes the steps taken during this study.

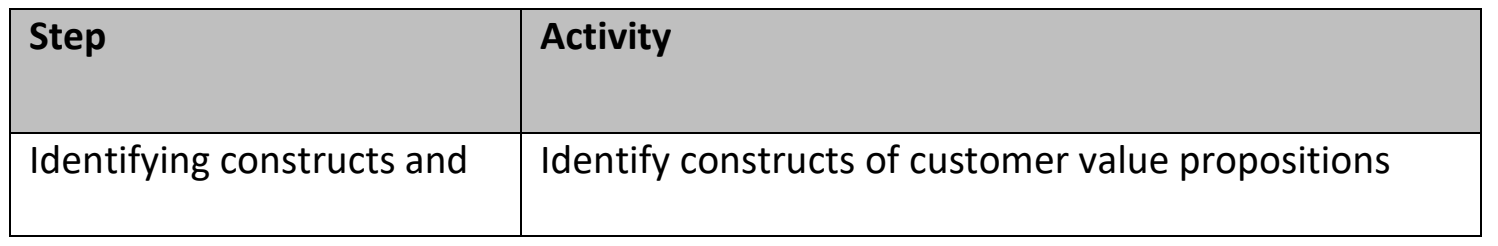




\begin{tabular}{|c|c|}
\hline theoretical framework & and build a theoretical framework for data analysis \\
\hline Data collection & $\begin{array}{l}\text { Obtain descriptions of } 13,829 \text { APIs from } \\
\text { www.programmableweb.com }\end{array}$ \\
\hline Data preprocessing & $\begin{array}{l}\text { Preprocessing data to prepare it for topic modeling by } \\
\text { removing stop words and importing into Mallet (Topic } \\
\text { Modeling and Mallet will be discussed in detail in } \\
\text { chapter 3) }\end{array}$ \\
\hline Topic Model training & $\begin{array}{l}\text { Use Mallet's Latent Dirichlet Allocation (LDA) } \\
\text { algorithm to train different Topic Models while } \\
\text { increasing the number of topics in every training }\end{array}$ \\
\hline Evaluation of models & $\begin{array}{l}\text { Evaluate the trained models based on a set of criteria } \\
\text { to find the model with the optimal number of topics } \\
\text { for this study. }\end{array}$ \\
\hline Interpretation of results & Interpret results in light of identified constructs \\
\hline Categorization & $\begin{array}{l}\text { Categorize the results based on the initial theoretical } \\
\text { framework. Produce the final categorization model. }\end{array}$ \\
\hline Topic Trend Analysis & $\begin{array}{l}\text { Produce topic trend graphs showing the evolution of } \\
\text { topic representations over the period from June } 2005 \\
\text { to July } 2016\end{array}$ \\
\hline
\end{tabular}




\begin{tabular}{|l|l|}
\hline Categorization Model and & Produce final categorization model and statements of \\
Statements of Association & association by comparing with extant literature. \\
\hline
\end{tabular}

\section{Table 1 - Summary of Research Method}

\subsection{Organization of the thesis}

This research is organized into six chapters. After this introduction, chapter 2 reviews the literature streams: (i) Web service composition, (ii) API service systems, and (iii) API customer value propositions. Chapter 3 details the research method used. Chapter 4 provides the results and chapter 5 discusses the results of this research. Chapter 6 concludes the study and provides research limitations and suggestions for future research. 


\section{Literature Review}

The literature review is organized as three streams. The first stream covers web services composition. The second stream surveys API service systems. The third stream reviews API customer value propositions. This chapter concludes with a summary and synthesis of the lessons pertinent to this research.

\subsection{Web service composition}

Service composition is the process of building new applications and services (composites) out of existing web services (Singh, 2001). Its philosophy of black box integration made web service composition the most prominent way for B2B integration (Garriga et al., 2016). Service composition literature can be organized to answer three questions:

- What is composed? Literature in this category describe the types of components that are being composed by web services, the interaction protocols that web services use, the description languages of the components and the format of data exchange, and finally the target applications or the final product of the composition.

- How is it composed? Literature in this category describe the process of service selection, service discovery, and service recommendation.

- Who is performing the composition? Literature in this category describe the types of developers that perform the composition.

In the following, the present study discusses each of these areas in more detail. 


\subsubsection{What is composed?}

\subsubsection{Component types}

The type of component used in the composition can be broken down into three categories: (i) Data component encapsulates a web resources using a certain format and a defined data structure; (ii) Application logic components provide business functionality such as checking stock availability or sending a text message; and (iii) User interface components are UI widgets such as login widgets, map widgets, and search widgets that require widget containers or engines to be instantiated (Lemos et al., 2015).

\subsubsection{Interaction protocols}

Components can be exposed in two ways: SOAP and REST. SOAP is an XML based protocol where information can be exchanged over HTTP or RPC (Box et al., 2000). REST is an architectural pattern that allows data to be represented as resources and accessed through dedicated URLs over HTTP (Fielding, 2000). REST is more a design philosophy based on navigational style while SOAP's design style is procedural. REST and SOAP are not necessarily opposite ways of doing the same thing, although debates in literature make them seem so (Muehlen et al., 2005). SOAP-based web services worked well inside enterprises while REST-based web services have taken momentum with Internetscale applications (Lanthaler \& Gutl, 2010). REST-based web services still face problems with formal description, discovery, and orchestration due to the lack of interface standards and universal service registries as in SOAP-based services (Lanthaler \& Gutl, 2010). 


\subsubsection{Description languages and data formats}

Components can be described in many different languages. The description languages are usually tied to interaction protocols. SOAP based web services can be described using Web Service Description Language (WSDL) (Christensen et al., 2001). REST based web services can be described in a variety of ways such as WADL (Hadley, 2006), RAML, and Swagger (Lemos et al., 2015). Data is exchanged between the service provider and the service consumer as JSON and RSS/Atom (Lemos et al., 2015). JSON is a text-based, human-readable, light weight data exchange format (Crockford, 2006). RSS (RSS Advisory Board, 2009) and Atom (Notingham \& Sayre, 2005) are mainly used for web feeds such as blog posts and online news (Lemos et al., 2015) and are supported by Mashup tools (Beletski, 2008).

\subsubsection{Target applications}

Service compositions provide value for three types of target applications: (i) Mashups are applications that are composed of multiple data sources, (ii) Business Process consists of a set of activities, functional roles, and relationships that achieve business goals by providing a business function, and (iii) Scientific Workflows are reusable experiments and data pipelines developed and used by the scientific communities (Lemos et al., 2015).

\subsubsection{How is the composition performed?}

Selection is the process by which a web service is discovered, identified and used based on the given composition requirements. Static composition is when selection takes 
place at design time when the developer is still building the composite service. Dynamic composition on the other hand involves selection happening at either deployment time when the composition is installed for execution or runtime when the composition is executed (Lemos et al., 2015).

Knowledge reuse is the underpinning nature of service composition. Reuse can be achieved by ways such as searching for and discovering an artifact based on a set of requirements, copying a composition from one repository or tool and pasting it into another, creating a replica of a composition by cloning it, and recommending artifacts that facilitate the composition process (Lemos et al., 2015).

Service discovery is one of the sub tasks of Service Oriented Architecture (Bachlechner et al., 2006). The lack of machine processable descriptions makes finding, understanding, and consuming web APIs a manually intensive process. (Maleshkova et al., 2010). Most of the web services discovery approaches are based on keyword search and category browsing with Google providing the best coverage and precision for finding web services (Bachlechner et al., 2006). Discovering and composing RESTful services requires a human manually searching through a web site such as Programmableweb.com that collects and categorizes these services (Lanthaler \& Gutl, 2010).

Deeper understanding of how web APIs are developed, exposed, and described needs to be reached before suggesting major improvements in existing web API technologies (Maleshkova et al., 2010). Developers face difficulty in reusing web services in $3^{\text {rd }}$ party 
application due to the different standards used in exposing web services. This difficulty is hindering the full potential of web services. This difficulty can be addressed by the representation of services using RDF graphs in a Service Graph Base (Chen et al., 2012). This representation allows services to be queried regardless of their type using common SPARQL queries. Many more selection, discovery, and recommendation solutions were proposed in the literature. Below are some of the proposed solutions:

- Driven by the need for e-business community to automate management of supply chain, the discovery of web services based on capabilities they provide become critical (Paolucci et al., 2002)

- A technique for composing services based on Quality of Service using genetic algorithms (Canfora et al., 2005)

- A method for the dynamic composition and management of composite e-services that are built on top of other basic services (Casati et al., 2000)

- A system for assisting mashup developers by suggesting relevant outputs by calculating the conditional probability that the output will be included given the current state of the mashup (Elmeleegy et al., 2008)

- A mashup component recommendation mechanism based on a top-k ranking algorithm that exploits the shared characteristics between mashups to rank and recommend mashup components (Elmeleegy et al., 2008)

- An interactive method of recommending services based on reusable composition patterns to address the difficulty of developing mashups faced by mashup developers (Chowdhury et al., 2011) 
- VisComplete: a tool that aids domain scientists with building scientific workflows and data pipelines by suggesting components for new pipelines and scientific workflows while being constructed using correspondence between pipelines in an existing database. (Koop et al., 2008)

- A dynamic recommendation system based on user feedback and collaborative filtering for dynamic web service selection using semantic matching service requirements (Manikrao \& Prabhakar, 2005)

- A solution for the semantic matching of web services based on the capabilities they provide (Paolucci et al., 2002)

- A method for allowing software developers to annotate web services with semantic descriptions (Rajasekaran et al., 2005)

\subsubsection{Who is performing the composition?}

There are three types of users that are mainly targeted by the practice of service compositions: (i) Professional programmers are highly skilled developers who can build complex compositions and even new APIs and components, (ii) End-user programmers can glue together different components and APIs and create new applications. They understand the principles of service composition, but are not skilled enough to produce APIs and components. They are usually domain experts and most of their applications are context specific or for personal use, (iii) End-user app remixers are not skilled in software development at all, but understand the web and can stitch together rule based applications based on the notion of "If This Then That". They usually use services such as 
Zapier $^{1}$ and IFTTT² (Lemos et al., 2015).

\subsection{API service systems}

Web services are modular applications that can be invoked across the Web (Bai et al., 2009). The interface these applications expose to be invoked is an API. The Software Engineering Body of Knowledge defines an API as "a set of signatures that are exported and available to the users of a library or a framework to write their applications" (Bourque \& Fairley, 2014:3-8). Web service systems consists of web services, service providers, service consumers, and service based applications (Lyu et al., 2014). The literature does not make a clear distinction between web service systems and API service systems. For the purposes of this study API service systems will be used to refer to service systems that enable API providers to publish, promote, and provision their APIs and API consumers to discover, select, and consume APIs (Wittern et al., 2014) and API service systems are actual instances of directories and repositories such as programmableweb.com that enable service systems.

The study of API service systems is of high value (Lyu et al., 2014). Information about APIs such as endpoint descriptions, data formats, and protocols provided by API providers play a key role in the consumption of APIs by API consumers. In addition, such information allows the evolution of the API service system by (Wittern et al., 2014):

- Enabling API consumers to easily discover and consume APIs by knowing about

\footnotetext{
${ }^{1}$ https://zapier.com/

${ }^{2}$ https://iftt.com/
} 
valuable API combinations and getting API suggestions based on requirements

- Enabling API providers to know about how their APIs are used, what needs are not met in the service system, and how they compare to competing APIs

- Enabling API service systems to know about gaps in the service system that need to be filled, how demand is changing in the service system, and what tooling is required for the service system to prosper

Several studies have empirically examined programmableweb.com. Most of these studies use the links between APIs and Mashups to construct service networks that can then be examined by social network analysis techniques. Methodologies for studying programmableweb.com were suggested based on network analysis techniques (Huang et al., 2012), phylogenetic trees (Weiss et al., 2013), and graph theory (Pan et al., 2012; Wittern et al., 2014).

Studies on programmableweb.com can be broken down into three groups: (i) studies that look at the structure of the service system and draw insights from visualizing it, (ii) studies that take an evolutionary look at the service system and reveal insight about its growth, (iii) studies that use empirical evidence to suggest recommendation and discovery solutions in the API service system.

Through studying the structure of programmableweb.com evidence showed that APIs are organized into three triers with Google maps at the center. The second and third tier are comprised of platform like APIs, while some of the second tier APIs and the third tier APIs act as data sources. Mashups are usually composed by combining APIs across the 
three tiers (Yu \& Woodard, 2008). The overall structure of the service system revealed a power-law distribution among Mashups to APIs, characteristic of a long tail distribution where a small number of APIs are used by the vast majority of Mashups and the remaining number of APIs are used by few or no Mashups (Yu \& Woodard, 2008; Weiss \& Gangadharan, 2010; Woodard, 2009). A power-law distribution occurs when a small number of occurrences account for the majority of observations and a large number of occurrences account for the rest of the observations (Clauset et al., 2009). The resulting curve has been described as the long tail curve (Anderson, 2006).

Programmableweb.com can be visualized at three levels, the web API graph, the tag graph, and the domain graph. This breakdown can aid discovery the service system (Lyu et al., 2014). Integration patterns were studied using social tags to reveal that mashups in the API service system experience hybrid integration patterns by integrating real-life applications in addition to composing APIs (Han et al., 2014). More recently, network analysis and visualization revealed that although APIs are proliferating in numbers, the service system is still seeing a power law distribution among API uses (Evans \& Basole, 2016).

The evolution of the mashup service system can be attributed to niche formation around central hub APIs (Weiss et al., 2013). In studying the characteristics of developers in the API service system, evidence suggest that frequently used APIs in the API service system attract large amounts of users who have similar ideas and similar behavior. Thus, developers tend to use similar design patterns in creating mashups (Wang et al., 2009). There is evidence to suggest that copying among developers play a 
significant role in the evolution of the mashup service system. This challenges the idea that selecting APIs is based on the APIs popularity (Weiss \& Sari, 2010). The relationship between APIs in the API service system is one of complementarity and is affected by the position of the API in the service system. 'Powerful hub' APIs tend to attract niche data providers as complements and the chance two APIs will be used together increases as they are used together more often (Weiss \& Gangadharan, 2010).

The idea that previous examples of how APIs were previously used influence how they will be used in the future could be used to recommend APIs to developers. By leveraging social information in the API service system, APIs could be re-ranked based on their history enhancing their discoverability (Torres et al., 2011). Detecting services based on their community structure is important for service computing. Two methods were suggested to detect communities in the API service system: competition-oriented based on the functional semantics of the web service, and collaboration-oriented based on topological analysis (Han et al., 2013). Link analysis and network prediction techniques were used to provide recommendations in the API service system (Huang et al., 2014). Finally, a time aware linear model was proposed to predict API popularity using the time series feature of APIs such as provider ranking and description (Wan et al., 2015)

\subsection{API customer value propositions}

This section reviews literature on customer value propositions in the API service system by first reviewing the notion of value propositions and its relation to service systems and service service system, and then reviews the general business value that APIs bring to 
enterprises and value networks.

\subsubsection{Value propositions and service systems}

API service systems can be thought of as service value networks (Weinhardt et al., 2011). Networks play a central role in value creation and exchange that underpins Service Dominant (S-D) logic (Lusch \& Vargo, 2006). Service system are comprised of complex combinations of goods, money, activities, and institutions where skills and knowledge based competencies are applied for the benefit of one another (Vargo \& Lusch, 2008). S-D logic forms the basic underpinning of service system, and it refers to an evolving view of service provisions as the fundamental element of economic exchange in markets. In S-D logic, enterprises can only make value propositions and value creation is only achieved when the service is consumed (Vargo \& Lusch, 2004).

Three service constructs make up value propositions in service systems: value propositions as invitations of service engagement between actors, engagement as alignment of connections and dispositions, and service experience as many-to-many engagement (Chandler \& Lusch, 2015). Value propositions as seen through the S-D logic are understood to be reciprocal promises of value. In light of this understanding, value propositions are used as a communication practice that enhances the firm's engagement with suppliers, customers, and other beneficiaries (Ballantyne et al., 2011).

Value propositions consist of provision practices, representational practices, and management and organizational practices that integrate operant and operand resources into new value propositions through an innovation process (Skalen et al., 2014). 
Customer value propositions communicate to target customer what matters most to them in terms of points of difference and points of parity compared with the next best alternative (Anderson et al., 2006).

In the context of service systems, value propositions play a key role in shaping the service system by acting as mechanisms for balancing resource sharing. In the service system, value propositions are a result of the actors' willingness to share and contribute their resources to others (Frow et al., 2014). They act as integrators and connectors between its actors, thus their change and evolution over time influence the shape of the service system and contribute to its health (Frow et al., 2014).

\subsubsection{Business value of APIs}

The benefits of adopting APIs for enterprises are: more agility to make firms more adaptable to changing requirements, less complexity in IT infrastructure to make it easier to deal with, increased reusability as software components can be reused to achieve different goals without the need of re-implementing them, and better interoperability as software components can interact and exchange information over standard interfaces (Hau et al., 2008) The adoption of APIs has led to increased performance in supply chain by reducing the negative effects of the complexity of information sharing (Kumar et al., 2007). APIs contribute to business process quality by complementing business process management in standardization, consolidation, and B2B integration (Beimborn \& Joachim, 2011). APIs attempt to facilitate the job of the information worker by automating tasks such as searching, analyzing, reformatting, and 
consolidating information (Lanthaler \& Gutl, 2010). In general, service based software is complementary to component based software, and is suitable for systems with frequently changing requirements (Elfatatry, 2007).

Outside the walls of the enterprise, APIs are becoming increasingly important for companies as they allow them to give their partners and customers access to their services and assets (Wittern et al., 2014). Web APIs allowed developers to combine different data sources into Mashups. These Mashups in turn allow non-technical users to innovate quickly by easily accessing data and mixing it together to try new ideas and concepts (Hinchcliffe \& Benson, 2011).

While service orientation facilitates integration of business components, businesses can operate in value nets using componentization (Cherbakov et al., 2005). A value network can be mapped using three elements: roles are played people or organizations in the network who perform the functions necessary for value creation, transactions are activities that originate from one role to another, and deliverables are the actual benefits that are moved during a transaction between two players (Allee, 2008).

Although the business value of APIs are well known within the walls of the enterprise, significant adoption of service technologies outside the enterprise environment has been slow. This is attributed to the lack of platforms that are able to deal with the heterogeneity in the service system and can provide simple yet powerful discovery mechanisms (Pedrinaci et al., 2010)

\subsection{Summary and synthesis of key findings from the literature}


Literature around the web service system can be conceptualized at three levels of abstraction (see Figure 1 for a representation of the levels). The highest level is literature on web service composition. Web service composition can be thought of as an abstract technical architecture. This body of literature discusses topics such as components, compositions, composers, and discovery. The second level focuses on one of the ways a web service composition can be implemented which is API service systems. This body of literature talks about service providers, service consumers, applications, and matching. At the third and most concrete level is literature that studied programmableweb.com. Programmableweb.com is one actual instance of the web service systems where there are API and Mashup listings.

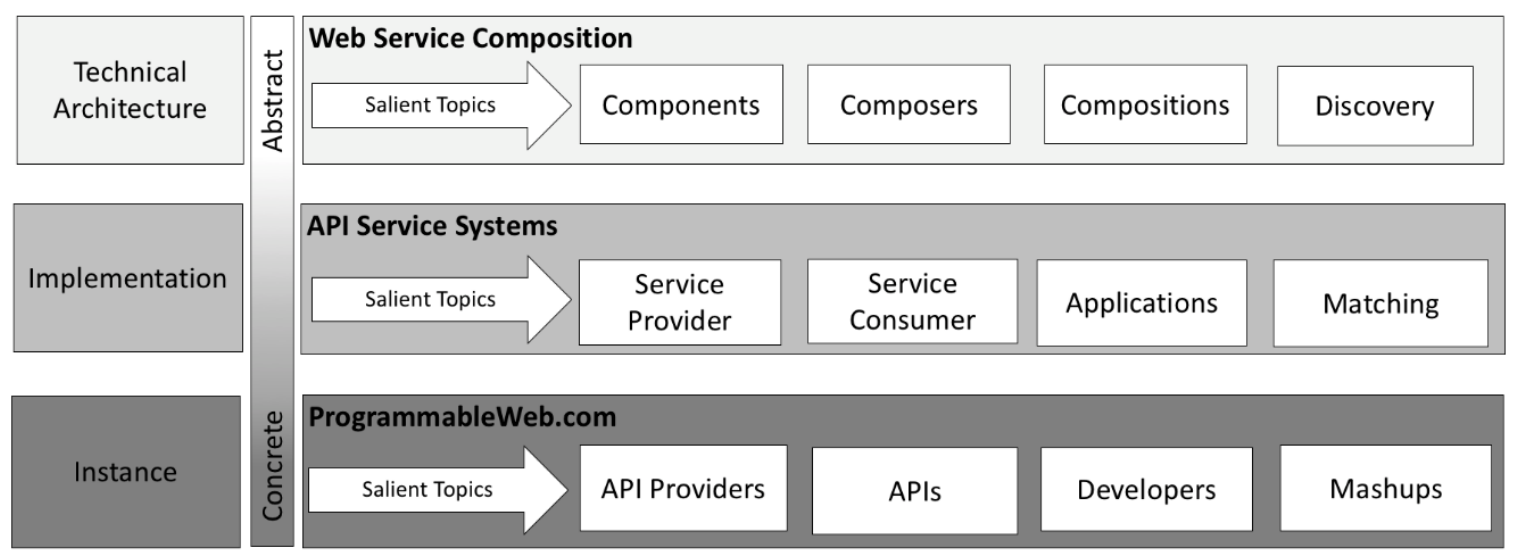

Figure 1 - Breakdown of literature

APIs are major drivers of value within the enterprise. They achieve technical and business value by streamlining processes, allowing the enterprise to be scalable and agile, and facilitating B2B integration. However, APIs are increasingly having trouble reaching their full potential outside the walls of the enterprise at the scale of the internet. 
API service systems have emerged in recent years with a huge potential for achieving value at an internet scale. Empirically studying these service systems is extremely important to allow service providers, service consumers, and service systems to reach their full potential. Past empirical studies of the web service system focused on network science perspectives and revealed many insights into the formation of the service system, the key players, and how the service system evolves. However, empirical studies of topics that require semantic analysis such as customer value propositions in the service system are rare and face the difficulty of massive amounts of data that are impossible for humans to process manually. This is a gap in literature that needs to be filled. 


\section{Methods}

This chapter discusses the research methods used in this thesis. An overview of Topic Modeling is given followed by details of the research steps.

\subsection{Research approach}

This is an inductive theory building research where descriptive theory is the ultimate goal of the study (Carlile \& Christensen, 2005). The steps of this research are based on the three stages of theory building pyramid suggested by Carlile and Christensen (2005). This research uses Topic Modeling as a data analysis and text mining technique.

\subsection{Unit of analysis}

The unit of analysis is a corpus of API descriptions obtained from www.programmableweb.com. API descriptions are statements written by the API provider that describes to potential API consumers what the API does. Figure 2 shows a typical API description from programmableweb.com.

APIs » Google Maps

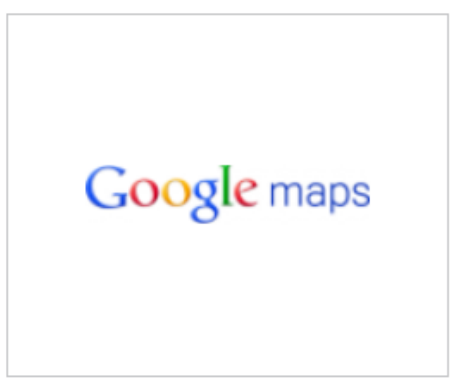

$\Theta$ TRACK API

\section{Google Maps API}

Mapping Viewer

The Google Maps API allow for the embedding of Google Maps onto web pages of outside developers, using a simple JavaScript interface or a Flash interface. It is designed to work on both mobile devices as well as traditional desktop browser applications. The API includes language localization for over 50 languages, region localization and geocoding, and has mechanisms for enterprise developers who want to utilize the Google Maps API within an intranet. The API HTTP services can be accessed over a secure (HTTPS) connection by Google Maps API Premier customers.

Figure 2 - An example of API description from programmableweb.com 


\subsection{Study period}

The collected data covers the period from June 2005 to July 2016 and includes 13,829 API descriptions, API names, API dates of submission, and API tags.

Programmableweb.com reports 15,816 APIs in its database. Hence, the data collected represents $87.4 \%$ of the total number of APIs published as of September 2016.

\subsection{Topic Modeling}

\subsubsection{Probabilistic Topic Modeling}

Probabilistic Topic Modeling is a set of statistical techniques and algorithms that allow thematic discovery and annotation of information in a large archive of documents (Blei, 2012). The techniques are based on the general field of Probabilistic Modeling. The three key elements of a topic model are a document, a topic, and a word. A document is a mixture of topics (Blei et al., 2003; Griffiths, \& Steyvers, 2002; 2003; 2004; Hofmann, $1999 ; 2001)$. A topic is a theme discussed in one or more documents and is represented as a probability distribution over words (Steyvers \& Griffiths, 2010).

The basic idea underlying probabilistic topic modeling is the formation of documents using a generative process. Documents are generated by choosing a probabilistic distribution over a number of topics. Then for each word in the document, a random topic is chosen according to this distribution and a word is drawn from the topic. The goal of topic modeling is to use standard statistical techniques to invert this process so that the set of topics that were responsible for the generation of the document can be deduced. 
For example, let us assume that we want to generate this thesis using the probabilistic generative process. We will first go through a generative process to that will create a thesis and then describe how topics can be inferred from a given thesis by inverting the generative process.

The first step of the generative process is to pick a probabilistic distribution over a number of topics. To demonstrate, let us pick five topics and choose a probability distribution over them.

The five topics are:

Topic 1: Web Services

$$
\begin{aligned}
& P(1)=0.20 \\
& P(2)=0.15 \\
& P(3)=0.13 \\
& P(4)=0.20 \\
& P(5)=0.32
\end{aligned}
$$

Topic 4: Service systems

Topic 5: Topic Modeling

Step two would be to assign a random probability distribution for words in the above topics over a fixed vocabulary. This simply means that if we hypothetically have 1,000 distinct words that we can choose from to make up our documents, each topic would have a different probability distribution over this set of distinct words. For the sake of this example, we will show five words and their probability distributions, and represent the rest with '...'.

Topic 1: Web Services

$\begin{array}{ll}\text { Provider } & 0.04 \\ \text { Consumer } & 0.03 \\ \text { Service } & 0.07\end{array}$


$\begin{array}{ll}\text { HTTP } & 0.02 \\ \text { REST } & 0.09\end{array}$

Topic 2: Service Composition

Selection $\quad 0.03$

Discovery $\quad 0.04$

Composition $\quad 0.08$

Recommendation $\quad 0.05$

$\begin{array}{ll}\text { Automation } & 0.07\end{array}$

Topic 3: Value Propositions

Difference $\quad 0.02$

$\begin{array}{ll}\text { Points } & 0.06\end{array}$

$\begin{array}{ll}\text { Customer } & 0.08\end{array}$

Competition $\quad 0.03$

$\begin{array}{ll}\text { Value } & 0.09\end{array}$

Topic 4: Service system

Mashup $\quad 0.05$

$\begin{array}{ll}\text { API } & 0.02\end{array}$

$\begin{array}{ll}\text { Service } & 0.09\end{array}$

Growth $\quad 0.03$

$\begin{array}{ll}\text { Network } & 0.08\end{array}$

$\cdots$

Topic 5: Topic Modeling

Word $\quad 0.04$ 


$\begin{array}{ll}\text { Vocabulary } & 0.02 \\ \text { Document } & 0.08 \\ \text { Topic } & 0.09 \\ \text { LDA } & 0.05 \\ \ldots & \end{array}$

Step 3 in the generative process would be to generate each word in the document in two steps:

1- Randomly choose a topic given the distribution of topics above

2- Randomly choose a word from the corresponding distribution of the vocabulary Due to that writing a thesis using this method would be overly exhaustive, we can reverse this process using standard statistical techniques to arrive at the topics and their corresponding distributions from a properly constructed thesis document. There are various standard statistical techniques that can do this job. Some of them include Collapsed Gibbs Sampling (Griffiths \& Steyvers, 2002), Mean Field Variational Methods (Blei et al., 2003), Expectation propagation (Minka \& Lafferty, 2002), and Collapsed Variational Inference (Teh et al., 2006). The algorithms that implement those techniques are the ones generally referred to as Topic Modeling algorithms.

The basic intuition behind these techniques is hiding (hence latent) the topics, the perdocument topic distributions, and the per-document per-word topic assignments, while revealing the document only. Using an iterative process of sampling try to guess the topic and word distributions while conditionally given the current posterior distribution of the topics and words. After enough iterations topics are inferred (Blei, 2012; Steyvers 
\& Griffiths, 2010)

\subsubsection{Types of Topic Modeling}

Topic modeling algorithms evolved over the past two decades and saw many applications within areas such as digital humanities and journalism. Latent Semantic Analysis (LSA) or Latent Semantic Indexing (LSI) kick-started Topic Modeling by proposing an automatic information indexing and retrieval method based on Singular Value Decomposition (Deerwester et al., 1990). LSA solved a problem that existed in traditional information retrieval methods where the synonymy and polysemy of words were not accounted for. Synonymy meant users referring to the same object using different ways and words, and polysemy meant that the same word can have more than one meaning (Deerwester et al., 1990). Probabilistic Latent Semantic Analysis/Indexing (PLSA or PLSI) based on the likelihood principle, added the statistical foundation that LSA missed by defining a probabilistic generative model (Hofmann, 1999).

LSA and PLSA were based on three principles: deriving semantic information from worddocument co-occurrence matrix; dimensionality reduction; and presenting words and documents as points in Euclidean space (Steyvers \& Griffiths, 2010). The third principle makes the assumption of exchangeability; the order of words and documents is not important.

Latent Dirichlet Allocation(LDA) uses LSA and PLSA's first two principles but expresses words and documents in terms of probabilistic topics rather than points in Euclidean space (Blei et al. 2003; Steyvers and Griffiths, 2010). LSA, PLSA, and LDA are static topic 
models because they assume that content does not change over time. Dynamic Topic Models (DTM) capture the evolution of topics in a sequentially ordered set of documents over time. Dynamic Topic Models use Gaussian models to incorporate time dynamics in the topic model (Blei \& Lafferty, 2006a) while Correlated Topic Models (CTM) represent correlation using logistic normal distribution for approximate posterior inference where documents cannot be correlated (Blei \& Lafferty, 2006b).

The evolution of topic models continues allowing features other than words to be included in the model. Supervised Latent Dirichlet Allocation (sLDA) accommodates external responses pairing them with documents for the goal of using the model to predict the responses. SLDA moves topic modeling into the supervised machine learning space where predictive analytics is the ultimate goal rather than the unsupervised machine learning space where clustering is the ultimate goal (Blei \& Mcauliffe, 2008).

Relational Topic Models (RTM) is another supervised topic model where the external responses are specifically links between the documents. Using links and words the model can be used to map out the document network, predict links between them given words, and predict words in them given links (Chang \& Blei, 2009).

Hierarchical Dirichlet Process (HDP) on the other hand extends LDA into groups of mixture models that are themselves linked by a mixture model. This allows cases where multiple corpora are to be analyzed together where topics need to be identified within each corpus as well as among the set of corpora (Teh et al., 2006)

\subsubsection{Applications of Topic Modeling}


Topic Modeling has been used in many applications such as analyzing scholarly

publications, data journalism and journalism research, analyzing web content, sentiment analysis, and analyzing software source code. Table 2 shows an account of Topic Modeling applications in various domains.

\begin{tabular}{|c|c|}
\hline Domain & Studies \\
\hline $\begin{array}{l}\text { Scholarly } \\
\text { Publications }\end{array}$ & $\begin{array}{l}\text { - } \quad \text { Citation influence (Dietz et al., 2007) } \\
\text { - Scientific publications (Erosheva et al., 2004) } \\
\text { - } \text { Measuring Scholarly impact (Gerrish \& Blei. 2010) } \\
\text { - Studying the history of ideas (Hall et al., 2008) } \\
\text { - } \text { Construct identity in literature reviews (Larsen \& Bong, 2016) } \\
\text { - } \quad \text { Recommending scientific articles (Wang \& Blei, 2011) }\end{array}$ \\
\hline $\begin{array}{l}\text { News and } \\
\text { Journalism }\end{array}$ & $\begin{array}{l}\text { - Analyzing news articles (Newman \& Chemudugunta, 2006) } \\
\text { - Comparing twitter and traditional media (Zhao et al., 2011) } \\
\text { - Analysis of multiple online news sources (Chuang et al., 2014) } \\
\text { - Analyzing journalistic text (Jacobi et al., 2015) } \\
\text { - Analyzing Wikipedia (Ni et al., 2009) } \\
\text { - Event summarization from news and social media (Geo et al., } \\
\text { 2012) }\end{array}$ \\
\hline Auth & $\begin{array}{l}\text { - } \text { Finding influential authors in a digital library (Mimno \& } \\
\text { McCallum, 2007) } \\
\text { - } \text { Author centric ranking of web content (Ali \& LaPaugh, 2013) } \\
\text { - Predicting author attributes from Twitter messages } \\
\text { (Mccollister et al., 2015) }\end{array}$ \\
\hline $\begin{array}{l}\text { Web Content and } \\
\text { Sentiment Analysis }\end{array}$ & $\begin{array}{l}\text { - } \text { Opinion integration (Lu \& Zhai, 2008) } \\
\text { - Sentiment analysis (Lin \& He, 2009) } \\
\text { - Sentiment analysis (Jadeja \& Pandya, 2014) } \\
\text { - } \text { Modeling online reviews (Titov \& McDonald, 2008) }\end{array}$ \\
\hline $\begin{array}{l}\text { Software Source } \\
\text { Code Analysis }\end{array}$ & $\begin{array}{l}\text { - } \text { Analyzing software evolution (Linstead et al., 2008) } \\
\text { - Source code mining (Linstead et al., 2007a) } \\
\text { - Mining eclipse developer contributions using author topic } \\
\text { - } \text { models (Linstead et al., 2007b) } \\
\text { Automating software traceability (Asuncion et al., 2010) }\end{array}$ \\
\hline
\end{tabular}




\begin{tabular}{|l|l|}
\hline Outside Text Mining & $\begin{array}{l}\bullet \text { Scene analysis and abnormality detection (Varadarajan \& } \\
\text { Odobez, 2009) } \\
\bullet \quad \text { Speech recognition (Chaney \& Blei, 2012) }\end{array}$ \\
$\qquad \begin{array}{l}\text { - Image analysis (Fei-Fei \& Perona, 2005; Sivic et al., 2005) } \\
\text { - Biological data analysis (Pritchard et al., 2000) }\end{array}$ \\
\hline
\end{tabular}

Table 2 - Topic Modeling Studies

\subsubsection{Software Implementations for Topic Modeling}

There are several open source software implementations for different Topic Modeling algorithms. Table 3 provides a list of existing packages and their most salient features.

\begin{tabular}{|c|c|c|}
\hline Author & Package & Features \\
\hline $\begin{array}{l}\text { McCallum } \\
(2002)\end{array}$ & Mallet & $\begin{array}{l}\text { - } \text { Built in Java } \\
\text { - A comprehensive software package for various } \\
\text { natural language process such as document } \\
\text { classification, clustering, and information extraction } \\
\text { - Implements LDA using Gibbs Sampling } \\
\text { - Well supported and maintained. A very popular tool } \\
\text { for topic modeling }\end{array}$ \\
\hline Blei (2003) & Ida-c & $\begin{array}{ll}\text { - } & \text { Built in C } \\
\text { - } & \text { Extremely fast } \\
\text { - } & \text { Implements LDA with Variational Sampling }\end{array}$ \\
\hline Steyvers (2005) & $\begin{array}{l}\text { Matlab } \\
\text { Topic } \\
\text { Modeling } \\
\text { Toolbox }\end{array}$ & $\begin{array}{l}\text { - Built in Matlab } \\
\text { - Well suited for research purposes but cannot be } \\
\text { used for commercial applications as it is built in } \\
\text { Matlab. } \\
\text { - Implements LDA with Gibbs Sampling }\end{array}$ \\
\hline Ramage (2009) & $\begin{array}{l}\text { Stanford } \\
\text { Topic } \\
\text { Modeling } \\
\text { Toolbox }\end{array}$ & $\begin{array}{l}\text { - } \text { Built in Scala } \\
\text { - Implements LDA } \\
\text { - Allows visualization of topics in Excel } \\
\text { - Not supported anymore by authors }\end{array}$ \\
\hline Rehurik \& Sojka & Gensim & $\begin{array}{l}\text { - } \text { Built in python } \\
\text { - Implements LSA, PLSA, and LDA using Gibbs }\end{array}$ \\
\hline
\end{tabular}




\begin{tabular}{|c|c|c|}
\hline (2010) & & $\begin{array}{l}\text { Sampling } \\
\text { - Well suited for commercial applications } \\
\text { - Allows real-time online update of the topic model } \\
\text { by feeding in more documents } \\
\text { - Very compatible with other python natural } \\
\text { language processing and machine learning libraries } \\
\text { such as NLTK, NumPy, and Sciketlearn }\end{array}$ \\
\hline $\begin{array}{l}\text { Hornik \& Grun } \\
\text { (2011) }\end{array}$ & $\begin{array}{l}\text { R package } \\
\text { topicmodels }\end{array}$ & $\begin{array}{l}\text { - } \text { Built in R } \\
\text { - An R wrapper around Ida-c by Blei (2003) } \\
\text { - Very well suited for research } \\
\text { - Works well with other R packages for NLP such as } \\
\text { tm and textmineR } \\
\text { - Well supported and very popular in the research } \\
\text { community }\end{array}$ \\
\hline Chang (2015) & $\begin{array}{l}\text { R package } \\
\text { Ida }\end{array}$ & 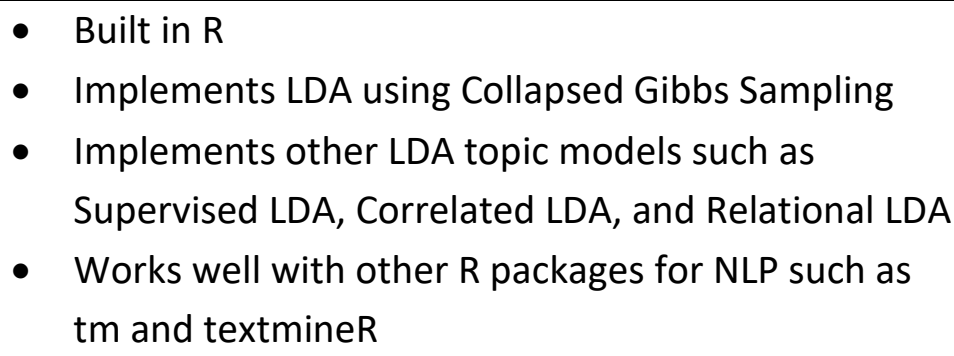 \\
\hline
\end{tabular}

Table 3 - Topic Modeling implementations

\subsection{Theoretical framework}

The API service system can be broken down into API providers, API consumers, and endusers. API providers create APIs and publish them in the API service system. API consumers use those published APIs to create applications for the end-users. Value creation in the API service system flows from the provider to the consumer to the enduser. The link between the API service provider and the API service consumer is what this research focuses on.

The first step service providers take to create value for service consumers is publish their APIs in the API service system along with an API description. API descriptions are 
composed of what the API does, or the service deliverable, as well as how it is beneficial to the consumer of the API. By communicating service deliverables and benefits, the API provider is communicating a customer value proposition to the API consumer.

The focus of this study is to use Topic Modeling to analyze API descriptions in the API service system of programmableweb.com. This allows the extraction of customer value propositions as communications of service deliverables and benefits.

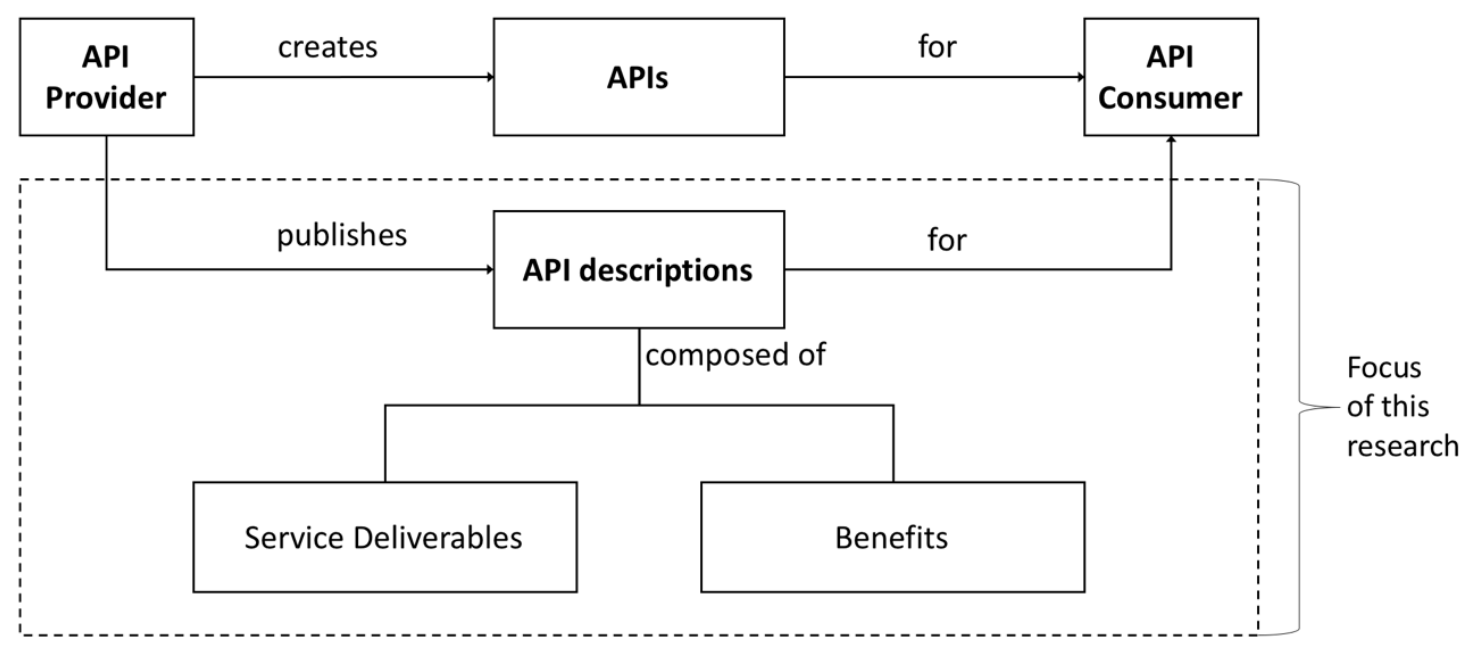

Figure 3 - Theoretical Framework

Figure 3 shows an illustrative diagram of the initial theoretical framework this study uses to guide data gathering and analysis. This framework is based on the literature review in Chapter 2. 


\subsection{Research steps}

This section details the research steps taken to get the results and deliverables of this research.

\subsubsection{Identify constructs}

Identify and define the constructs and dimensions that are most salient to answering the research questions by: conducting a literature review, using observations from www.programmableweb.com and other web service systems such as Mashape ${ }^{3}$, and using the researcher's own experience delivering an API program to a startup company in Ottawa. Section 2.4 covered this step.

\subsubsection{Create initial theoretical framework}

Organize the constructs in a framework that captures the initial relationship between the constructs. The framework will be used to focus efforts and guide the data collection and analysis. Section 3.5 covered this step.

\subsubsection{Collect data}

Using a Python script specifically designed for the purpose, crawl API descriptions, API names, tags, and submission dates from www.programmableweb.com.

\subsubsection{Clean and import data into Mallet}

Using a Python script, extract API descriptions from the database and create a text file

\footnotetext{
${ }^{3}$ https://market.mashape.com/
} 
for each API where the file name is the API name and the text file contains the API description stripped from trailing and leading white space.

Using Mallet's import-doc command, import the files into mallet with the options of removing stop words and keeping the sequence of the documents.

\subsubsection{Train the Topic Model}

Run topic modeling on API descriptions in mallet with hyper parameter optimization and start from five topics with increments of 5. For each model create a table that includes the topic id and top 10 topic words. To find the model with the optimal number of topics:

1- Find the delta between the general topic interpretation between the current model and the previous model

2- Note the number of topics that include more than one theme

3- Note the number of topics that are semantically duplicates of other topics

4- The model with the optimal number of topics is the one that has the minimal delta with the previous topic, the minimal number of duplicate topics and the maximum number of topics with one theme.

\subsubsection{Interpret the model}

Prepare the model with the optimal number of topics for interpretation by removing topics that are too general to extract the necessary constructs using the metrics: tokens, document entropy, coherence, and rank 1 doc. 
For the remaining topics create a table with

- Topic ID: This is the topic id assigned to the topic by Mallet they are digits that start from 0 for the first topic and go up to the number of topics. For clarity, increase all topic numbers by 1 so that topic number go from 1 to 40 .

- Topic Category: This is a brief description that can uniquely identify the topics from each other based. This category is most similar to categories on programmableweb.com

- Top 10 Words: These are the top 10 words according to their distribution over the topic and are the output of Mallet.

- Service Deliverables: These are what the providers choose to offer to their API consumers. They are identified by looking at the verbs in the list of top 10 topic words and choosing the most meaningful verb that denotes what is actually delivered to the consumer.

- Benefits: These are what the APIs will benefit the API consumer.

Interpret the topic model by analyzing the semantic meaning of the top 10 words along with example API descriptions that are best represented by the topic.

\subsubsection{Categorize customer value propositions}

Create a table with the columns Topic ID, Topic Category, Service Deliverables, Benefits, and Customer Value Proposition Category.

The Service Deliverables and Benefits are under a general column of Customer Value Propositions. 
The Customer Value Proposition Category is assigned based on the researcher's interpretation and analysis of the extracted information from the topic model.

\subsubsection{Produce topic trend graphs}

Time is an important dimension in studying processual and evolving phenomena such as networks (Halinen et al., 2012). Although the aim of this research is to identify and categorize customer value propositions in the API service system, the API service system is a continuously evolving network. The analysis of customer value propositions should include their evolution over time.

For each topic produce a graph that shows how the accumulative proportion of the topic presentation as a function of time. The topic proportion is calculated by identifying all documents that have this topic as the topic with the highest distribution to date divided by the total number of documents to date. Equation 1 gives document proportion value as a function of time.

$$
T P_{i}=\frac{\sum_{t} d_{i t}}{\sum_{t} d_{t}}
$$

Equation 1 - Topic Proportion

where:

$T P_{i} \rightarrow$ is the Topic proportion for topic $\boldsymbol{i}$

$t \rightarrow$ current time

$\boldsymbol{d}_{i t} \rightarrow$ number of documents with topic $\boldsymbol{i}$ as the topic with highest distribution at time $\boldsymbol{t}$ 
$\boldsymbol{d}_{\boldsymbol{t}} \rightarrow$ total number of documents that have been posted until time $\boldsymbol{t}$.

Topic trend graphs were plotted for the period from June 2005 to July 2016 . However, due to having very few APIs in the period from June 2005 to December 2005, the resulting graphs were uninterpretable as some of the curves started at 1.0 on the $\mathrm{Y}$-axis while the rest of the curves varied between 0 and 0.7 . To solve this problem, the graphs were looked at during the period from January 2006, to July 2016.

\subsubsection{Categorization and statements of association}

Create the final categorization model that categorizes the Customer Value Propositions based on the constructs of service deliverables and benefits.

Produce propositions and associations based on extant literature and findings. 


\section{Results}

This chapter details the results of this research. The chapter starts by showing how the model with the optimal number of topics was chosen. It then describes the process used to prepare the model for interpretation. Next, the analysis and interpretation of the model are presented. Finally, topic trend graphs are produced and analyzed. The chapter ends with a brief summary of the findings. Where applicable, summaries of the results are presented and detailed results are referenced in the Appendices.

\subsection{Identifying optimal model}

The ultimate purpose of this part of the research is to extract the assets and service deliverables from a topic model that best represents the corpus of API descriptions in hand. While there are quantitative methods that determine the optimal number of topics, quantitatively significant models are not necessarily the most interpretable (Chang et al., 2009). Since the purpose is to find the model with the best interpretation, the exercise was qualitative and subjectively based on the researcher's ability to interpret the model. The researcher relied on three metrics to find the model with the optimal number of topics: the delta of new topics, the number of duplicate topics, and the number of topics with more than one theme. The delta between models in terms of the number of new topics added indicates saturation and that further models with higher number of topics will not add any new information. The number of semantically duplicate topics, that is two topics that are essentially the same theme, gives a further indication of saturation. An increased number of duplicates indicates reaching 
saturation. Finally, the number of topics with more than one theme indicates the granularity of the model. More topics with more than one theme indicates that further models with higher number of topics will break certain topics into two or more topics. The model that minimizes all three is the best model.

Models were trained with increasing the number of topics from 5 to 45 . Table 4 shows a summary of the results for each model. Appendix A.1 shows the detailed analysis for each of the models. In every iteration, topics were interpreted and given a 1 to 3 -word phrase with the purpose of uniquely identifying this topic within the model and across models. Topics that included more than one theme were given two phrases separated by a comma. Each topic was given a letter denoting whether it is: a semantically New topic that was not in the previous model $(\mathrm{N})$ or a semantic Duplicate of one of the topics in the current model (D). The number of topics that included more than one theme was also noted.

\begin{tabular}{|c|c|c|c|c|}
\hline Iteration & $\begin{array}{l}\text { Number of } \\
\text { Topics }\end{array}$ & $\begin{array}{c}\text { Delta New } \\
\text { Topics }\end{array}$ & $\begin{array}{l}\text { Number of } \\
\text { Duplicates }\end{array}$ & $\begin{array}{l}\text { Number } \\
\text { topics with } \\
>1 \text { theme }\end{array}$ \\
\hline 1 & 5 & 5 & 0 & 5 \\
\hline 2 & 10 & 5 & 0 & 3 \\
\hline 3 & 15 & 6 & 0 & 4 \\
\hline 4 & 20 & 4 & 0 & 1 \\
\hline 5 & 25 & 6 & 0 & 4 \\
\hline 6 & 30 & 3 & 0 & 2 \\
\hline 7 & 35 & 2 & 3 & 1 \\
\hline 8 & 40 & 1 & 2 & 1 \\
\hline 9 & 45 & 0 & 6 & 0 \\
\hline
\end{tabular}

Table 4 - Results for optimal topic model

The delta of new topics was between 4 and 5 until model 6 with 30 topics and then 
dropped significantly at models with 35 and 40 , reaching 0 at 45 topics. The number of duplicate topics stayed at 0 until 30 topics and increased at 35 and 40 . However, the number of duplicates spiked at 45 . The number of topics with $>1$ theme stayed became 0 at 45 topics and was 1 for the 35 and 40 topic models. This makes the two models with 35 and 40 topics the best candidates for the best model. Since categorization is the ultimate goal of the research, more topics will improve the results of the categorization. However, a model with 100 topics will make categorization difficult since there will be many topics that are different than each other according to the LDA algorithm, but are the same in terms of human interpretation. Hence, model 8 with 40 topics was chosen to be the optimal topic for the purposes of this research.

\subsection{Preparing model for interpretation}

The Mallet toolkit produces some diagnostic metrics that helps with the interpretation of the model. This section provides the results from these metrics and explains how they were used to exclude some of the topics in the model before interpretation. The metrics were visualized using a visualization tool ${ }^{4}$ obtained from the mallet website. Appendix A.2 includes a table with the diagnostics values.

\subsubsection{Topic-Tokens metric}

This metric measures the number of word tokens currently assigned to the topic. A number that is too high or too low relative to other topics signals that the topic may be

\footnotetext{
${ }^{4}$ http://mallet.cs.umass.edu/diagnostics.html
} 
a bad one. If the measure is too small, it means that there are not enough observations to get a good sense of the topic's word distribution. A number that is too large means that this topic is too frequent, and may indicate that the topic words may be close enough to stop words.
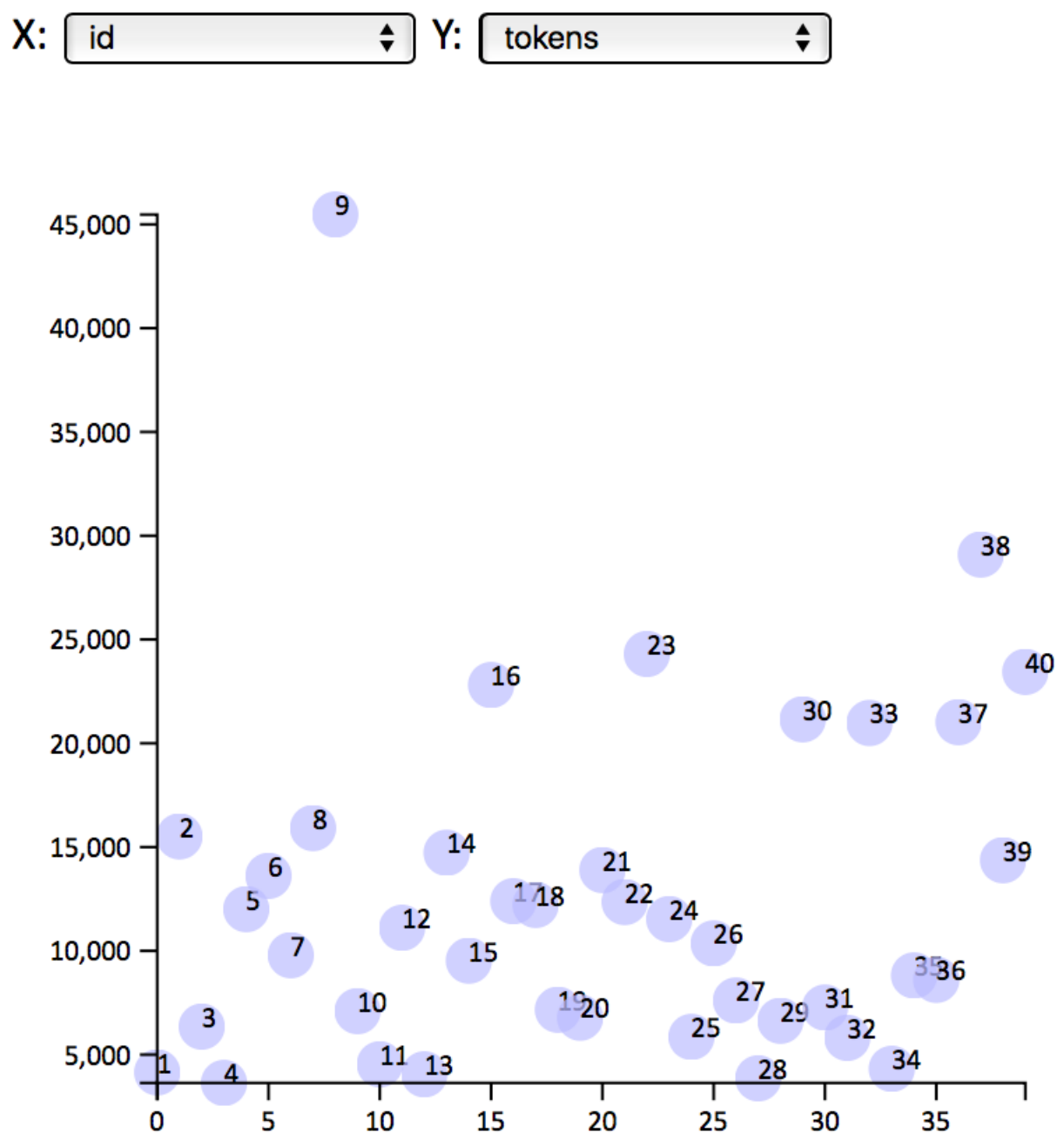

Figure 4 - Topic-Tokens metric

Figure 4 shows a scatter plot of topic Ids vs tokens. Relative to the majority of topics, topic 9 is at an extreme high with 45,475 tokens. This signals that the topic is too 
frequent. The lowest token count is topic 4 with 3,637 tokens. Beyond topic 9 , there are no major hikes or dips in the token metric. Topic 9 is:

\{services applications web platform service integrate content offers access application\}

The theme of the topic describes the general topic of web services, where words such as platform, access, content, and integrate are words that are too commonly used in any API description. According to the topic-tokens metric, topic 9 will be excluded from the final analysis of constructs.

\subsubsection{Document Entropy metric}

The document entropy metric measures the entropy of the probability of a document given a topic. Topics with lower entropy are concentrated in fewer documents, while higher entropy indicates the topic is evenly spread over many documents. 

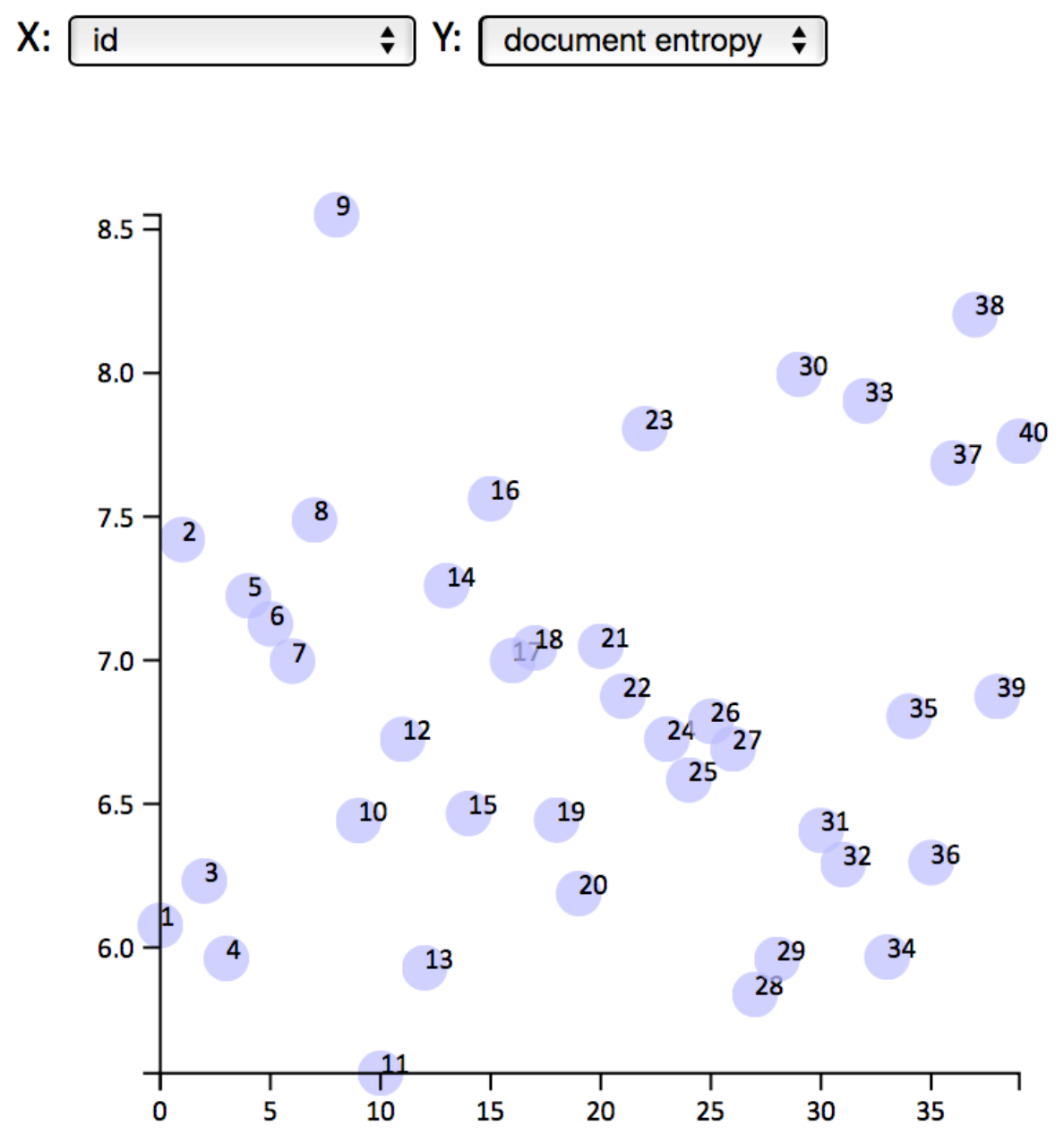

Figure 5 - Topic - Document Entropy metric

Entropy for model 8 ranged from 5.5621 to 8.5506 . At the bottom of the scale is topic 11 , and the topic with the highest entropy is topic 9 . There were no major hikes or dips in the entropy metric. Figure 5 shows a scatter plot of topic ids vs entropy. Table 5 shows topics at the lower end of the scale and Table 6 show topics with the highest entropy. 


\begin{tabular}{|l|l|l|}
\hline Topic & Top 10 words & Interpretation \\
\hline 4 & $\begin{array}{l}\text { github software development application applications } \\
\text { providers range wide integrate repository }\end{array}$ & $\begin{array}{l}\text { Integration APIs for } \\
\text { software code } \\
\text { repositories }\end{array}$ \\
\hline 29 & $\begin{array}{l}\text { data sequence database protein sequences analysis } \\
\text { biological soap research genes }\end{array}$ & $\begin{array}{l}\text { APIs for accessing } \\
\text { databases of protein } \\
\text { sequence analysis }\end{array}$ \\
\hline 13 & $\begin{array}{l}\text { health medical information data healthcare care } \\
\text { insurance providers fitness drug }\end{array}$ & $\begin{array}{l}\text { APIs for accessing } \\
\text { health information }\end{array}$ \\
\hline 28 & $\begin{array}{l}\text { print printing questions answer answers service } \\
\text { design webknox knowledge models }\end{array}$ & $\begin{array}{l}\text { APIs for question and } \\
\text { answer sites }\end{array}$ \\
\hline 11 & $\begin{array}{l}\text { data ondemand barchart vehicle analysis number xml } \\
\text { car request index }\end{array}$ & $\begin{array}{l}\text { APIs for accessing } \\
\text { vehicle information }\end{array}$ \\
\hline
\end{tabular}

Table 5 - Topics with low entropy

\begin{tabular}{|l|l|l|}
\hline Topic & Top $\mathbf{1 0}$ words & Interpretation \\
\hline 16 & $\begin{array}{l}\text { methods service support functions submission } \\
\text { including retrieval specific information status }\end{array}$ & $\begin{array}{l}\text { Discusses the general } \\
\text { concept of calling } \\
\text { functions and } \\
\text { methods as well as } \\
\text { information retrieval } \\
\text { as an integral part of } \\
\text { web services }\end{array}$ \\
\hline 37 & $\begin{array}{l}\text { search data access database information results } \\
\text { metadata library query research }\end{array}$ & $\begin{array}{l}\text { Discusses the general } \\
\text { concept of searching } \\
\text { and database access }\end{array}$ \\
\hline 40 & $\begin{array}{l}\text { applications access functionality integrate include } \\
\text { methods information retrieving managing create }\end{array}$ & $\begin{array}{l}\text { Discusses the general } \\
\text { concept of integrating } \\
\text { functionality. }\end{array}$ \\
\hline 23 & $\begin{array}{l}\text { data management business software platform } \\
\text { systems businesses services customer service }\end{array}$ & $\begin{array}{l}\text { This topic discusses } \\
\text { the general concept } \\
\text { of web services from } \\
\text { the business } \\
\text { perspective }\end{array}$ \\
\hline 33 & $\begin{array}{l}\text { web site website url service page javascript websites } \\
\text { link links }\end{array}$ & $\begin{array}{l}\text { This topic discusses } \\
\text { the general concept } \\
\text { of web services from }\end{array}$ \\
\hline
\end{tabular}




\begin{tabular}{|c|c|c|}
\hline & & $\begin{array}{l}\text { a more technical } \\
\text { perspective. }\end{array}$ \\
\hline 30 & $\begin{array}{l}\text { responses json } \mathrm{xml} \text { formatted restful calls data service } \\
\text { protocol web }\end{array}$ & $\begin{array}{l}\text { This topic discusses } \\
\text { the general concept } \\
\text { of web services } \\
\text { protocols and } \\
\text { specifically the } \\
\text { RESTFul APIs }\end{array}$ \\
\hline 38 & $\begin{array}{l}\text { json key http rest authentication requests service } \\
\text { access data account }\end{array}$ & $\begin{array}{l}\text { This topic discusses } \\
\text { the general concept } \\
\text { of keys and } \\
\text { authentication in web } \\
\text { services. Showing } \\
\text { how APIs in general } \\
\text { are used }\end{array}$ \\
\hline 9 & $\begin{array}{l}\text { services applications web platform service integrate } \\
\text { content offers access application }\end{array}$ & $\begin{array}{l}\text { This topic discusses } \\
\text { the general concept } \\
\text { of integrating } \\
\text { applications with } \\
\text { platforms as the } \\
\text { general purpose of } \\
\text { web services. }\end{array}$ \\
\hline
\end{tabular}

Table 6 - Topics with highest entropy

Topics towards the higher end of the scale discuss general topics in web services such as their business aspect, their technical aspects, their protocols, how the web services are called, and what is the main purpose of calling the API. While these topics are interesting in that they give a nice break down of how APIs are presented on programmableweb.com, they are not helpful when it comes to trying to extract concepts such as assets exposed and service deliverables. Therefore, according to the entropy metric, topics $8,16,37,40,23,33,30,38$, and 9 will not be included in the list of topics for extracting assets exposed and service deliverable. However, they will be used as secondary points of data to triangulate findings. 


\subsubsection{Coherence metric}

Coherence is a metric that measures the co-occurrence of the words in a given topic.

The scores are log probabilities and therefore they are negative. Topics with scores closer to zero indicated that their words tend to co-occur together and therefore are more coherent. Figure 6 shows a scatter plot of topic-id vs coherence.
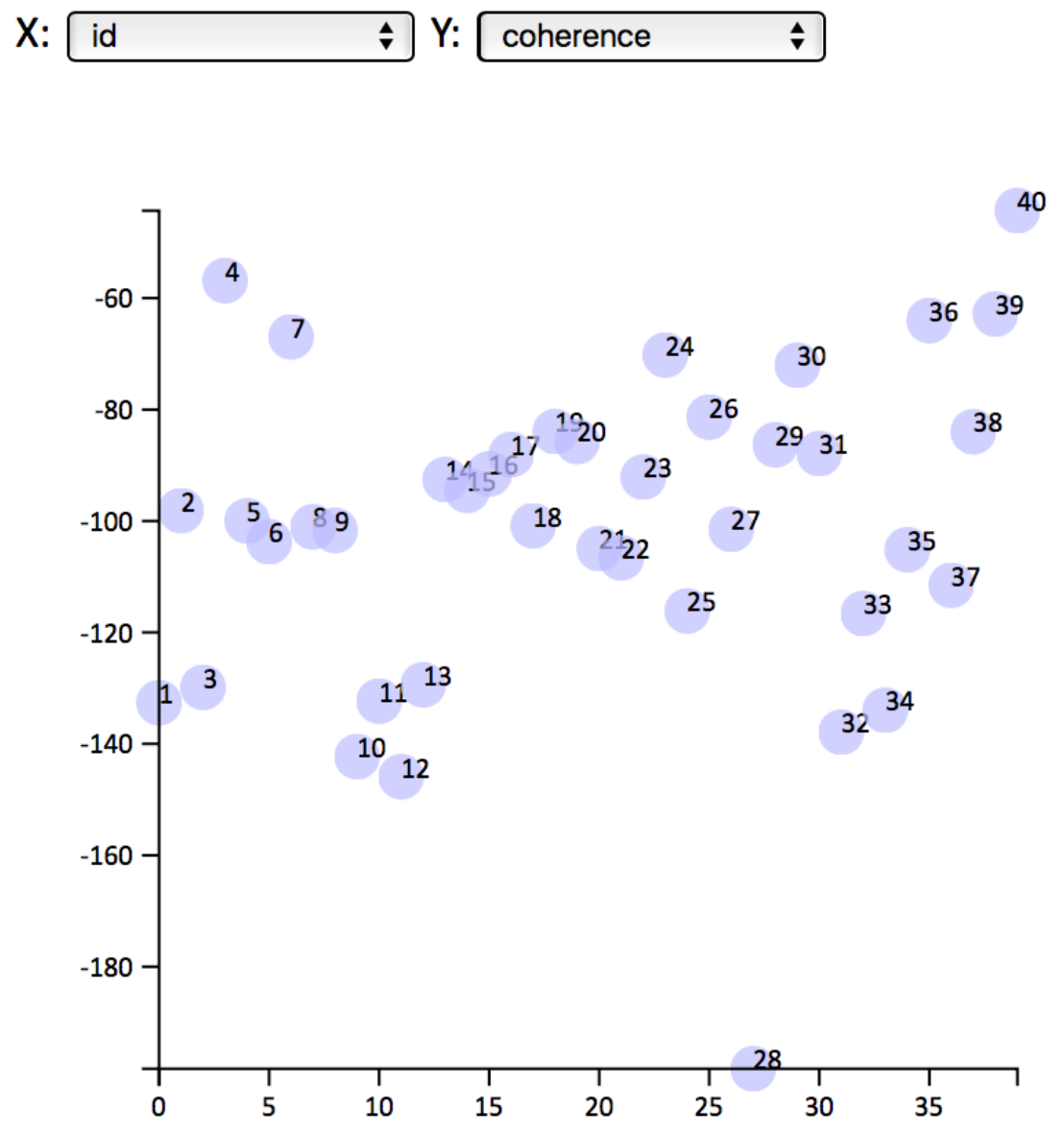

Figure 6 - Topic id vs coherence

Topic 28 shows significant incoherence relative to other topics in the corpus. According 
to the coherence metric, topic 28 will be excluded from the final list of topics where assets exposed and service deliverables will be extracted.

\subsubsection{Rank 1 Documents metric}

Rank 1 documents is a metric that measures the amount of burstiness of a topic. $A$ lower number indicates that the topic is a "background" topic that may arise from a certain style of writing or a certain context that is prevalent across the corpus. Figure 7 shows a scatter plot of topic-ids vs Rank-1-Documents.
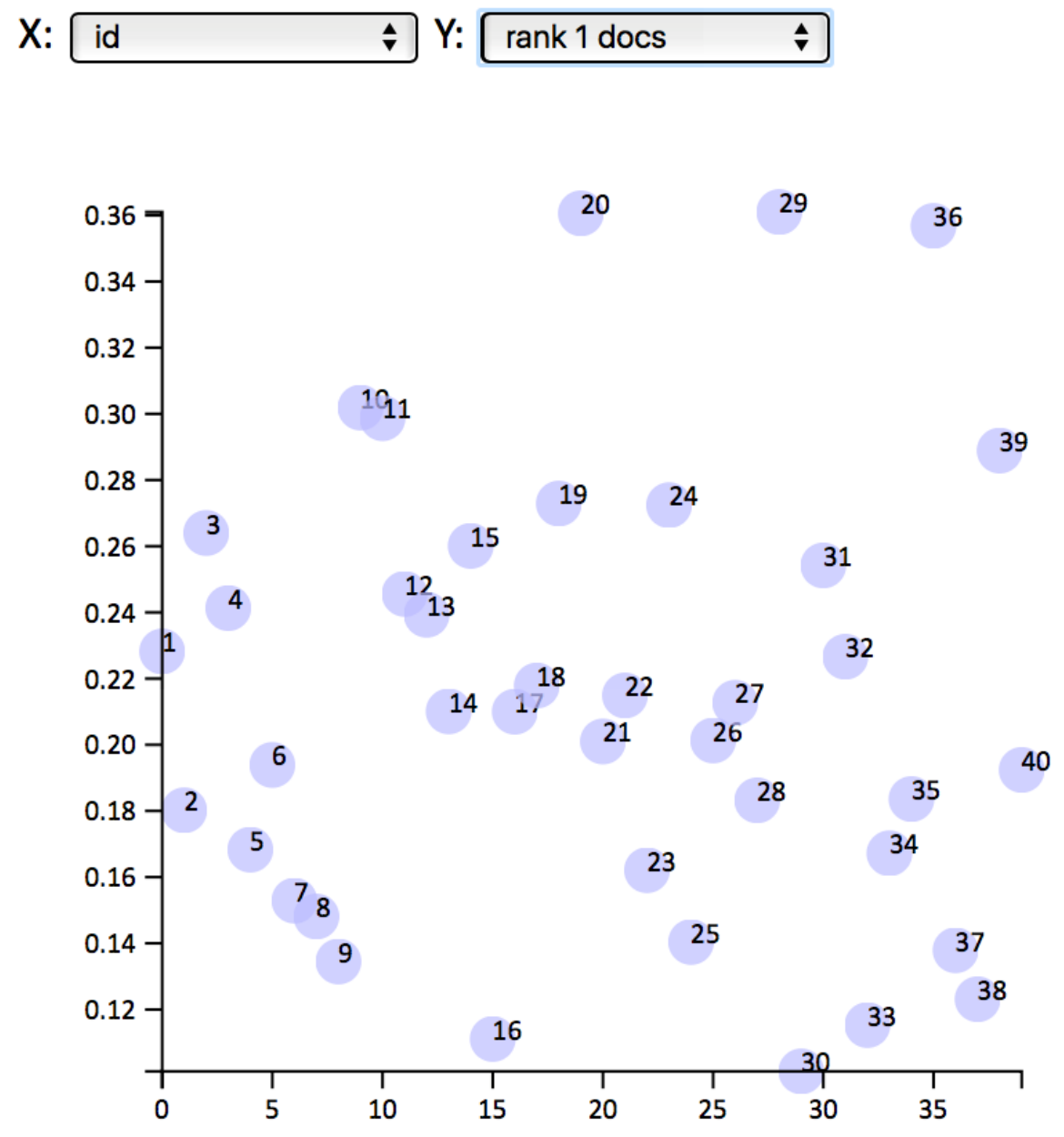
This metric confirms that topics $8,9,16,23,30,33,37$, and 38 are generic topics that do not contain specific information about certain API types. Two more topics have low rank 1 doc measures and can be added to the list of background topics, they are topics 7 and 25. Table 7 shows topics 7 and 25

\begin{tabular}{|l|l|l|}
\hline Topic & Top 10 words & Interpretation \\
\hline 7 & $\begin{array}{l}\text { website information soap calls provided format } \\
\text { programmatically service } \mathrm{xml} \text { documentation }\end{array}$ & $\begin{array}{l}\text { Discusses the general } \\
\text { concept of web } \\
\text { services protocols } \\
\text { and in this case SOAP. }\end{array}$ \\
\hline 25 & $\begin{array}{l}\text { code php java python javascript ruby codes net } \\
\text { sample languages }\end{array}$ & $\begin{array}{l}\text { A general collection } \\
\text { of programming } \\
\text { languages. }\end{array}$ \\
\hline
\end{tabular}

Table 7 - Topics excluded due to rank 1 docs metric

\subsubsection{Topics to exclude from the final model}

Table 8 shows each metric and the concluded topics to be removed as well as the associated reason.

\begin{tabular}{|l|l|l|}
\hline Metric & Topics to be excluded & Reason \\
\hline Tokens & 9 & $\begin{array}{l}\text { Extremely high token count } \\
\text { indicating the topic is too } \\
\text { generic }\end{array}$ \\
\hline Document Entropy & $\begin{array}{l}\text { 8, 16,37,40,23,33,30,38, } \\
9\end{array}$ & $\begin{array}{l}\text { Topics with high entropy } \\
\text { showing that they describe } \\
\text { general aspects of web } \\
\text { services. }\end{array}$ \\
\hline Coherence & 28 & Extremely low coherence. \\
\hline Rank 1 Documents & $\begin{array}{l}8,9,16,23,30,33,37,38, \\
7,25\end{array}$ & $\begin{array}{l}\text { Topics with low rank 1 } \\
\text { documents indicating they }\end{array}$ \\
\hline
\end{tabular}




\begin{tabular}{|l|l|l|}
\hline & & are too general. \\
\hline Unable to interpret & 32 & $\begin{array}{l}\text { Example documents were } \\
\text { inconsistent and not } \\
\text { related. }\end{array}$ \\
\hline
\end{tabular}

Table 8 - Topic excluded from the final model

Excluding these topics from the final model leaves 26 topics to be analyzed for extracting customer value propositions. Table 9 shows the topics in the final model.

\begin{tabular}{|r|l|}
\hline Topic & Words \\
\hline 1 & $\begin{array}{l}\text { property real affiliate estate search listings properties rental website } \\
\text { program }\end{array}$ \\
\hline 2 & $\begin{array}{l}\text { social content twitter news media share facebook access data } \\
\text { information }\end{array}$ \\
\hline 3 & $\begin{array}{l}\text { domain shipping delivery service services domains tracking mail dns } \\
\text { customers }\end{array}$ \\
\hline 4 & $\begin{array}{l}\text { github software development application applications providers range } \\
\text { wide integrate repository }\end{array}$ \\
\hline 5 & $\begin{array}{l}\text { mobile devices app apps device applications data android platform } \\
\text { application }\end{array}$ \\
\hline 6 & $\begin{array}{l}\text { cloud data storage service server access servers monitoring amazon } \\
\text { management }\end{array}$ \\
\hline 10 & $\begin{array}{l}\text { music events event information movie movies shows radio database } \\
\text { artists }\end{array}$ \\
\hline 11 & $\begin{array}{l}\text { data ondemand barchart vehicle analysis number xml car request } \\
\text { index }\end{array}$ \\
\hline 12 & $\begin{array}{l}\text { data travel booking market stock financial access information flight } \\
\text { hotel }\end{array}$ \\
\hline 13 & $\begin{array}{l}\text { health medical information data healthcare care insurance providers } \\
\text { fitness drug }\end{array}$ \\
\hline 14 & $\begin{array}{l}\text { marketing email campaigns platform analytics customers social } \\
\text { customer advertising media }\end{array}$ \\
\hline 15 & $\begin{array}{l}\text { data weather information energy access time conditions location } \\
\text { national solar }\end{array}$ \\
\hline 17 & $\begin{array}{l}\text { location map maps information data code address locations service } \\
\text { mapping }\end{array}$ \\
\hline &
\end{tabular}




\begin{tabular}{|c|c|}
\hline 18 & $\begin{array}{l}\text { product products information online shopping deals search access } \\
\text { price store }\end{array}$ \\
\hline 19 & $\begin{array}{l}\text { voice call calls phone service applications services chat businesses } \\
\text { integrate }\end{array}$ \\
\hline 20 & $\begin{array}{l}\text { game games data information sports players live player statistics } \\
\text { scores }\end{array}$ \\
\hline 21 & data information open access government state public u.s tax states \\
\hline 22 & $\begin{array}{l}\text { text language analysis content translation semantic sentiment machine } \\
\text { words word }\end{array}$ \\
\hline 24 & $\begin{array}{l}\text { payment payments online card credit processing transactions account } \\
\text { transaction cards }\end{array}$ \\
\hline 26 & $\begin{array}{l}\text { address data email addresses number service validation numbers } \\
\text { phone verification }\end{array}$ \\
\hline 27 & video videos content photos media photo audio share sharing upload \\
\hline 29 & $\begin{array}{l}\text { data sequence database protein sequences analysis biological soap } \\
\text { research genes }\end{array}$ \\
\hline 31 & data information traffic transit routes times public service bus time \\
\hline 34 & project rest bot bots platform tools life projects goals management \\
\hline 35 & $\begin{array}{l}\text { images image files file pdf documents upload recognition document } \\
\text { conversion }\end{array}$ \\
\hline 36 & $\begin{array}{l}\text { bitcoin exchange trading service account trade currency calls orders } \\
\text { information }\end{array}$ \\
\hline 39 & $\begin{array}{l}\text { sms messages send messaging text mobile message bulk sending } \\
\text { service }\end{array}$ \\
\hline
\end{tabular}

Table 9 - Topics in the final model

\subsection{Model interpretation}

A topic is a reduced set of dimensions that represent a prevalent theme in a corpus of text. The top 10 words in any given topic only reveals the general semantic meaning of the topic. Interpreting each topic could be done by the help of documents that are best represented by the given topic. To extract the information required for the required 
analysis in this research, the use of actual API description documents had to be used in addition to the topic model. To narrow down a set of documents best represented by the given topic, a script was used to find all documents for every topic where the distribution for the highest topic is greater than 0.8 and the distribution for the second highest is less than 0.2. The script ran on the output-doc-topics file from Mallet that contains the documents and their topic distributions. The file was set to only include the distributions of the top 3 topics for each document. Appendix A.3 shows a sample of the output-doc-topics file.

This gives us documents that are mostly made up of one topic, which is the topic under examination. Using this criteria, topics 1 and 13 had no documents with more than 0.8 distribution. To get sample documents for these two topics, another script was written to find all documents in the corpus with topics 1 and 13 as their top most topics. The findings were sorted and the 3 documents with the highest topic distributions were selected as samples. Appendix A.4 shows the resulting examples along with topic distributions.

Topics were then interpreted by iteratively examining the top 10 words and samples of documents or API descriptions that are best represented by the topic. For each topic, the customer value proposition was extracted by interpreting the topic and the sample documents for the benefits and service deliverables that a consumer of this API would gain. The topics and the customer value propositions were then categorized. Table 10 gives a summary of the findings. Detailed analysis for each topic can be found in Appendix A.5. 


\begin{tabular}{|c|c|c|c|c|c|}
\hline \multirow{2}{*}{$\begin{array}{c}\text { Topic } \\
\text { ID }\end{array}$} & \multirow{2}{*}{$\begin{array}{c}\text { Topic } \\
\text { Category }\end{array}$} & \multirow[t]{2}{*}{ Words } & \multicolumn{2}{|c|}{ Customer Value Propositions } & \multirow{2}{*}{$\begin{array}{c}\text { Customer } \\
\text { Value } \\
\text { Proposition } \\
\text { Category } \\
\end{array}$} \\
\hline & & & $\begin{array}{l}\text { Service } \\
\text { Deliverables }\end{array}$ & Benefits & \\
\hline 4 & $\begin{array}{l}\text { Repository } \\
\text { Management }\end{array}$ & $\begin{array}{l}\text { github } \\
\text { software } \\
\text { development } \\
\text { application } \\
\text { applications } \\
\text { providers } \\
\text { range wide } \\
\text { integrate } \\
\text { repository }\end{array}$ & $\begin{array}{l}\text { Provide } \\
\text { access to } \\
\text { software } \\
\text { repository } \\
\text { management } \\
\text { functionality }\end{array}$ & $\begin{array}{l}\text { Integrate } \\
\text { software } \\
\text { repository } \\
\text { management } \\
\text { functionality } \\
\text { without } \\
\text { building the } \\
\text { infrastructure } \\
\text { in house. It } \\
\text { also allows } \\
\text { developers to } \\
\text { have } \\
\text { programmatic } \\
\text { access to the } \\
\text { provider's } \\
\text { services. }\end{array}$ & $\begin{array}{l}\text { Enhance } \\
\text { capability }\end{array}$ \\
\hline 6 & $\begin{array}{l}\text { Cloud } \\
\text { Management }\end{array}$ & $\begin{array}{l}\text { cloud data } \\
\text { storage } \\
\text { service server } \\
\text { access } \\
\text { servers } \\
\text { monitoring } \\
\text { amazon } \\
\text { management }\end{array}$ & $\begin{array}{l}\text { Access and } \\
\text { management } \\
\text { of cloud } \\
\text { storage and } \\
\text { Server } \\
\text { management } \\
\text { functionality }\end{array}$ & $\begin{array}{l}\text { Utilize cloud } \\
\text { capabilities } \\
\text { and resources } \\
\text { without } \\
\text { acquiring } \\
\text { infrastructure }\end{array}$ & $\begin{array}{l}\text { Enhance } \\
\text { capability }\end{array}$ \\
\hline 14 & $\begin{array}{l}\text { Digital } \\
\text { Marketing }\end{array}$ & $\begin{array}{l}\text { marketing } \\
\text { email } \\
\text { campaigns } \\
\text { platform } \\
\text { analytics } \\
\text { customers } \\
\text { social } \\
\text { customer } \\
\text { advertising } \\
\text { media }\end{array}$ & $\begin{array}{l}\text { Access to } \\
\text { marketing and } \\
\text { digital } \\
\text { services } \\
\text { capabilities } \\
\text { provided by } \\
\text { the API } \\
\text { developer }\end{array}$ & $\begin{array}{l}\text { Gives } \\
\text { developers } \\
\text { access to } \\
\text { functionality } \\
\text { that is costly } \\
\text { to develop in } \\
\text { terms of } \\
\text { infrastructure } \\
\text { and know-how }\end{array}$ & $\begin{array}{l}\text { Enhance } \\
\text { capability }\end{array}$ \\
\hline 17 & $\begin{array}{l}\text { Location and } \\
\text { Mapping }\end{array}$ & $\begin{array}{l}\text { location map } \\
\text { maps } \\
\text { information } \\
\text { data code } \\
\text { address } \\
\text { locations }\end{array}$ & $\begin{array}{l}\text { Access to } \\
\text { locating and } \\
\text { mapping } \\
\text { functionality }\end{array}$ & $\begin{array}{l}\text { Gives } \\
\text { developers } \\
\text { access to } \\
\text { functionality } \\
\text { that is hard to } \\
\text { develop in }\end{array}$ & $\begin{array}{l}\text { Enhance } \\
\text { capability }\end{array}$ \\
\hline
\end{tabular}




\begin{tabular}{|c|c|c|c|c|c|}
\hline & & $\begin{array}{l}\text { service } \\
\text { mapping }\end{array}$ & & $\begin{array}{l}\text { terms of } \\
\text { know-how }\end{array}$ & \\
\hline 19 & $\begin{array}{l}\text { Voice and } \\
\text { Chat }\end{array}$ & $\begin{array}{l}\text { voice call calls } \\
\text { phone service } \\
\text { applications } \\
\text { services chat } \\
\text { businesses } \\
\text { integrate }\end{array}$ & $\begin{array}{l}\text { Access to } \\
\text { voice calling } \\
\text { functionality }\end{array}$ & $\begin{array}{l}\text { Ability to } \\
\text { integrate } \\
\text { functionality } \\
\text { that is hard to } \\
\text { develop } \\
\text { because of the } \\
\text { lack of know- } \\
\text { how or the } \\
\text { time needed } \\
\text { for } \\
\text { development }\end{array}$ & $\begin{array}{l}\text { Enhance } \\
\text { capability }\end{array}$ \\
\hline 22 & $\begin{array}{l}\text { Natural } \\
\text { Language } \\
\text { Processing }\end{array}$ & $\begin{array}{l}\text { text language } \\
\text { analysis } \\
\text { content } \\
\text { translation } \\
\text { semantic } \\
\text { sentiment } \\
\text { machine } \\
\text { words word }\end{array}$ & $\begin{array}{l}\text { Gives access } \\
\text { to a range of } \\
\text { Natural } \\
\text { Language } \\
\text { Processing } \\
\text { functionality } \\
\text { such as } \\
\text { keyword } \\
\text { extraction, } \\
\text { predict } \\
\text { language } \\
\text { sentiment, } \\
\text { and extract } \\
\text { relevant } \\
\text { topics from } \\
\text { text based on } \\
\text { relevant } \\
\text { categories. }\end{array}$ & $\begin{array}{l}\text { The ability to } \\
\text { do } \\
\text { complicated } \\
\text { NLP tasks } \\
\text { without the } \\
\text { need to } \\
\text { develop the } \\
\text { algorithms or } \\
\text { invest in the } \\
\text { infrastructure } \\
\text { themselves. }\end{array}$ & $\begin{array}{l}\text { Enhance } \\
\text { capability }\end{array}$ \\
\hline 26 & Verification & $\begin{array}{l}\text { address data } \\
\text { email } \\
\text { addresses } \\
\text { number } \\
\text { service } \\
\text { validation } \\
\text { numbers } \\
\text { phone } \\
\text { verification }\end{array}$ & $\begin{array}{l}\text { Validate email } \\
\text { addresses, } \\
\text { validate } \\
\text { routing } \\
\text { numbers, and } \\
\text { validate } \\
\text { postcodes. }\end{array}$ & $\begin{array}{l}\text { Access to } \\
\text { functionality } \\
\text { that is hard to } \\
\text { implement } \\
\text { due to the } \\
\text { high cost of } \\
\text { gathering the } \\
\text { necessary data } \\
\text { and the lack of } \\
\text { know-how }\end{array}$ & $\begin{array}{l}\text { Enhance } \\
\text { capability }\end{array}$ \\
\hline 27 & Content & $\begin{array}{l}\text { video videos } \\
\text { content }\end{array}$ & $\begin{array}{l}\text { Sharing and } \\
\text { uploading }\end{array}$ & $\begin{array}{l}\text { The ability to } \\
\text { integrate }\end{array}$ & $\begin{array}{l}\text { Enhance } \\
\text { capability }\end{array}$ \\
\hline
\end{tabular}




\begin{tabular}{|c|c|c|c|c|c|}
\hline & & $\begin{array}{l}\text { photos media } \\
\text { photo audio } \\
\text { share sharing } \\
\text { upload }\end{array}$ & $\begin{array}{l}\text { video, audio, } \\
\text { and media } \\
\text { content }\end{array}$ & $\begin{array}{l}\text { functionality } \\
\text { that is hard to } \\
\text { develop into } \\
\text { their } \\
\text { applications }\end{array}$ & \\
\hline 29 & $\begin{array}{l}\text { Bio- } \\
\text { informatics }\end{array}$ & $\begin{array}{l}\text { data } \\
\text { sequence } \\
\text { database } \\
\text { protein } \\
\text { sequences } \\
\text { analysis } \\
\text { biological } \\
\text { soap research } \\
\text { genes }\end{array}$ & $\begin{array}{l}\text { Provide a } \\
\text { programmatic } \\
\text { interface to } \\
\text { functionality } \\
\text { such as } \\
\text { protein } \\
\text { sequencing, } \\
\text { protein } \\
\text { sequence } \\
\text { analysis, } \\
\text { alignment of } \\
\text { mass } \\
\text { spectrometry } \\
\text { images for } \\
\text { comparison, } \\
\text { and DNA } \\
\text { sequencing. }\end{array}$ & $\begin{array}{l}\text { Access to very } \\
\text { complex } \\
\text { machine } \\
\text { learning } \\
\text { algorithms } \\
\text { that are hard } \\
\text { to develop } \\
\text { due to lack of } \\
\text { know-how and } \\
\text { the high cost } \\
\text { of needed } \\
\text { infrastructure. }\end{array}$ & $\begin{array}{l}\text { Enhance } \\
\text { capability }\end{array}$ \\
\hline 35 & $\begin{array}{l}\text { Format } \\
\text { Conversion }\end{array}$ & $\begin{array}{l}\text { images image } \\
\text { files file pdf } \\
\text { documents } \\
\text { upload } \\
\text { recognition } \\
\text { document } \\
\text { conversion }\end{array}$ & $\begin{array}{l}\text { Allows } \\
\text { developers to } \\
\text { perform file } \\
\text { format } \\
\text { conversions } \\
\text { between } \\
\text { multiple file } \\
\text { formats }\end{array}$ & $\begin{array}{l}\text { Access to hard } \\
\text { to develop } \\
\text { functionality } \\
\text { due to lack of } \\
\text { know-how and } \\
\text { time required }\end{array}$ & $\begin{array}{l}\text { Enhance } \\
\text { capability }\end{array}$ \\
\hline 36 & $\begin{array}{l}\text { Crypto- } \\
\text { currency }\end{array}$ & $\begin{array}{l}\text { bitcoin } \\
\text { exchange } \\
\text { trading } \\
\text { service } \\
\text { account trade } \\
\text { currency calls } \\
\text { orders } \\
\text { information }\end{array}$ & $\begin{array}{l}\text { Allows } \\
\text { developers to } \\
\text { perform } \\
\text { cryptocurrenc } \\
\text { y related tasks } \\
\text { such as } \\
\text { mining } \\
\text { bitcoin, query } \\
\text { exchange rate } \\
\text { information } \\
\text { and market } \\
\text { statistics, and } \\
\text { perform } \\
\text { trading }\end{array}$ & $\begin{array}{l}\text { Access to hard } \\
\text { to gather data } \\
\text { and hard to } \\
\text { develop } \\
\text { functionality }\end{array}$ & $\begin{array}{l}\text { Enhance } \\
\text { capability }\end{array}$ \\
\hline
\end{tabular}




\begin{tabular}{|c|c|c|c|c|c|}
\hline & & & $\begin{array}{l}\text { transactions } \\
\text { like } \\
\text { purchasing, } \\
\text { holding, and } \\
\text { selling } \\
\text { bitcoins }\end{array}$ & & \\
\hline 18 & E-Commerce & $\begin{array}{l}\text { product } \\
\text { products } \\
\text { information } \\
\text { online } \\
\text { shopping } \\
\text { deals search } \\
\text { access price } \\
\text { store } \\
\end{array}$ & $\begin{array}{l}\text { Searching } \\
\text { Product } \\
\text { pricing and } \\
\text { deals }\end{array}$ & $\begin{array}{l}\text { Allows } \\
\text { developers to } \\
\text { become } \\
\text { affiliates and } \\
\text { resellers to } \\
\text { the main } \\
\text { service } \\
\text { provider. }\end{array}$ & $\begin{array}{l}\text { Enhance } \\
\text { capability }\end{array}$ \\
\hline 3 & Logistics & $\begin{array}{l}\text { domain } \\
\text { shipping } \\
\text { delivery } \\
\text { service } \\
\text { services } \\
\text { domains } \\
\text { tracking mail } \\
\text { dns } \\
\text { customers }\end{array}$ & $\begin{array}{l}\text { Integrating } \\
\text { shipping, } \\
\text { tracking, and } \\
\text { delivery } \\
\text { functionality }\end{array}$ & $\begin{array}{l}\text { The ability to } \\
\text { provide } \\
\text { shipping and } \\
\text { delivery } \\
\text { services } \\
\text { without } \\
\text { owning a } \\
\text { shipping } \\
\text { company or } \\
\text { building a } \\
\text { shipping } \\
\text { infrastructure }\end{array}$ & $\begin{array}{l}\text { Enhance } \\
\text { capability }\end{array}$ \\
\hline 10 & Media & $\begin{array}{l}\text { music events } \\
\text { event } \\
\text { information } \\
\text { movie movies } \\
\text { shows radio } \\
\text { database } \\
\text { artists }\end{array}$ & $\begin{array}{l}\text { Ability to } \\
\text { programmatic } \\
\text { ally search } \\
\text { databases of } \\
\text { music, } \\
\text { movies, } \\
\text { shows, artists, } \\
\text { and events }\end{array}$ & $\begin{array}{l}\text { Ability to use } \\
\text { information in } \\
\text { applications } \\
\text { that they } \\
\text { could not have } \\
\text { access to } \\
\text { previously }\end{array}$ & $\begin{array}{l}\text { Increase } \\
\text { information } \\
\text { resources }\end{array}$ \\
\hline 12 & $\begin{array}{l}\text { Travel and } \\
\text { Finance }\end{array}$ & $\begin{array}{l}\text { data travel } \\
\text { booking } \\
\text { market stock } \\
\text { financial } \\
\text { access } \\
\text { information } \\
\text { flight hotel }\end{array}$ & $\begin{array}{l}\text { Booking } \\
\text { Flights and } \\
\text { Hotels and } \\
\text { access to } \\
\text { flight and } \\
\text { hotel } \\
\text { information.- } \\
\text { Access to } \\
\text { financial }\end{array}$ & $\begin{array}{l}\text { Access to } \\
\text { financial and } \\
\text { travel data } \\
\text { gathered, } \\
\text { aggregated, } \\
\text { and analyzed } \\
\text { by the } \\
\text { provider }\end{array}$ & $\begin{array}{l}\text { Increase } \\
\text { information } \\
\text { resources }\end{array}$ \\
\hline
\end{tabular}




\begin{tabular}{|c|c|c|c|c|c|}
\hline & & & $\begin{array}{l}\text { information } \\
\text { and } \\
\text { performing } \\
\text { financial } \\
\text { services tasks } \\
\text { such as } \\
\text { currency } \\
\text { conversion } \\
\text { and analysis }\end{array}$ & & \\
\hline 15 & Weather & $\begin{array}{l}\text { data weather } \\
\text { information } \\
\text { energy access } \\
\text { time } \\
\text { conditions } \\
\text { location } \\
\text { national solar }\end{array}$ & $\begin{array}{l}\text { Access to } \\
\text { weather } \\
\text { related } \\
\text { information }\end{array}$ & $\begin{array}{l}\text { Gives } \\
\text { developers } \\
\text { access to data } \\
\text { that requires } \\
\text { large } \\
\text { infrastructure } \\
\text { and } \\
\text { knowledge } \\
\text { investments to } \\
\text { gather, } \\
\text { aggregate, and } \\
\text { store. }\end{array}$ & $\begin{array}{l}\text { Increase } \\
\text { information } \\
\text { resources }\end{array}$ \\
\hline 20 & $\begin{array}{l}\text { Sports } \\
\text { Statistics }\end{array}$ & $\begin{array}{l}\text { game games } \\
\text { data } \\
\text { information } \\
\text { sports players } \\
\text { live player } \\
\text { statistics } \\
\text { scores }\end{array}$ & $\begin{array}{l}\text { Access to } \\
\text { Sports, } \\
\text { players, and } \\
\text { game } \\
\text { information } \\
\text { such as } \\
\text { statistics and } \\
\text { metrics }\end{array}$ & $\begin{array}{l}\text { Getting access } \\
\text { to hard to } \\
\text { collect and } \\
\text { aggregate } \\
\text { sports data }\end{array}$ & $\begin{array}{l}\text { Increase } \\
\text { information } \\
\text { resources }\end{array}$ \\
\hline 21 & $\begin{array}{l}\text { Open } \\
\text { Government }\end{array}$ & $\begin{array}{l}\text { data } \\
\text { information } \\
\text { open access } \\
\text { government } \\
\text { state public } \\
\text { u.s tax states }\end{array}$ & $\begin{array}{l}\text { Access to } \\
\text { government } \\
\text { open data. } \\
\text { Provide } \\
\text { functionality } \\
\text { for modeling } \\
\text { and searching } \\
\text { open data. }\end{array}$ & $\begin{array}{l}\text { Allow data } \\
\text { providers to } \\
\text { model and } \\
\text { open their } \\
\text { data in a } \\
\text { standardized } \\
\text { and consistent } \\
\text { way and allow } \\
\text { developers to } \\
\text { access hard to } \\
\text { collect and } \\
\text { aggregate } \\
\text { data }\end{array}$ & $\begin{array}{l}\text { Increase } \\
\text { information } \\
\text { resources }\end{array}$ \\
\hline
\end{tabular}




\begin{tabular}{|c|c|c|c|c|c|}
\hline 31 & Transit Data & $\begin{array}{l}\text { data } \\
\text { information } \\
\text { traffic transit } \\
\text { routes times } \\
\text { public service } \\
\text { bus time }\end{array}$ & $\begin{array}{l}\text { Access to real- } \\
\text { time bus, } \\
\text { subway, and } \\
\text { train } \\
\text { information } \\
\text { such as } \\
\text { location and } \\
\text { schedule }\end{array}$ & $\begin{array}{l}\text { Access to hard } \\
\text { to gather } \\
\text { information } \\
\text { that only a city } \\
\text { can provide. }\end{array}$ & $\begin{array}{l}\text { Increase } \\
\text { information } \\
\text { resources }\end{array}$ \\
\hline 13 & $\begin{array}{l}\text { Medical } \\
\text { Information }\end{array}$ & $\begin{array}{l}\text { health } \\
\text { medical } \\
\text { information } \\
\text { data } \\
\text { healthcare } \\
\text { care } \\
\text { insurance } \\
\text { providers } \\
\text { fitness drug }\end{array}$ & $\begin{array}{l}\text { Access to } \\
\text { medical } \\
\text { information } \\
\text { from multiple } \\
\text { sources }\end{array}$ & $\begin{array}{l}\text { Gives } \\
\text { developers } \\
\text { the ability to } \\
\text { access } \\
\text { multiple } \\
\text { resources } \\
\text { aggregated } \\
\text { and connected } \\
\text { to by the } \\
\text { provider. }\end{array}$ & $\begin{array}{l}\text { Increase } \\
\text { Information } \\
\text { Resources }\end{array}$ \\
\hline 1 & Real Estate & $\begin{array}{l}\text { property real } \\
\text { affiliate } \\
\text { estate search } \\
\text { listings } \\
\text { properties } \\
\text { rental } \\
\text { website } \\
\text { program }\end{array}$ & $\begin{array}{l}\text { Searching for } \\
\text { real estate } \\
\text { information }\end{array}$ & $\begin{array}{l}\text { Access to } \\
\text { expensive to } \\
\text { collect data } \\
\text { they } \\
\text { previously did } \\
\text { not have } \\
\text { access to }\end{array}$ & $\begin{array}{l}\text { Increase } \\
\text { information } \\
\text { resources }\end{array}$ \\
\hline 5 & $\begin{array}{l}\text { Mobile } \\
\text { Integration }\end{array}$ & $\begin{array}{l}\text { mobile } \\
\text { devices app } \\
\text { apps device } \\
\text { applications } \\
\text { data android } \\
\text { platform } \\
\text { application }\end{array}$ & $\begin{array}{l}\text { Integrate } \\
\text { mobile } \\
\text { applications } \\
\text { with } \\
\text { functionality } \\
\text { provided by a } \\
\text { platform }\end{array}$ & $\begin{array}{l}\text { Allows } \\
\text { developers to } \\
\text { customize and } \\
\text { personalize } \\
\text { the use of the } \\
\text { product. }\end{array}$ & $\begin{array}{l}\text { Person- } \\
\text { alization }\end{array}$ \\
\hline 34 & $\begin{array}{l}\text { Workplace } \\
\text { Collab- } \\
\text { oration }\end{array}$ & $\begin{array}{l}\text { project rest } \\
\text { bot bots } \\
\text { platform } \\
\text { tools life } \\
\text { projects goals } \\
\text { management }\end{array}$ & $\begin{array}{l}\text { Enable the } \\
\text { users of the } \\
\text { products to } \\
\text { customize and } \\
\text { integrate } \\
\text { project } \\
\text { management, } \\
\text { collaboration } \\
\text { and chatting } \\
\text { tools provide } \\
\text { by the }\end{array}$ & $\begin{array}{l}\text { The main } \\
\text { benefit these } \\
\text { APIs provide is } \\
\text { interoperabilit } \\
\mathrm{y} \text { and } \\
\text { personalizatio } \\
\mathrm{n} \text { of the main } \\
\text { service } \\
\text { provided by } \\
\text { the vendors. }\end{array}$ & $\begin{array}{l}\text { Inter- } \\
\text { operability }\end{array}$ \\
\hline
\end{tabular}




\begin{tabular}{|c|c|c|c|c|c|}
\hline & & & $\begin{array}{l}\text { vendors with } \\
\text { other } \\
\text { applications }\end{array}$ & & \\
\hline 2 & Social Media & $\begin{array}{l}\text { social content } \\
\text { twitter news } \\
\text { media share } \\
\text { facebook } \\
\text { access data } \\
\text { information }\end{array}$ & $\begin{array}{l}\text { Sharing } \\
\text { content on } \\
\text { multiple social } \\
\text { media sites }\end{array}$ & $\begin{array}{l}\text { Reduces the } \\
\text { cost of } \\
\text { implementatio } \\
\mathrm{n} \text { as they only } \\
\text { have to } \\
\text { integrate with } \\
\text { one supplier } \\
\text { and they get } \\
\text { access to } \\
\text { multiple social } \\
\text { media sites at } \\
\text { once }\end{array}$ & $\begin{array}{l}\text { Linking } \\
\text { Services }\end{array}$ \\
\hline 24 & Payment & $\begin{array}{l}\text { payment } \\
\text { payments } \\
\text { online card } \\
\text { credit } \\
\text { processing } \\
\text { transactions } \\
\text { account } \\
\text { transaction } \\
\text { cards }\end{array}$ & $\begin{array}{l}\text { Provide } \\
\text { payment } \\
\text { processing } \\
\text { functionality } \\
\text { for digital and } \\
\text { real } \\
\text { currencies }\end{array}$ & $\begin{array}{l}\text { The ability to } \\
\text { process } \\
\text { payments } \\
\text { without } \\
\text { having to deal } \\
\text { with banking } \\
\text { systems, } \\
\text { compliance, } \\
\text { fraud, and } \\
\text { security }\end{array}$ & $\begin{array}{l}\text { Linking } \\
\text { Services }\end{array}$ \\
\hline 39 & $\begin{array}{l}\text { SMS } \\
\text { Messaging }\end{array}$ & $\begin{array}{l}\text { sms } \\
\text { messages } \\
\text { send } \\
\text { messaging } \\
\text { text mobile } \\
\text { message bulk } \\
\text { sending } \\
\text { service }\end{array}$ & $\begin{array}{l}\text { Access to SMS } \\
\text { messaging } \\
\text { functionality } \\
\text { and } \\
\text { connectivity } \\
\text { to multiple } \\
\text { mobile } \\
\text { network } \\
\text { operators } \\
\text { around the } \\
\text { world }\end{array}$ & $\begin{array}{l}\text { Ability to } \\
\text { connect to } \\
\text { multiple } \\
\text { mobile } \\
\text { network } \\
\text { operators at } \\
\text { once, reducing } \\
\text { the cost of } \\
\text { connectivity } \\
\text { and } \\
\text { integration }\end{array}$ & $\begin{array}{l}\text { Linking } \\
\text { Services }\end{array}$ \\
\hline 11 & $\begin{array}{l}\text { Vehicle } \\
\text { Registration }\end{array}$ & $\begin{array}{l}\text { data } \\
\text { ondemand } \\
\text { barchart } \\
\text { vehicle } \\
\text { analysis }\end{array}$ & $\begin{array}{l}\text { Access to } \\
\text { Vehicle } \\
\text { registration } \\
\text { information } \\
\text { from multiple }\end{array}$ & $\begin{array}{l}\text { Access to data } \\
\text { they could not } \\
\text { get access to } \\
\text { before as well } \\
\text { as querying }\end{array}$ & Linking Data \\
\hline
\end{tabular}




\begin{tabular}{|l|l|l|l|}
$\mid$\begin{tabular}{l|l|} 
number $x m l$ \\
car request \\
index
\end{tabular} & countries & $\begin{array}{l}\text { multiple } \\
\text { sources of } \\
\text { data at once. }\end{array}$ & \\
\hline
\end{tabular}

Table 10 - Model interpretation and categorization summary

\subsection{Topic trend graphs}

Topic trend graphs were produced by plotting the proportion of the cumulative number of documents mostly composed of a given topic versus the overall cumulative number of documents in a given date in time. Two types of graphs were produced: individual graphs and aggregate graphs. Individual graphs were produced by plotting a graph of topic proportion versus time for each topic for the given topic ids, while aggregate graphs were produced by plotting the sum of topic proportions for a given set of topic ids versus time. Individual graphs are useful in identifying trends among topics that belong to a certain customer value proposition category, and aggregate graphs are useful in identifying trends among categories of customer value propositions.

\subsubsection{Aggregate topic trend graphs for all categories}

Figure 8 shows the aggregate plots of topic trend graphs for all the categories that emerged in section 4.3. They category Increasing Capabilities takes the highest share of the documents at around $27 \%$ in 2016 . It increased steadily from $20-25 \%$ in $2006 / 2007$. The second place is occupied by the category of Increasing Information Resources. This category showed a constant and steady variation around the $13 \%$ mark. Linking Services comes at third place with $9 \%$ in 2016 . These three categories combined are taking around $50 \%$ of the overall document count. The next three categories are 
Personalization at $2.5 \%$, Linking data and Interoperability both at $1 \%$. The next three categories combined form $5.5-6 \%$ of the document share, indicating that they fall more towards niche categories than mainstream categories. One thing to note about these curves is, except for Linking Data, the rest of the curves are mostly steady throughout time. However, as will be shown in the next sections, within these categories there are many variations at the individual topic levels. This indicates movement within the industry from niche to mainstream, and vice versa.

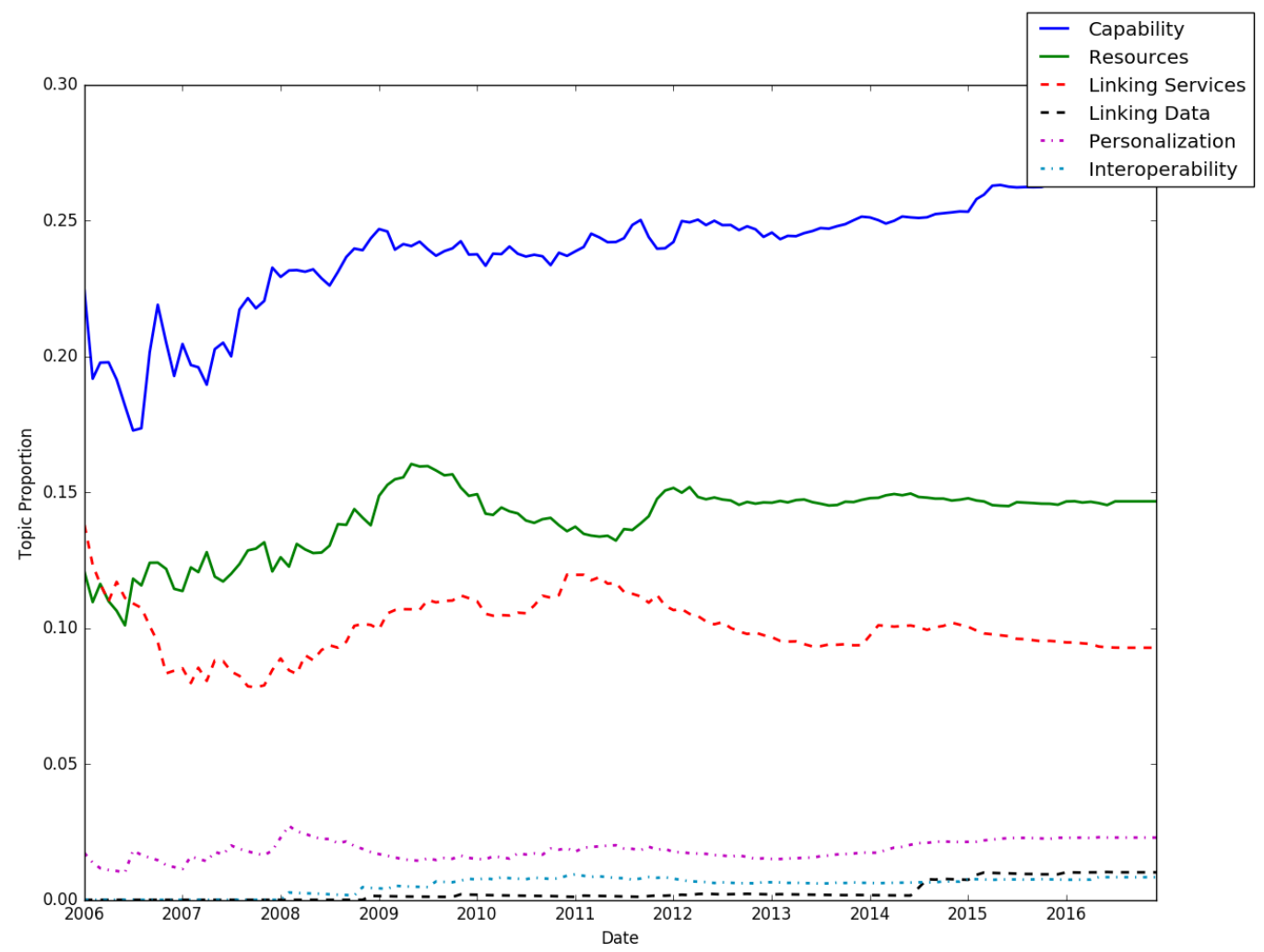

Figure 8 - Aggregate topic trend graphs for all categories

\subsubsection{Individual topic trend graphs for category: Increasing Capability}

Figure 9 shows plots for individual topic trend graphs in the category Increasing 
Capability showing a lot of variation during the period 2008 to 2009. This is expected as the API service system was just forming and getting in shape. A period of stability followed between 2009 to 2011, where most categories were well established and in position. During this period, Location and Mapping had the highest share of the topics followed by E-commerce. This result is again expected as mapping and e-commerce APIs were the most common use cases in the API economy.

In mid-2011 and beginning 2012 a lot of movement occurred within the API service system where niche areas rose significantly taking their positions among the top categories in the service system. The categories of Bioinformatics and Cryptocurrency saw significant increase in the document share. Also, Digital Marketing, Cloud Management, and Natural Language Processing saw increases in this period. In 2015, the category of Repository Management saw a jump, however it remains a niche area in the API service system. 


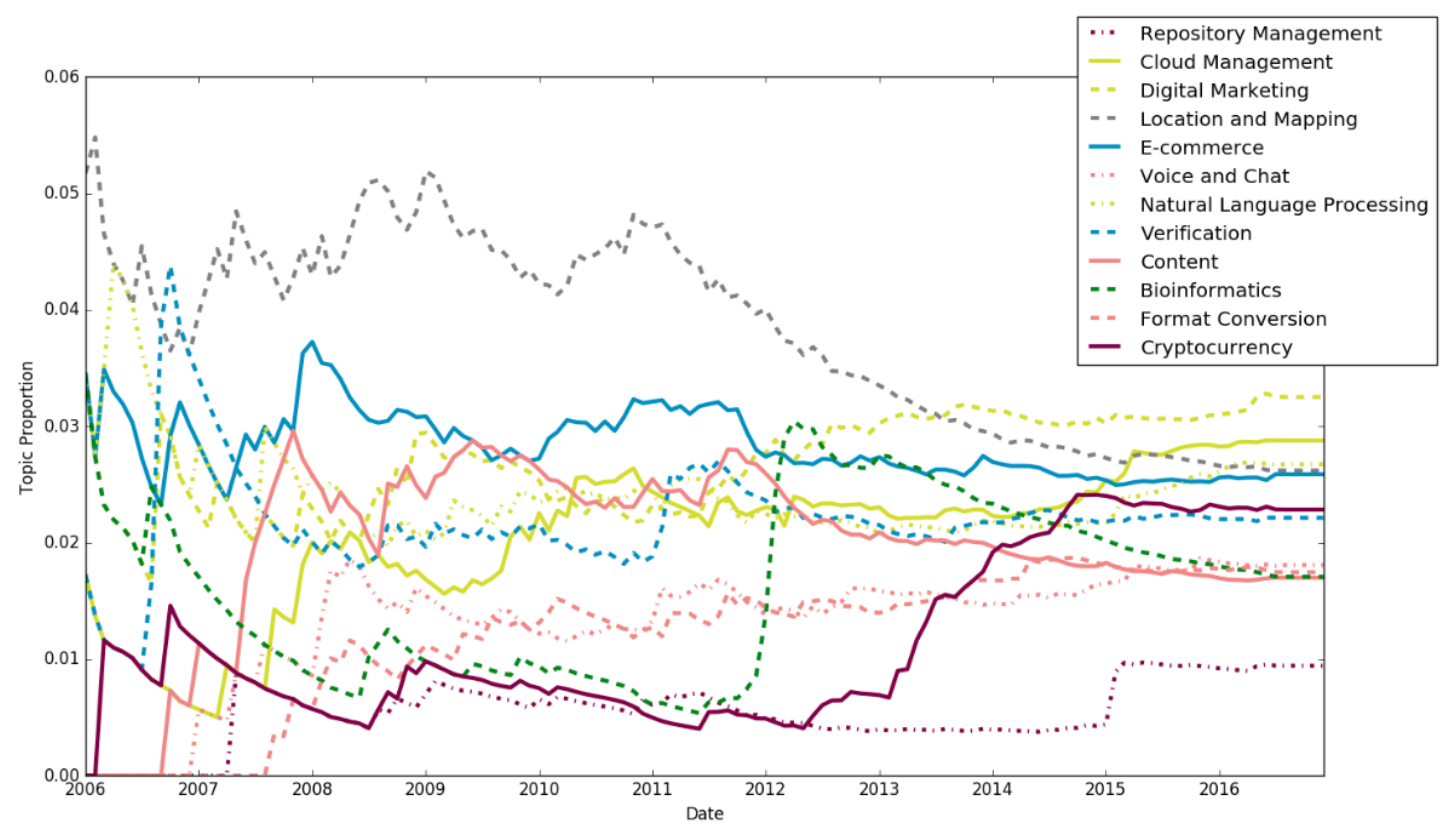

Figure 9 - Individual topic trends for Increasing Capability.

\subsubsection{Individual topic trend graphs for category: Increasing Information Resources}

Figure 10 shows topic trend graphs for individual topics in the category of Increasing Information Resources. Similar to Increasing Capability, this category saw a period of high movement between the inception of the API service system and early 2009. This was followed by a relatively stable period between 2009 and mid 2011. After mid 2011 some categories saw upward movement to join the mainstream.

This graph can be seen as composed of two clusters: 1) Travel and Finance, Open Government, and Media, 2) Weather, Real Estate, Transit Data, and Sports Statistics. During the stable period, cluster 1 took the highest share of the API service system, while cluster 2 came in second place. Medical Information was the lowest among all of them. Between mid-2011 and 2012 Weather and Transit Data from cluster 2 rose, 
coming close to the declining Travel and Finance, and Media from cluster 1 . In cluster 1 Open Government increased as well, which correlates well with Transit Data. In cluster 2, Real Estate declined, while Medical Information increased coming close to Real Estate.

These movements show that mainstream categories such as Travel and Finance, Media, and Real Estate declined compared to emerging categories such as Weather, Open Data, and Medical Information.

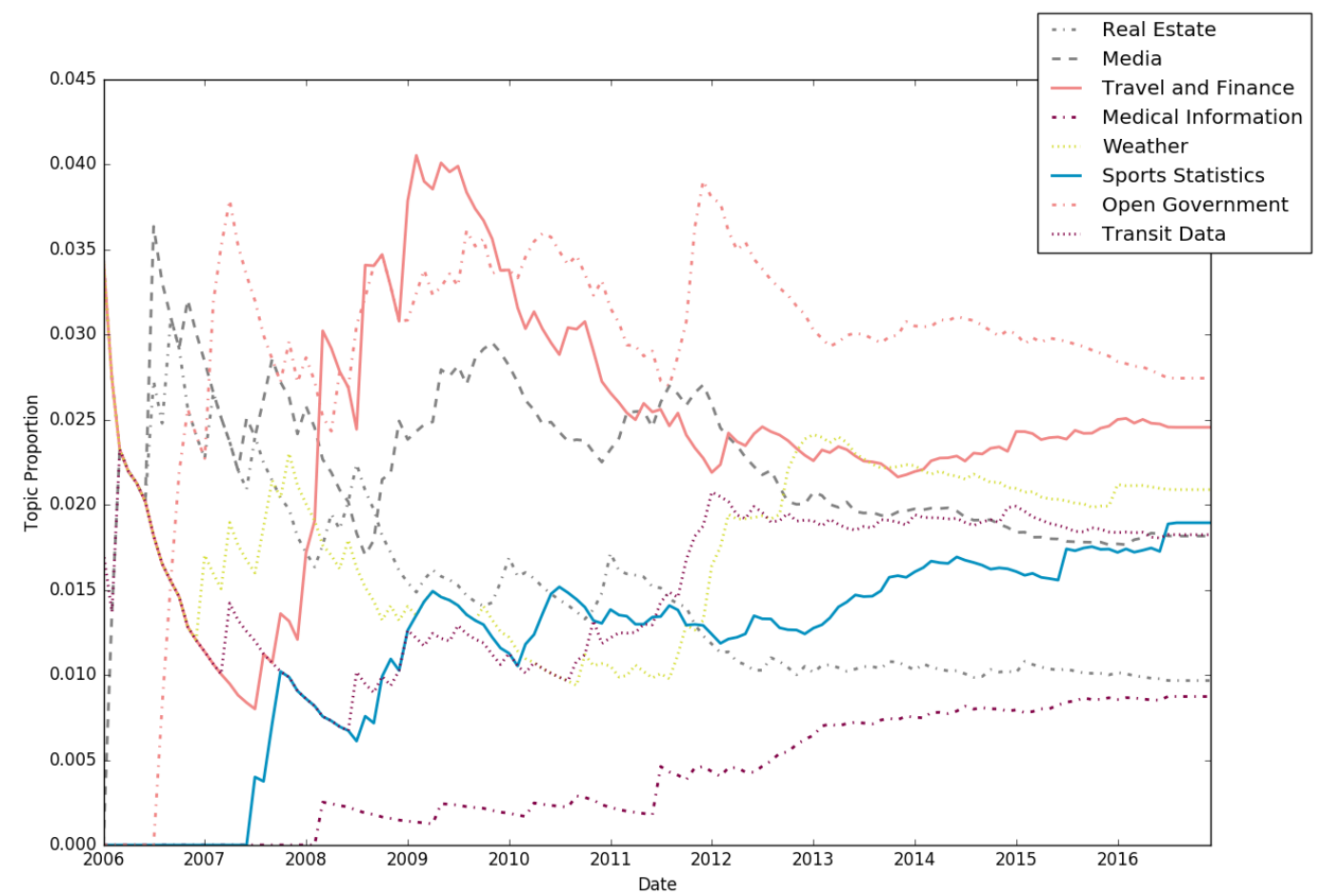

Figure 10 - Individual topic trend graphs for Increasing Information Resources

\subsubsection{Individual topic trend graphs for category: Personalization and Interoperability}

Figure 11 shows the plots for individual topics in the categories of Personalization and 
Interoperability. The graph shows a steady increase in both categories since the beginning of the API service system. Mobile Integration takes the larger share of the service system. An interesting observation to note in this graph is the sharp peak in Mobile Integration around 2008. This was the period where the global financial crises occurred, this peak shows a sudden drop in Mobile Integration use cases from the exponential increase it was observing. However, Mobile Integration which is categorized as Personalization saw a comeback in 2009 increasing steadily since then.

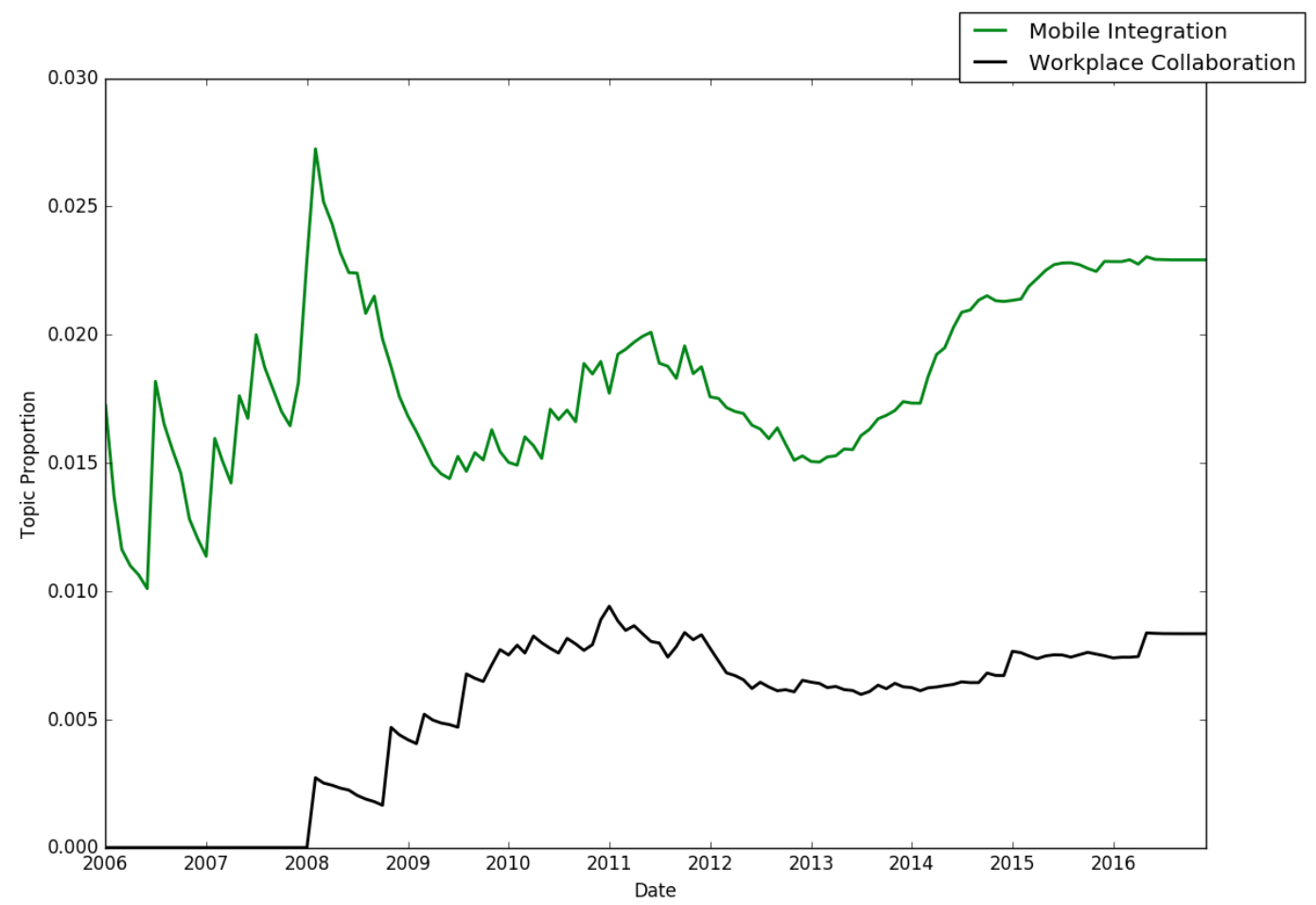

Figure 11 - Individual topic trends for Personalization and Interoperability.

\subsubsection{Individual topic trend graphs for categories: Linking services, and Linking data}

Figure 12 shows individual topic graphs for categories Linking Services and Linking Data. The graph shows similar trends to the previous graphs, where the period between 2006 
and 2009 show large variability, the period between 2009 and 2012 show steadiness and the period after 2012 show more movement. Social Media here shows the largest movement at the mid 2011 mark declining to join the remaining topics. Both SMS Messaging and Vehicle Registration saw a step increase around 2014.

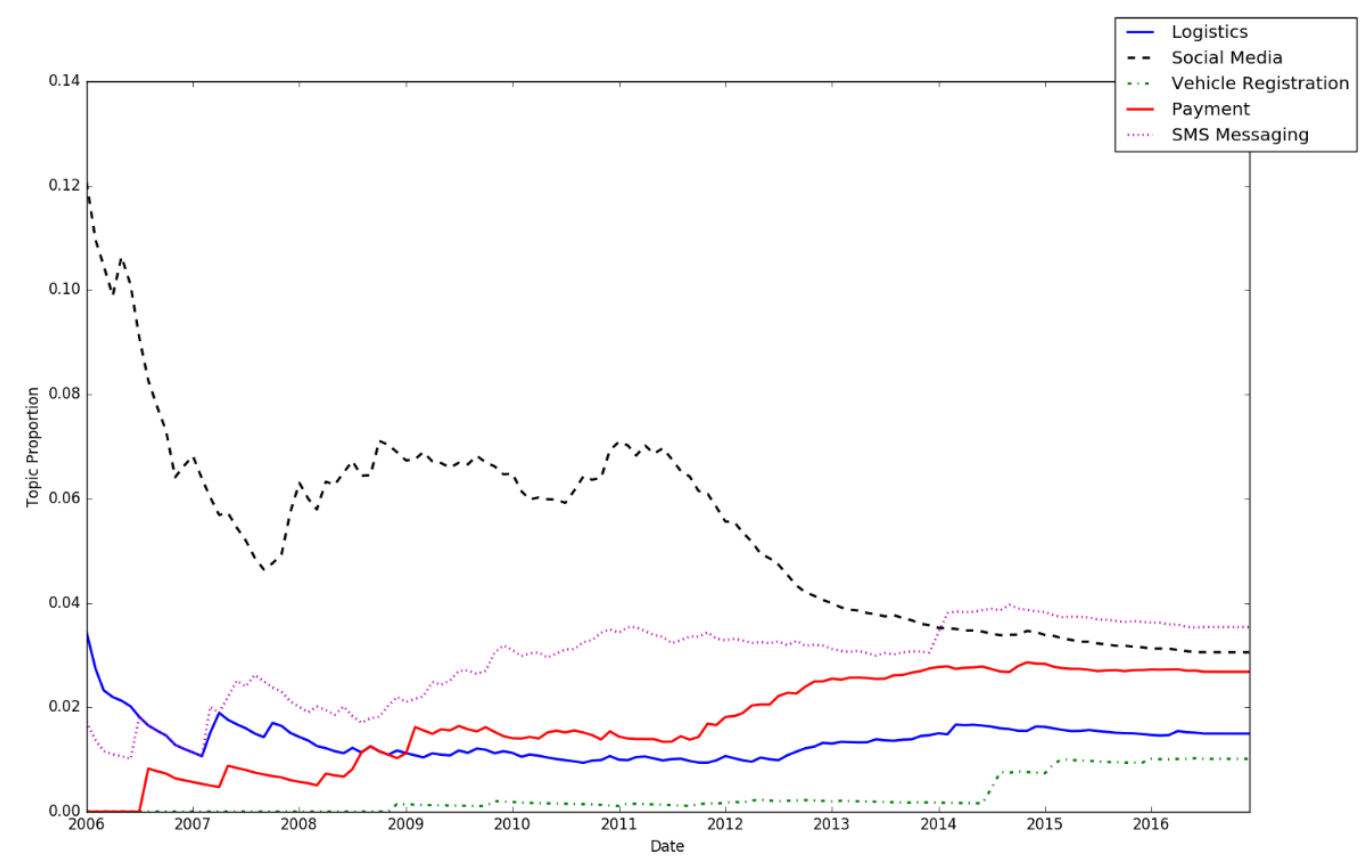

Figure 12 - Individual topic trend graphs for Linking Services and Linking Data

\subsubsection{Individual topic trend graphs for all topics}

Figure 13 shows individual topic trend graphs for all topics. In this graph the three periods reported in previous graphs are very obvious. The first period is between 2006 to 2009. This period was the inception of the API service system, and many topics got introduced making movements and variability high in this period. Between 2009 and mid 2011 was a period of relative steadiness in all topics. After 2012 more movement occurred and all topics converged coming very close to each other. 
The period between 2009 and 2011 showed a distribution in topics that is characteristic of a power law distribution where few topics had the highest share and many topics had smaller shares. However, in 2016 this distribution seems to disappear showing a steady declining distribution between all topics.

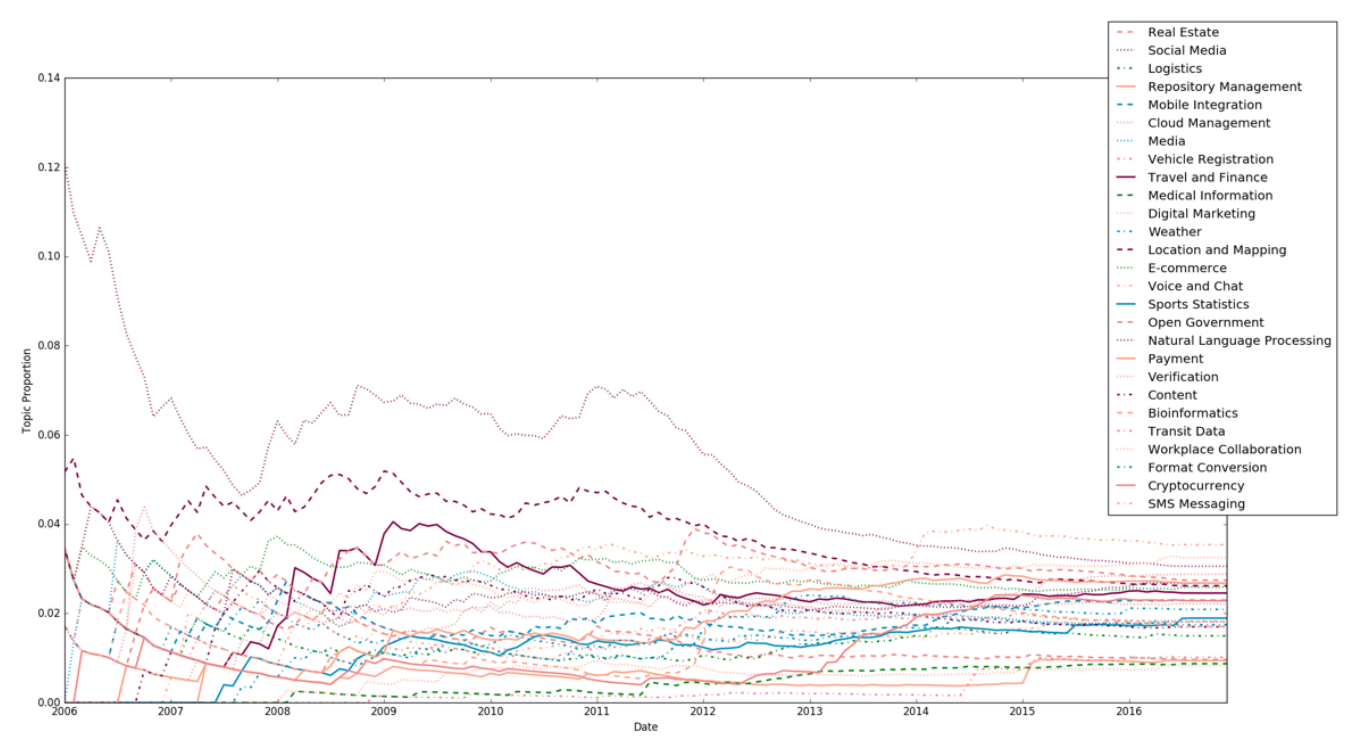

Figure 13 - Individual topic trend graphs for all topics.

\subsubsection{Long tail graphs}

The observation from section 4.4.6 of a disappearing power law like distribution signals a long tail in the API service system among topic distributions. This calls for plotting topic proportions versus topic ranks to see how the service system has evolved. The curves would need to be plotted at a snapshot of time and two snapshots were chosen: June 2009, and January 2016. June 2009 was the beginning of the steady period where most topics have taken their position in the service system and not much movement is going on. January 2016 is a later stage of the second high movement period where 
topics movement has also settled.

Figure 14 shows the two curves plotted on the same graph. The June 2009 curve is typical of a long tail curve where few topics have the largest share of the API service system and the rest have lower shares. The January 2016 curve however shows a steady declining slope where topics have steady decreasing distributions. These results show that the API service system had a long tail distribution that has flattened out.

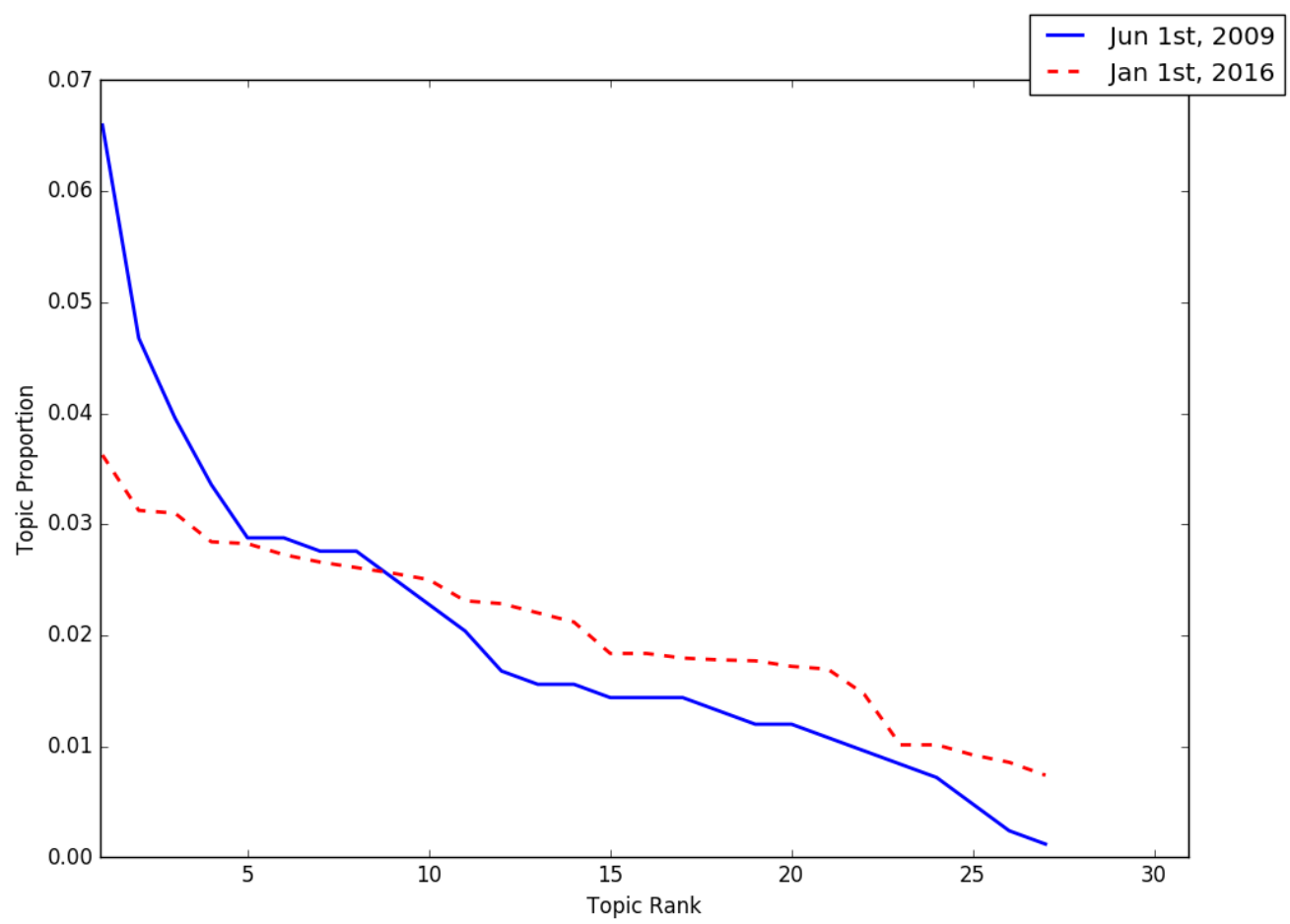

Figure 14 - Topic proportions vs Topic Rank

\subsubsection{Long tail topics and topic proportions}

To further break down what happened in the long tail a table with topic categories and topic proportions was created for each period snapshot. The topics were sorted decreasing order of topic proportions to reflect the long tail curve. To identify the head 
and the tail of the long tail the area under the curve was calculated for each topic going from left to right (Area Increasing) and from right to left (Area Decreasing). The area was calculated by adding the topic proportions up to the current topic. The two topics around which the area increasing and the area decreasing cross each other was marked as the cutoff between the head and the tail. Essentially this marks the cutoff where the area under the curve for the head is equal to the area under the curve for the tail.

Table 11 shows the topic proportions for the June 2009 snapshot. The head included topics that were considered mainstream for the longest time. Topics such as Social Media, Mapping, Travel and Finance topped the head with the largest share of APIs. Closer to the head were Media and SMS Messaging both with topic proportions that are very close to topics in the head. Due to the way the head cut-off was calculated these topics did not make it into the head, however Media for example has the same distribution of documents as Digital marketing.

\begin{tabular}{|c|r|l|r|r|r|}
\hline Jun-09 & \multicolumn{1}{l}{$\begin{array}{l}\text { Topic } \\
\text { ID }\end{array}$} & Topic Category & $\begin{array}{l}\text { Topic } \\
\text { Proportion }\end{array}$ & $\begin{array}{l}\text { Area } \\
\text { Increasing }\end{array}$ & $\begin{array}{l}\text { Area } \\
\text { Decreasing }\end{array}$ \\
\hline \multirow{4}{*}{$\begin{array}{c}\text { Head } \\
\text { Hits }\end{array}$} & 2 & Social Media & 0.065947242 & 0.066 & 0.540 \\
\cline { 2 - 6 } & 17 & Location and Mapping & 0.04676259 & 0.113 & 0.474 \\
\cline { 2 - 6 } & 12 & Travel and Finance & 0.039568345 & 0.152 & 0.427 \\
\cline { 2 - 6 } & 21 & Open Government & 0.033573141 & 0.186 & 0.387 \\
\cline { 2 - 6 } & 27 & Content & 0.028776978 & 0.215 & 0.354 \\
\cline { 2 - 6 } & 18 & E-commerce & 0.028776978 & 0.243 & 0.325 \\
\hline \multirow{4}{*}{\begin{tabular}{c} 
Tail \\
\cline { 2 - 6 }
\end{tabular}} & 14 & Digital Marketing & 0.027577938 & 0.271 & 0.296 \\
\cline { 2 - 6 } & 10 & Media & 0.027577938 & 0.299 & 0.269 \\
\cline { 2 - 6 } & 39 & SMS Messaging & 0.025179856 & 0.324 & 0.241 \\
\cline { 2 - 6 } & 22 & Natural Language & & & \\
\cline { 2 - 6 } & 26 & Verification & 0.022781775 & 0.347 & 0.216 \\
\cline { 2 - 6 } & 6 & Cloud Management & 0.016786571 & 0.367 & 0.193 \\
\hline
\end{tabular}




\begin{tabular}{|r|l|r|r|r|} 
& & & \\
& Real Estate & 0.01558753 & 0.399 & 0.156 \\
\hline 24 & Payment & 0.01558753 & 0.415 & 0.140 \\
\hline 5 & Mobile Integration & 0.014388489 & 0.429 & 0.125 \\
\hline 15 & Weather & 0.014388489 & 0.444 & 0.110 \\
\hline 20 & Sports Statistics & 0.014388489 & 0.458 & 0.096 \\
\hline 19 & Voice and Chat & 0.013189448 & 0.471 & 0.082 \\
\hline 35 & Format Conversion & 0.011990408 & 0.483 & 0.068 \\
\hline 31 & Transit Data & 0.011990408 & 0.495 & 0.056 \\
\hline 3 & Logistics & 0.010791367 & 0.506 & 0.044 \\
\hline 29 & Bioinformatics & 0.009592326 & 0.516 & 0.034 \\
\hline 36 & Cryptocurrency & 0.008393285 & 0.524 & 0.024 \\
\hline & Repository & & & \\
\hline 4 & Management & 0.007194245 & 0.531 & 0.016 \\
\hline 34 & Workplace & & & \\
\hline 13 & Medical Information & 0.002398082 & 0.538 & 0.004 \\
\hline 11 & Vehicle Registration & 0.001199041 & 0.540 & 0.001 \\
\hline
\end{tabular}

Table 11 - Topic categories vs topic proportions in the long tail curve of June 2009

Table 12 shows the topic categories vs topic proportions for the period of January 2016.

The head of the long tail curve in 2016 was expanded by SMS Messaging, Payment, and Natural Language Processing. In addition, Cryptocurrency, Mobile Integration,

Verification, and Weather came very close to the head. We can also observe that topic distributions came closer to each other with the difference between the highest and the lowest topic distributions being 0.023 in 2016 from 0.065 in 2009.

\begin{tabular}{|c|r|l|l|r|r|}
\hline Jan-06 & \multicolumn{1}{|l|}{$\begin{array}{l}\text { Topic } \\
\text { ID }\end{array}$} & Topic Category & $\begin{array}{l}\text { Topic } \\
\text { Proportion }\end{array}$ & $\begin{array}{l}\text { Area } \\
\text { Increasing }\end{array}$ & $\begin{array}{l}\text { Area } \\
\text { Decreasing }\end{array}$ \\
\hline \multirow{4}{*}{$\begin{array}{c}\text { Head - } \\
\text { Hits }\end{array}$} & 39 & SMS Messaging & 0.036233691 & 0.036 & 0.559 \\
\cline { 2 - 6 } & 2 & Social Media & 0.031247403 & 0.067 & 0.523 \\
\cline { 2 - 6 } & 14 & Digital Marketing & 0.030998089 & 0.098 & 0.492 \\
\cline { 2 - 6 } & 21 & Open Government & 0.02842184 & 0.127 & 0.461 \\
\cline { 2 - 6 } & 6 & Cloud Management & 0.02825563 & 0.155 & 0.432 \\
\cline { 2 - 6 } & 24 & Payment & 0.027258373 & 0.182 & 0.404 \\
\hline
\end{tabular}




\begin{tabular}{|c|c|c|c|c|c|}
\hline & 22 & $\begin{array}{l}\text { Natural Language } \\
\text { Processing }\end{array}$ & 0.026094906 & 0.235 & 0.350 \\
\hline & 18 & E-commerce & 0.025596277 & 0.261 & 0.324 \\
\hline & 12 & Travel and Finance & 0.025014543 & 0.286 & 0.299 \\
\hline \multirow{17}{*}{$\begin{array}{l}\text { Tail - } \\
\text { Niches }\end{array}$} & 36 & Cryptocurrency & 0.023103133 & 0.309 & 0.274 \\
\hline & 5 & Mobile Integration & 0.022853819 & 0.332 & 0.251 \\
\hline & 26 & Verification & 0.022022771 & 0.354 & 0.228 \\
\hline & 15 & Weather & 0.021191723 & 0.375 & 0.206 \\
\hline & 19 & Voice and Chat & 0.01836616 & 0.393 & 0.184 \\
\hline & 31 & Transit Data & 0.01836616 & 0.412 & 0.166 \\
\hline & 29 & Bioinformatics & 0.017950636 & 0.430 & 0.148 \\
\hline & 35 & Format Conversion & 0.017784426 & 0.447 & 0.130 \\
\hline & 10 & Media & 0.017701321 & 0.465 & 0.112 \\
\hline & 20 & Sports Statistics & 0.017202693 & 0.482 & 0.094 \\
\hline & 27 & Content & 0.016953378 & 0.499 & 0.077 \\
\hline & 3 & Logistics & 0.014709549 & 0.514 & 0.060 \\
\hline & 11 & Vehicle Registration & 0.010138785 & 0.524 & 0.045 \\
\hline & 1 & Real Estate & 0.010138785 & 0.534 & 0.035 \\
\hline & 4 & $\begin{array}{l}\text { Repository } \\
\text { Management }\end{array}$ & 0.009224632 & 0.543 & 0.025 \\
\hline & 13 & Medical Information & 0.008559794 & 0.552 & 0.016 \\
\hline & 34 & $\begin{array}{l}\text { Workplace } \\
\text { Collaboration }\end{array}$ & 0.007396327 & 0.559 & 0.007 \\
\hline
\end{tabular}

Table 12 - Topic categories vs topic proportions in the long tail curve of Jan 2016

\subsection{Summary of findings}

This research presents an exploratory study and methodology for studying the practical problem of articulating customer value propositions in the API service system. Topic Modeling was used as text mining and knowledge discovery technique to analyze a corpus of API descriptions obtained from programmableweb.com. Two types of analyses were run on the resulting Topic Model: topic interpretation and topic trend analysis.

Topic interpretation delivered a categorization of customer value propositions in the API service system. Six categories of customer value propositions were identified: 
- Increasing Capability by allowing API consumers to do things they could not do before such as mining cryptocurrency, verifying email addresses, or sequencing proteins.

- Increasing Information Resources by allowing API consumers to access data resources they could not access before such as sports statistics, transit schedules, or weather data.

- Linking Services by connecting the API consumer with multiple services from one place, thus reducing the cost of connectivity.

- $\quad$ Linking Data by giving the API consumer access to multiple databases or sources of data, thus reducing the cost of aggregating data.

- Allowing Interoperability by allowing the API consumer to integrate existing applications and services with a product or a service provided by the API provider

- Allowing Personalization by allowing the API consumer to build custom applications that personalize a service or a product provided by the API provider.

Topic trend analysis delivered a long term distribution over topic proportions in the API service system. Analysis of the long tail curve revealed that curve is flattening and moving away from a long tail to becoming a declining slope. The flattening of the long tail is caused by niche areas becoming mainstream as well as convergence in the distribution of areas overall. 


\section{Discussion}

This research focused on studying customer value propositions in the API service system using Topic Modeling as a data analysis technique. Using the interpretation of the Topic Model, customer value propositions were categorized into six categories. By analyzing Topic trends over time, a long tail distribution of topics was revealed in the API service system. This section discusses the findings by: (i) constructing a categorization model for customer value propositions in the API service system, (ii) taking a closer look at the flattening of the long tail and how it affects the current state of the API service system, and (iii) proposing managerial recommendations for three groups of stakeholders.

\subsection{Categorization Model of Customer Value Propositions in the API Service system}

Topic modeling enables the discovery of latent semantic themes in a corpus of text. This implies that the topics discovered are abstract themes revealing the hidden semantic structure of the text. Every API description in the data corpus is composed of some proportion of each of the topic instances listed in this categorization model. This categorization model enables the classification of an API description based on the category of customer value proposition to which it belongs. 


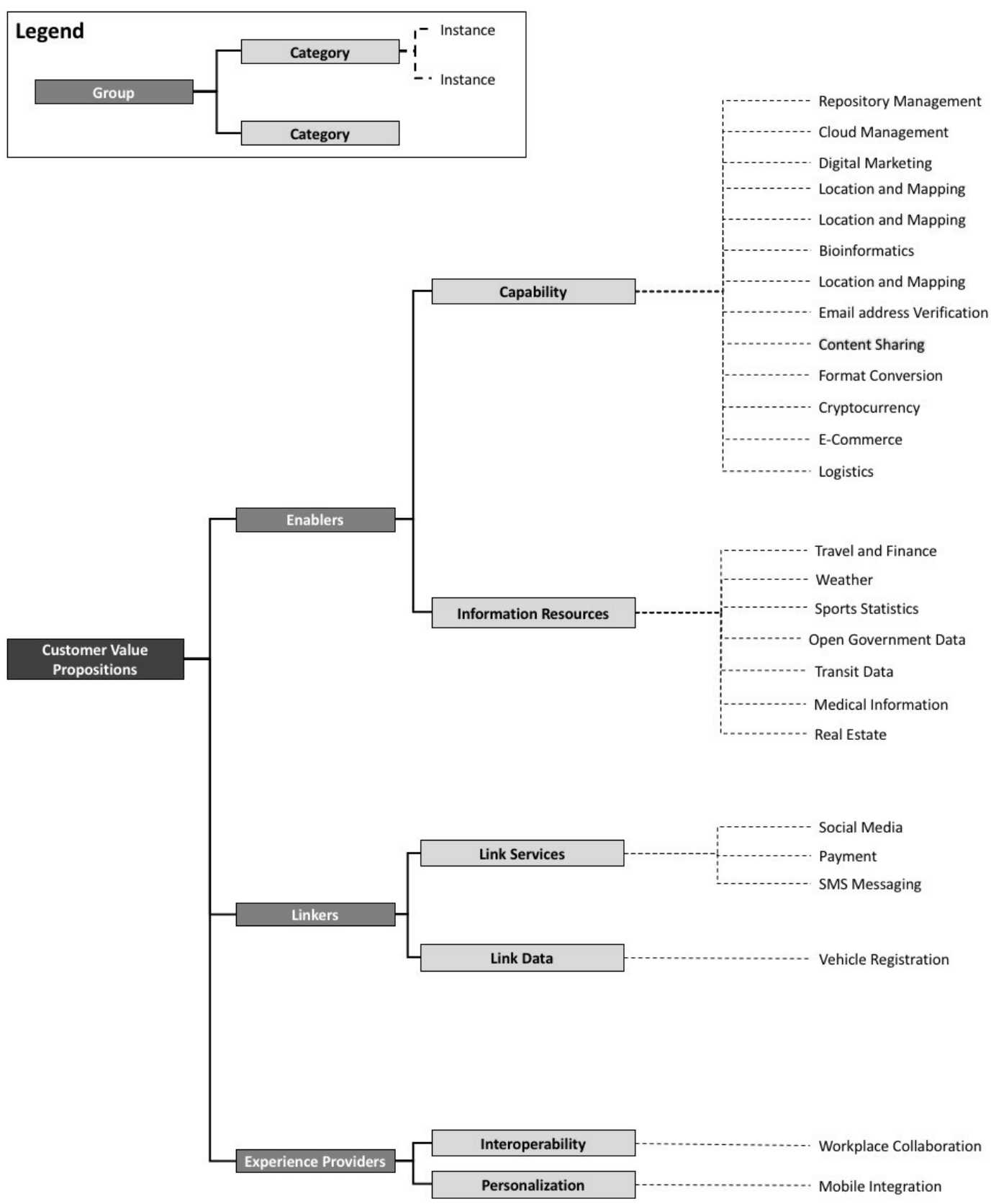

Figure 15 - Customer value propositions categorization model

Figure 15 shows a categorization model of customer value propositions in programmableweb.com's API service system. The model is composed of 3 groups of 
customer value propositions: Enablers, Linkers, and Experience Providers. Under each group there are two categories, and for each category the instances of topics that make this category are listed.

\subsubsection{Enablers}

This group of customer value propositions promise to enable the customer to do something they are not able to currently do and for this reason they are called enablers. Enablers form the vast majority of customer value propositions in the API service system and are broken down into two categories: increasing capabilities, and increasing information resources.

Providers with value propositions that promise to increase capabilities provide services that are heavy on functionality such as cloud resource management, mining cryptocurrency, file format conversion, and taking care of shipping logistics. The APIs created by these providers enable the API consumer to use the functionality without the need for building it themselves, thus increasing the capability of the API consumer. The complexity of the functionality provided can vary tremendously. The complexity of the functionality can range from simple tasks such as uploading a file or a video to extremely complex tasks such as mining bitcoins and protein sequence analysis.

The second category in the enablers group is value propositions that promise to increase information resources. Providers communicating these value propositions create APIs that give access to some data or information resource such as weather data, open government data, or sports statistics. Information resources vary in the level of 
insight they enable the API consumer to gain. At one end there is crude data resources such as open government data, or a list of hotels in a certain area. On the other end are information resources with high levels of insight such as financial market trends, and sports analyses. In addition to the level of insight, time is a major factor in the type of information resources provided. The information can be changing real-time such as in the case of hotel room prices, stock prices, or live game statistics and metrics. Or it can be on demand and query driven like hotel locations, real estate listings, sports profile information, and medical insurance information. It is important to note that even hotel locations and real estate listings change over time, but the rate of change and the method of update is different than things like stock prices and live game statistics. Realtime driven information resources are pushed to the API consumer, while on demand information is pulled by the API consumer.

\subsubsection{Experience Providers}

The second group of customer value propositions in the API service system allow the API consumer to personalize, or interoperate with a product or a Software as a Service. The API in this case is not the primary focus of the service provider, but is used to enhance the experience of a product or a service that drives the core value. API providers promise to enhance experience by either increasing the interoperability or personalization of the product or service they are providing to their customer. Interoperability refers to the ability to integrate existing applications and infrastructure with the new product. While personalization allows the customer to modify the use of the product or service in ways that suit their needs. Personalization can be achieved by 
allowing customers to build their own mobile applications using the provided API.

\subsubsection{Linkers}

The third group of customer value propositions allow API consumers to connect to multiple services and multiple sources of data. API providers with this type of customer value propositions promise to link API consumers to multiple services such as multiple social media providers, or multiple sources of data such as vehicle registration database from different countries, through one interface. API providers promise to take the headache of dealing with things like different regulations, compliance, aggregation of data, and heterogeneous interfaces away from API consumers.

The two categories of customer value propositions that make up the linkers group are reducing the cost of connectivity, and reducing the cost of data aggregation. One example of reducing the cost of connectivity is value propositions by SMS messaging API providers. API providers that provide SMS messaging services establish connection with tens or hundreds of mobile network operators around the world and allow the API consumer to send a text message to any phone around the world from one interface. There is a high cost involved in establishing all these connections. This cost is mainly dealing with different regulations, establishing multiple agreements, interfacing with operators that implement different standards and making sure the messaging service is always up and running. SMS Messaging API consumers do not have to do all of these steps, and hence their cost of implementing SMS messaging functionality is reduced.

An example for linkers that promise to reduce the cost of aggregating multiple sources 
of data is customer value propositions by vehicle registration API providers. Vehicle registration API providers gather, administer, and maintain large databases of vehicle and vehicle registration related information. Their value propositions promise API consumers to reduce the cost involved in accessing multiple databases at once.

\subsection{The long tail of customer value propositions}

Studying the API service system using network science techniques based on the links between mashups and APIs revealed a power-law distribution of mashups to APIs. Researchers linked this finding to the idea of a "long tail", where a distribution is characterized by a large number of low frequency occurrences and a very small number of high frequency occurrences (Woodard, 2009).

Studying the API service system using the lens of Topic Modeling revealed another long tail distribution. This long tail is the distribution of topic proportions over topics in the API service system. It reflects how customer value propositions are communicated in the service system as well as how areas of the API service system have evolved. Earlier in the evolution of the programmableweb.com API service system, the distribution of topic proportions followed a long tail curve as reported in section 4.4. In 2009 , the head of the long tail included areas such as Social Media, Mapping, Finance, and E-commerce. These were the four main areas where APIs strived during that period of time. In 2016, this demographic changed in two ways. First, areas such as SMS messaging, Cloud Management, and Natural Language Processing jumped in ranks and joined the head, causing the head to expand. Second, the distributions along the tail got closer to each 
other causing the curve as a whole to flatten out and become more of a declining slope than a long tail.

The emergence of SMS Messaging, Cloud, and Natural Language Processing can be seen to correlate with the emergence of the Mobile, Cloud, and Big Data and Machine learning industries. This implies that the API industry is a secondary industry that reflects what occurs in other industries rather than influence it. Thus, primary innovations that create new industries are scarce and the API economy is not reaching its full potential.

The flattening of the long tail could be argued to be due to the saturation of APIs in every category in the API service system. When the API service system started some categories like Social and Mapping APIs enjoyed wide popularity in terms of number of APIs and number of uses. At this point, other categories such as Cryptocurrency and Bioinformatics emerged with the number of posted APIs large enough to cause the flattening of the long tail. This implies that the supply is increasing in the API service system.

The increase of supply in the API service system does not necessarily result in the shift of demand towards that supply. According to the long tail theory, "filters" are needed to shift the demand down the tail. Filters are people or software that help consumers find what they need in an increasingly saturated market (Anderson, 2006). The stagnation of mashup listings indicates that the demand is not being shifted towards the rising tail and that API service systems such as programmableweb.com are not filling the "filters" role 
properly in the API economy.

\subsection{Connecting supply and demand in the API economy}

There are three forces that shape the long tail of an economy: (i) democratizing production, (ii) democratizing distribution, and (iii) connecting supply and demand (Anderson, 2006). Open APIs based on the RESTful architecture have democratized the production of web services by making it increasingly simple to create APIs. Directories such as programmableweb.com' API directory and Mashape's API marketplace have democratized distributions by aggregating and listing APIs. The missing link in the API economy are the filters that connect supply and demand.

To demonstrate how API service systems can play the role of filters effectively the we will take the angel of differentiation in the API service system. Differentiation is the realm of a properly communicated customer value proposition (Anderson et al., 2006). There are three models by which value propositions can be communicated: (i) all benefits, (ii) favorable points of difference, and (iii) resonating focus.

Best practices in customer value propositions entail presenting and communicating value propositions using the resonating focus model. In this model the API provider should communicate the one or two points of difference and a point of parity whose improvement will deliver the greatest value to the customer in the foreseeable future (Anderson et al., 2006). The main idea behind the resonating focus is to answer the customer question: "What is most worthwhile to keep in mind about your offering?". Resonating focus requires very high level of knowledge about one's own offering, the 
next best alternative and the customer.

To enable API service providers to communicate resonating focus value propositions to their potential customers, APIs need to move away from being a white technology where the emphasis is on features and characteristics of the API, to a branded technology where the emphasis is on the brand behind the API. To make the move API service providers need to focus on their brands and API service systems need to establish the proper environment for API service providers to communicate their brands. This is one way the API service systems can play the role of a filter connecting supply and demand in the API economy.

\subsection{API service systems from aggregators to filters}

In a recent post, programmableweb.com announced a new API data model that reflects the current trends in the API service system. The new model reflects things like the rise of Software Development Kits(SDKs), and the proliferation of different types of APIs such as product embedded APIs and browser APIs (Berlind, 2016). However, the new described data model still focuses on listing aspects of the API that do not allow API providers to differentiate themselves. The new model consists of information such as the API name, the provider's home page, the API portal's home page, and the API type according to what programmableweb.com defines as API type. This information is only helpful in directing API consumers to the API's homepage where more information can be found about the API and the provider.

Another famous API service system is Mashape which goes a step further than pure 
listings by enabling developers to test drive the APIs during the search process. This is done through an interface to the API inside Mashape's website where a developer can make test calls to the API to see if the results are what they are expecting. However, this approach is still short of enabling API service providers to reveal their brand and communicate resonating focused value propositions to customers.

Studies on web service discovery mechanisms can hint to some ideas that can enable the formation of an API service system that supports resonating focus value propositions. Researchers have suggested leveraging social information such as who used the API to enable the discovery of APIs (Torres et al., 2011), graph based methods for personalizing API selection (Dojchivnovski et al., 2012), and API recommendation based on network prediction (Huang \& Tan, 2014). These studies show that knowing how the API ranks with respect to other APIs can be used to recommend APIs for potential developers. Therefore, an API service system that supports branding of the API based on who used it, what was made with it, famous success stories, and star like ranking is needed.

The current state of API service systems is similar to SourceForge and similar Open Source Software (OSS) directories in the early stages of OSS. At that time, basic "yellow pages" like directories of OSS and free software was all what is available in the market. Later, GitHub came along and took the OSS industry by a storm eventually taking over the OSS industry and becoming the most used OSS service system. GitHub provides OSS developers more than just listings. GitHub provides features such as starring, wikis, blogs, dedicated website, and more. All of these features allow OSS developers to create 
communities around their OSS, making differentiation possible. This makes GitHub an service system of service systems rather than just a directory of OSS repositories. Hence, coming closer to playing the role of filters connecting supply and demand.

\subsection{Managerial recommendations}

Next, results of this study are used to provide some recommendations to three groups of practitioners: API service systems, API service providers, and entrepreneurs.

\subsubsection{Recommendations for API service systems}

API service systems are at a unique position to become filters in the API economy and meet a much needed need of connecting supply and demand. Current API service systems such as programmableweb and Mashape can meet this need by transforming their data model to include a ranking system for the APIs. The ranking system could be based on concrete aspects such as service uptime, licensing compatibility, quality of documentation, and ease of use. Developers who use the APIs can rank them providing real-time feedback to other developers searching for APIs.

Service systems can also increase the engagement between API providers and consumers by giving each API provider the ability to create forums, wikis, or dedicated webpages for their APIs. These features will allow API service providers to create and foster communities around their APIs. API service providers can also showcase successful case studies and recommendations from well-known customers.

Community building is a non-trivial task, and API service providers may not have the capacity to undertake it. Hence, API service systems can help. Tasks such as asking a 
developer to rank an API, or ask a service provider to post successful case studies can go a long way in community development, and can be integrated in the features developed by the API service system.

\subsubsection{Implications for API service providers}

API service providers can benefit from the available features in the existing service system by becoming aware of their communications and fine tuning it. The current programmableweb.com 'submit API' form contains a field that asks "Why is your API different?" that can be filled to communicate aspects of the service provider that makes their API different than others. These aspects should communicate trust and credibility to potential developers. Things like having excellent uptime, having a flexible terms of service, or having a customer with a resonating name matter a lot to potential developers and can differentiate the provider's API.

API providers can make use of the categorization model developed in this study to position their communications among the 6 categories depending on their core strengths. Whether the API provider is communicating enablers, linkers, or experience providers, focusing on features that can be most relevant to target developers such as uptime and service quality for enablers, variety and breadth of connected data and services for linkers, and ease of use and quality of documentation for experience providers can differentiate the provider's API.

\subsubsection{Recommendations for entrepreneurs}

There is a lot of commercial potential in filling the filters gap by creating new companies 
and API service systems that address it. New API service systems should act as supply and demand connectors by utilizing new innovations and technology. Big data and machine learning can play a crucial role in addressing this problem, as well as community building and service system development. Entrepreneurs should become more like service system enablers than service systems.

At the moment, companies addressing this gap are focusing on large enterprise players who have the capacity and the budget to contract expensive services. A potential strategy for incumbents is to focus on smaller companies and startups in specific markets such as Medical Devices, the Internet of Things, or Fintech. 


\section{Conclusion}

APIs have delivered on a promise of having tremendous value within the walls of the enterprise but have fallen short from delivering on the same promise at an internet scale. API service systems are the primary manifestation of APIs at the internet scale. Empirically studying API service systems has the potential of revealing the reason behind their inability to scale APIs at the level of the internet.

Using Topic Modeling to empirically study API descriptions in programmableweb.com, the largest API service system at the moment, a long tail of customer value proposition distributions was revealed. Analyzing the evolution of the tail through time revealed that niche areas are moving into the mainstream and the overall distributions are converging causing the tail to flatten.

The flattening of the tail signals an increase in supply that needs to be met by shifting the demand towards the tail, a need that is unmet at the moment. API service systems can shift the demand towards the tail by acting as filters connecting supply and demand. One example of how they can do that is by allowing API service providers to brand and differentiate their APIs through communicating resonating focus value propositions. To do so, API service systems need to provide features that enables API service providers to create communities and foster them around their APIs. This gap in the industry is up for grasp by aspiring and existing entrepreneurs. 


\subsection{Lessons learned from applying Topic Modeling}

Topic modeling can serve a great value when it comes to analyzing topics that require semantic analysis. Applying Topic Modeling to a corpus of API descriptions allowed the researcher to perform two types of analyses: topic interpretation, and trend analysis. Topic interpretation was based on analyzing the top words associated with each topic. A good model would allow the interpretation to be done through the words only, however, for some topics example documents were required to analyze the topics. The final outcome of the interpretation was the identification and categorization of API customer value propositions. Trend analysis was based on plotting the relevant topic proportions in the documents of the corpus. Topic trend analysis revealed insight into the evolution of API customer value propositions over time and how that affects the API service system as a whole.

The data used in this research were a corpus of API descriptions that were written by API service providers. This limited the study to only draw insights about communicated customer value propositions. In a previous attempt, news articles from programmableweb.com about APIs and how they help API consumers were used. The resulting topics were substantially different, and different analysis could have been done. However, due to the amount of preprocessing required the idea of analyzing news articles was abandoned.

Preprocessing of the data also changes the outcome of the model significantly. The size of the document plays a role in the quality of the outcome. Topic modeling works well with large documents. Small documents such as twitter feeds do not produce good results. API descriptions can be considered small documents, however, they are not as 
small as twitter feeds. Having the ultimate judgement being the interpretability of topics, the size of API descriptions did not affect the final outcome. Preprocessing techniques such as stemming, lemmatization, and removal of stop words also play a role in the final outcome. It was found that removing words such as "api" and "service" improved the final outcome and produced topics that are more interpretable.

The number of topics and the hyper-optimization of model parameters affect the final outcome. Mallet has the option of automatically optimizing the LDA parameters during the model training. It was found that keeping this option on produced better results. The number of topics was the highest impact factor in the quality of the outcome. Fewer number of topics produced more general topics and higher number of topics produced more fine-tuned topics.

Using topic modeling requires programming and command line skills that can hinder researchers from applying it in contexts outside of computer science. There is a need for simple and interactive graphical user interface based applications to aid the use of Topic Modeling in areas such as humanities and social science.

\subsection{Limitations}

This research was limited by two factors, the sources of data used and the analysis technique used. On the data side, the source of data used in this research is secondary and only contains what API service providers say about themselves. Thus, the type of analysis and the conclusions drawn to be only about how providers communicate limiting the depth of the conclusions reached. In addition, due to the large number of 
API descriptions obtained, verifying each API description was not possible. This caused the data to contain some descriptions for outdated APIs which may have caused some skewness in the final outcome.

Limitations caused by Topic Modeling as a data analysis technique are mainly due to the fact that Topic Modeling is a machine learning technique and follows the principle of "garbage in garbage out". Analyzing the Topic Model is only as good as what you feed it and can vary tremendously based on the input. Topic Modeling is also known with limitations regarding short documents and API descriptions are considered somewhat short documents. While the final outcome of the topic was interpretable, longer documents could have revealed more abstract topics.

The interpretation of the Topic Model is very subjective and requires a lot of domain expertise to identify gaps in the model or topics that do not make sense. This was remedied by using actual example documents to interpret the topics.

Finally, the LDA algorithm does not take in consideration the dynamism and evolution of the topics. Topic trend analysis was performed after the Topic Model was trained making it only an approximation for how topics evolved over time.

\subsection{Future Work}

Future research directions can be pursued in using different Topic Modeling algorithms to reveal different types of insight. Other types of Topic Modeling algorithms include 
Dynamic Topic Models and Relational Topic Models. Dynamic Topic Models can be used to study the evolution of topics over time instead of constructing approximate trend graphs. While Relational Topic Models could be used along with links between APIs and Mashups to predict links based on content in the API descriptions.

The identified categorization model and trained Topic Model can be used in combination with extra data sources to create a service value map for the API service system. This map can be analyzed to reveal new insight such as the health of the service system, the value gaps in the service system, and answer questions such as how to best create and deliver value in the service system.

The methodology presented here can be used to study other types of service systems and communities such as open source service systems or developer communities. Results from these studies can be used as grounds for comparison between different types of service systems. In addition, lessons learned from more advanced service systems like some of the open source ones could be used guide API service systems. 


\section{References}

Ali, M., \& LaPaugh, A. 2013. Enabling Author-Centric Ranking of Web Content. International Workshop on the Web and Databases (WebDB).

Allee, V. 2008. Value network analysis and value conversion of tangible and intangible assets. Journal of Intellectual Capital, 9(1): 5-24.

Anderson, J. C., Narus, J. A., \& Van Rossum, W. 2006. Customer value propositions in business markets. Harvard Business Review, 84(3): 91-99.

Anderson, C. 2006. Long tail, the, revised and updated edition: Why the future of business is selling less of more. Hyperion.

Asuncion, H. U., Asuncion, A. U., \& Taylor, R. N. 2010. Software traceability with topic modeling. 2010 ACM/IEEE 32nd International Conference on Software Engineering, 1: 95-104.

Bachlechner, D., Siorpaes, K., Fensel, D., \& Toma, I. 2006. Web service discovery-a reality check. 3rd European Semantic Web Conference, 308.

Bai, J., Xiao, H., Yang, X., \& Zhang, G. 2009. Study on integration technologies of building automation systems based on web services. 2009 ISECS International Colloquium on Computing, Communication, Control, and Management Study, 262-266.

Ballantyne, D., Frow, P., Varey, R. J., \& Payne, A. 2011. Value propositions as communication practice: Taking a wider view. Industrial Marketing Management, 40(2): 202-210.

Barros, A. P., \& Dumas, M. 2006. The rise of web service service systems. IT Professional, 8(5): 31-37.

Beimborn, D., \& Joachim, N. 2011. The joint impact of service-oriented architectures and business process management on business process quality: An empirical evaluation and comparison. Information Systems and E-Business Management, 9(3): 333362.

Beletski, O. 2008. End user mashup programming environments. In T-111.5550 Seminar onMultimedia.

Berlind, D. 2016. ProgrammableWeb's New API Directory Data Model Explained. http://www.programmableweb.com/news/programmablewebs-new-api-directorydata-model-explained/analysis/2016/07/08. Accessed Sept 2016. 
Bizer, C., Heath, T., \& Berners-Lee, T. 2009. Linked Data - The Story So Far. Semantic Services, Interoperability and Web Applications: Emerging Concepts, 5(3): 205227.

Blei, D. M., \& Lafferty, J. D. 2006a. Dynamic topic models. Proceedings of the 23rd international conference on Machine learning, pp. 113-120.

Blei, D., \& Lafferty, J. 2006b Correlated topic models. Advances in neural information processing systems, 18(147).

Blei, D. M., \& Mcauliffe, J. D. 2008. Supervised topic models. Advances in Neural Information Processing Systems 22, 121-128.

Blei, D. M. 2012. Probabilistic Topic Models. Communications of the ACM, 55(4): 77-84.

Blei, D. M., Ng, A. Y., \& Jordan, M. I. 2003. Latent Dirichlet Allocation David. Journal of Machine Learning Research, 3: 993-1022.

Box, D., Ehnebuske, D., Kakivaya, G., Layman, A., Mendelsohn, N., Nielsen, H. F., Thatte, S., \& Winer, D. 2000. Simple Object Access Protocol (SOAP) 1.1. World Wide Web Consortium note (2000). http://www.w3.org/TR/2000/NOTE-SOAP-20000508/. Accessed August 2016.

Bourque, P., \& Fairley, R. E. 2014. Guide to the Software Engineering - Body of Knowledge. IEEE Computer Society. www.swebok.org.

Canfora, G., Di Penta, M., Esposito, R., \& Villani, M. L. 2005. An approach for QoS-aware service composition on algorithms. GECCO 2005 - Genetic and Evolutionary Computation Conference, 1069-1075.

Carlile, P. R., \& Christensen, C. M. 2004. The Cycles of Theory Building in Management Research. Working paper.

Casati, F., Ilnicki, S., Jin, L., Krishnamoorthy, V., \& Shan, M.-C. 2000. Adaptive and Dynamic Service Composition in eFlow. 12th International Conference Advanced Information Systems Engineering (CAiSE), 3084: 13-31.

Chandler, J. D., \& Lusch, R. F. 2015. Service Systems: A Broadened Framework and Research Agenda on Value Propositions, Engagement, and Service Experience. Journal of Service Research, June(1): 1-17.

Chaney, A., \& Blei, D. 2012. Visualizing Topic Models. Icwsm, 419-422. 
Chang, J., \& Blei, D. M. 2009. Relational Topic Models for Document Networks Jonathan. Proceedings of the 12th International Confe-rence on Artificial Intelligence and Statistics (AISTATS), (PART 1): 81-88.

Chang, J., Gerrish, S., Wang, C., Boyd-Graber, J. L., \& Blei, D. M. 2009. Reading tea leaves: How humans interpret topic models. Advances in neural information processing systems, 288-296.

Chang, J. 2015. R-Package LDA. CRAN. https://cran.rproject.org/web/packages/lda/lda.pdf. Accessed August 2016.

Chen, X., Lemos, A. L., Barukh, M. C., \& Benatallah, B. 2012. Service graph base: A unified graph-based platform for representing and manipulating service artifacts. Proceedings - 2012 5th IEEE International Conference on Service-Oriented Computing and Applications, SOCA 2012, (Section II).

Cherbakov, L., Galambos, G., Harishankar, R., Kalyana, S., \& Rackham, G. 2005. Impact of service orientation at the business level. IBM Systems Journal, 44(4): 653-668.

Christensen, E., Curbera, F., Meredith, G., \& Weerawarana, S. 2001. Web Services Description Langauge (WSDL) 1.1. W3C Note 15 March 2001. https://www.w3.org/TR/wsdl. Accessed August 2016.

Chuang, J., Fish, S., Larochelle, D., Li, W. P., \& Weiss, R. 2014. Large-Scale Topical Analysis of Multiple Online News Sources with Media Cloud. Data Science for News Publishing.

Clauset, A., Rohilla Shalizi, C., \& J Newman, M. E. 2009. Power-Law Distributions in Empirical Data. SIAM Review, 51(4): 661-703.

Crockford, D. 2006. The application/JSON media type for JavaScript Object Notation (JSON). IETF Tools. http://www.ietf.org/rfc/rfc4627.txt. Accessed August 2016.

Deerwester, S., Dumais, S. T., Furnas, G. W., \& Landauer, T. K. 1990. Indexing by Latent Semantic Analysis. Journal of the American Society for Information Science Sep, 41(6): 391.

Dietz, L., Bickel, S., \& Scheffer, T. 2007. Unsupervised prediction of citation influences. Proceedings of the 24th international conference on Machine learning, pp. 233240.

Elfatatry, A. 2007. Dealing with Change: Components Versus Services. COMMUNICATIONS OF THE ACM, 50(8): 35-39. 
Elmeleegy, H., Ivan, A., Akkiraju, R., \& Goodwin, R. 2008. MashupAdvisor: A recommendation tool for mashup development. Proceedings of the IEEE International Conference on Web Services, ICWS 2008, 337-344.

Endres-Niggemeyer, B. 2013. Semantic Mashups. Semantic Mashups:1-51. Springer Berlin Heidelberg.

Erosheva, E. A. 2002. Grade of membership and latent structure models with application to disability survey data. Doctoral dissertation, Office of Population Research, Princeton University.

Erosheva, E., Fienberg, S., \& Lafferty, J. 2004. Mixed-membership models of scientific publications. Proceedings of the National Academy of Sciences, 101(1):52205227.

Evans, P. C., \& Basole, R. C. 2016. Economic and Business Dimensions Revealing the API Service system and Enterprise Strategy via Visual Analytics. COMMUNICATIONS OF THE ACM, 59(2).

Fei-Fei, L., \& Perona, P. 2005. A bayesian hierarchical model for learning natural scene categories. 2005 IEEE Computer Society Conference on Computer Vision and Pattern Recognition. 2:524-531.

Fielding, R. T. 2000. Architectural styles and the design of network-based software architectures. Doctoral dissertation, University of California, Irvine.

Frow, P., McColl-Kennedy, J. R., Hilton, T., Davidson, A., Payne, A., et al. 2014. Value propositions: A service service systems perspective. Marketing Theory, 14(3): 327351.

Garriga, M., Mateos, C., Flores, A., Cechich, A., \& Zunino, A. 2016. RESTful service composition at a glance: A survey. Journal of Network and Computer Applications, 60: $32-53$.

Gao, W., Li, P., \& Darwish, K. 2012. Joint topic modeling for event summarization across news and social media streams. Cikm, (OCTOBER): 1173.

Gerrish, S., \& Blei, D. M. 2010. A language-based approach to measuring scholarly impact. Proceedings of the 27th International Conference on Machine Learning, pp. 375-382.

Goble, C. A., Bhagat, J., Aleksejevs, S., Cruickshank, D., Michaelides, D., et al. 2010. myExperiment: A repository and social network for the sharing of bioinformatics workflows. Nucleic Acids Research, 38(2): 677-682. 
Griffiths, T. L., \& Steyvers, M. 2002. A probabilistic approach to semantic representation. In Proceedings of the 24th Annual Conference of the Cognitive Science Society.

Griffiths, T. L., \& Steyvers, M. 2003. Prediction and semantic association. Neural information processing systems, (15).

Griffiths, T. L., \& Steyvers, M. 2004. Finding scientific topics. Proceedings of the National Academy of Science, (101):5228-5235.

Halinen, A., Medlin, C. J., \& Tornroos, J.-A. 2012. Time and process in business network research. Industrial Marketing Management, 41(2): 215-223.

Hall, D., Jurafsky, D., \& Manning, C. D. 2008. Studying the history of ideas using topic models. Proceedings of the conference on empirical methods in natural language processing, pp. 363-371.

Han, Y., Chen, S., \& Feng, Z. 2014. Mining Integration Patterns of Programmable Service system with Social Tags. Journal of Grid Computing, 12(2): 265-283.

Hau, T., Ebert, N., Hochstein, A., \& Brenner, W. 2008. Where to Start with SOA Criteria for Selecting SOA Projects. Proceedings of the 41st Hawaii International Conference on System Sciences, 1-9.

Hinchcliffe, D., \& Benson, J. 2011. EMML Changes Everything: Profitability, Predictability, \& Performance through Enterprise Mashups. Technical Report. Open Mashup Alliance. http://mdc.jackbe.com/enterprisemashup/sites/default/files/oma_whitepaper_120309_0.pdf. Accessed August 2016.

Hofmann, T. 1999. Probabilistic latent semantic indexing. Proceedings of the 22nd Annual International ACM SIGIR Conference on Research and Development in Information Retrieval, 50-57.

Hofmann, T. 2001. Unsupervised Learning by Probabilistic Latent Semantic Analysis. Machine Learning Journal, 42(1):177-196.

Hornik, K., \& Grün, B. 2011. topicmodels: An R package for fitting topic models. Journal of Statistical Software, 40(13):1-30.

Huang, K., Fan, Y., \& Tan, W. 2012. An empirical study of programmable web: A network analysis on a service-mashup system. 19th International Conference on Web Services, 552-559. IEEE. 
Jacobi, C., van Atteveldt, W., \& Welbers, K. 2015. Quantitative analysis of large amounts of journalistic texts using topic modelling. Digital Journalism, 811(November): 118.

Jadeja, N., \& Pandya, A. 2014. Multi-aspect sentiment analysis with topic models modeling. International Journal of Advance Engineering and Research Development, 1(5).

Koop, D., Schiedegger, C. E., Callahan, S. P., Juliana, F., \& Silva, C. T. 2008. VisComplete: Automating Suggestions for Visualization Pipelines. IEEE Transactions on Visualization and Computer Graphics, 14(6): 1691-1698.

Kumar, S., Dakshinamoorthy, V., \& Krishnan, M. 2007. SOA and Information Sharing in Supply Chain: "How" Information is Shared Matters! Twenty Eighth International Conference on Information Systems, 21-27.

Lanthaler, M., \& Gütl, C. 2010. Towards a RESTful service service system: Perspectives and challenges. 4th IEEE International Conference on Digital Service systems and Technologies, 209-214.

Larsen, K. R., \& Bong, C. H. 2016. a Tool for Addressing Construct Identity in Literature Reviews and Meta-Analyses. MIS Quarterly, 40(3): 1-23.

Lemos, A. L., Daniel, F., \& Benatallah, B. 2015. Web service composition: A survey of techniques and tools. ACM Computing Surveys, 48(3): 33:1-33:41.

Lin, C., \& He, Y. 2009. Joint sentiment/topic model for sentiment analysis. Proceedings of the 18th ACM conference on Information and knowledge management, 375384.

Linstead, E., Rigor, P., Bajracharya, S., Lopes, C., \& Baldi, P. 2007a. Mining concepts from code with probabilistic topic models. Proc. ASE, (April 2016): 461.

Linstead, E., Rigor, P., Bajracharya, S., Lopes, C., \& Baldi, P. 2007b. Mining eclipse developer contributions via author-topic models. Proceedings - ICSE 2007 Workshops: Fourth International Workshop on Mining Software Repositories, MSR 2007.

Linstead, E., Lopes, C., \& Baldi, P. 2008. An application of Latent Dirichlet Allocation to analyzing software evolution. Proceedings - 7th International Conference on Machine Learning and Applications, ICMLA 2008, 813-818.

Lu, Y., \& Zhai, C. 2008. Opinion integration through semi-supervised topic modeling. Proceeding of the 17th international conference on World Wide Web - WWW'08, 
121-130.

Lusch, R. F., \& Vargo, S. L. 2006. Service-dominant logic: reactions, reflections and refinements. Marketing Theory, 6(3): 281-288.

Lyu, S., Liu, J., Tang, M., Kang, G., Cao, B., et al. 2014. Three-level views of the web service network: An empirical study based on programmableweb. Proceedings 2014 IEEE International Congress on Big Data, BigData Congress 2014, 374-381.

Maleshkova, M., Pedrinaci, C., \& Domingue, J. 2010. Investigating Web APIs on the world wide Web. Proceedings - 8th IEEE European Conference on Web Services, ECOWS 2010, 107-114.

Manikrao, U. S., \& Prabhakar, T. V. 2005. Dynamic selection of web services with recommendation system. IEEE International Conference on Next Generation Web Services Practices (NWeSP'05), pp. 5-pp.

McCallum, A. K. 2002. Mallet: A machine learning for language toolkit.

Mccollister, C., Huang, S., \& Luo, B. 2015. Building Topic Models to Predict Author Attributes from Twitter Messages. CLEF 2015 Labs and Workshops, Notebook Papers.

Mimno, D., \& McCallum, A. 2007. Mining a digital library for influential authors. Proceedings of the 7th ACM/IEEE-CS joint conference on Digital libraries, pp. 105106.

Minka, T., \& Lafferty, J. 2002. Expectation-propagation for the generative aspect model. Proceedings of the Eighteenth conference on Uncertainty in artificial intelligence, pp. 352-359.

Muehlen, M. Z., Nickerson J., \& Swenson K. 2005. Developing web services choreography standards - the case of REST vs. SOAP. Decision Support Systems, 40(1):9-29.

Newman, D., \& Chemudugunta, C. 2006. Analyzing Entities and Topics in News Articles. International Conference on Intelligence and Security Informatics, 93-104. Springer Berlin Heidelberg.

Ni, X., Sun, J. T., Hu, J., \& Chen, Z. 2009. Mining multilingual topics from wikipedia. Proceedings of the 18th international conference on World wide web, pp. 11551156.

Nottingham, M., \& Syre, R. 2005. The Atom Syndication Format (RFC 4287). Proposed 
Standard. IETF Network Working Group. https://tools.ietf.org/html/rfc4287. Accessed August 2016

Paolucci, M., Kawamura, T. . b, Payne, T. R., \& Sycara, K. . 2002. Semantic matching of web services capabilities. Lecture Notes in Computer Science (Including Subseries Lecture Notes in Artificial Intelligence and Lecture Notes in Bioinformatics), 2342 LNCS: 333-347.

Pedrinaci, C., Liu, D., Maleshkova, M., Lambert, D., Kopecky, J., \& Domingue, J. 2010. iServe: A linked services publishing platform. CEUR Workshop Proceedings, 596.

Pan, W., Chen, S., \& Feng, Z. 2012. Investigating the collaborative intention and semantic structure among co-occurring tags using graph theory. Proceedings of the 2012 IEEE 16th International Enterprise Distributed Object Computing Conference Workshops, EDOCW 2012, 190-195.

Pritchard, J. K., Stephens, M., \& Donnelly, P. 2000). Inference of population structure using multilocus genotype data. Genetics, 155(2):945-959.

Rajasekaran, P., Miller, J., Verma, K., \& Sheth, A. 2005. Enhancing Web Services Description and Discovery to Facilitate Composition. Semantic Web Services and Web Process Composition: First International Workshop, SWSWPC 2004, San Diego, CA, USA, July 6, 2004, Revised Selected Papers, 3387: 55-68.

Ramage, D., Rosen, E. 2009. Stanford Topic Modeling Toolbox.

Rehurek, R., \& Sojka, P. 2010. Software Framework for Topic Modelling with Large Corpora. Proceedings of the LREC 2010 Workshop on New Challenges for NLP Frameworks, 45-50. Valletta, Malta: ELRA.

Ren, M., \& Lyytinen, K. K. 2008. Building enterprise architecture agility and sustenance with SOA. Communications of the Association for Information Systems, 22(January 2008): 75-86.

Rosenblum, H. 2011. Customer Values of Communication Enabled Application Mashup Types. Unpublished master's thesis, Carleton University, Ottawa.

Roy Chowdhury, S., Daniel, F., \& Casati, F. 2011. Efficient, interactive recommendation of mashup composition knowledge. Lecture Notes in Computer Science (Including Subseries Lecture Notes in Artificial Intelligence and Lecture Notes in Bioinformatics), 7084 LNCS: 374-388. 
RSS Advisory Board. 2009. RSS 2.0 Specification. http://www.rssboard.org/rssspecification. Accessed August 2016.

Singh, M. P. 2001. Physics of service composition. IEEE Internet Computing, 5(June): 67.

Sivic, J., Russell, B. C., Efros, A. A., Zisserman, A., \& Freeman, W. T. 2005. Discovering objects and their location in images. Tenth IEEE International Conference on Computer Vision, 1:370-377.

Skalen, P., Gummerus, J., von Koskull, C., \& Magnusson, P. R. 2014. Exploring value propositions and service innovation: a service-dominant logic study. Journal of the Academy of Marketing Science, 1-22.

Steyvers, M., \& Griffiths, T. 2005. Matlab Topic Modeling Toolbox.

Steyvers, M., \& Griffiths, T. 2010. Probabilistic Topic Models. MIS Quarterly, 3(3): 9931022.

Tan, W., Fan, Y., Ghoneim, A., Hossain, M. A., \& Dustdar, S. 2016. From the ServiceOriented Architecture to the Web API Economy. IEEE Internet Computing, 20(4): 64-68.

Teh, Y. W., Jordan, M. I., Beal, M. J., \& Blei, D. M. 2006. Hierarchical Dirichlet Processes. Journal of the American Statistical Association, 101(476): 1566-1581.

Titov, I., \& McDonald, R. 2008. Modeling online reviews with multi-grain topic models. Proceeding of the 17th international conference on World Wide Web (WWW).

Torres, R., Tapia, B., \& Astudillo, H. X. B. N. 2011. Improving Web API Discovery by Leveraging Social Information. 2011 IEEE International Conference on Web Services, 744(1): 744-745.

Varadarajan, J., \& Odobez, J. 2009. Topic Models for Scene Analysis and Abnormality Detection.pdf. Computer Vision Workshops.

Vargo, S. L., \& Lusch, R. F. 2004. Evolving to a new dominant logic for marketing. Journal of marketing, 68(1):1-17.

Vargo, S. L., \& Lusch, R. F. 2008. Service-dominant logic: continuing the evolution. Journal of the Academy of marketing Science, 36(1):1-10. 
Wan, Y., Chen, L., Wu, J., \& Yu, Q. 2015. Time-Aware API Popularity Prediction via Heterogeneous Features. Proceedings - 2015 IEEE International Conference on Web Services, ICWS 2015, 424-431.

Wang, J., Chen, H., \& Zhang, Y. 2009. Mining user behavior pattern in mashup community. 2009 IEEE International Conference on Information Reuse and Integration, IRI 2009, 126-131.

Wang, C., \& Blei, D. M. 2011. Collaborative topic modeling for recommending scientific articles. Proceedings of the 17th ACM SIGKDD International Conference on Knowledge Discovery and Data Mining - KDD'11, 448-456.

Weinhardt, C., Blau, B., \& Conte, T. 2011. Business aspects of web services. Springer Science \& Business Media.

Weiss, M., \& Gangadharan, G. R. 2010. Modeling the mashup service system: Structure and growth. $R$ and D Management, 40(1): 40-49.

Weiss, M., \& Sari, S. 2010. Evolution of the mashup service system by copying. Proceedings of the 3rd and 4th International Workshop on Web APIs and Services Mashups, 11:1-11:7.

Weiss, M., Sari, S., \& Noori, N. 2013. Niche Formation in the Mashup Service system. Technology Innovation Management Review, 3(5).

Wittern, E., Laredo, J., Vukovic, M., Muthusamy, V., \& Slominski, A. 2014. A graph-based data model for API service system insights. Proceedings - 2014 IEEE International Conference on Web Services, ICWS 2014, 41-48.

Woods, D., Brail, G., Jacobson, D. 2011. APIs: A Strategy Guide. O’Reilly Media, Inc.

Yu, S., \& Woodard, C. J. 2008. Innovation in the programmable web: Characterizing the mashup service system. International Conference on Service-Oriented Computing, 136-147. Springer Berlin Heidelberg.

Zhao, W. X., Jiang, J., Weng, J., He, J., Lim, E.-P., et al. 2011. Comparing twitter and traditional media using topic models. 33rd European Conference on IR Research, ECIR 2011, 338-349. 


\section{Appendix A}

\section{A.1 Optimal Topic Model Analysis}

\begin{tabular}{|c|c|c|c|c|c|}
\hline \multicolumn{6}{|c|}{ 5-topics } \\
\hline $\begin{array}{l}\text { Topic } \\
\text { ID }\end{array}$ & Words & $\begin{array}{l}\text { General } \\
\text { Interpretation }\end{array}$ & $\begin{array}{l}\text { N-New } \\
\text { D-Duplicate }\end{array}$ & \multicolumn{2}{|c|}{ Delta 5-0 } \\
\hline 0 & $\begin{array}{l}\text { service information data } \\
\text { access online payment } \\
\text { applications services } \\
\text { integrate account }\end{array}$ & $\begin{array}{l}\text { Payment } \\
\text { Service, } \\
\text { Integration, } \\
\text { Data access }\end{array}$ & $\mathrm{N}$ & $\begin{array}{l}\text { New } \\
\text { Topics }\end{array}$ & 5 \\
\hline 1 & $\begin{array}{l}\text { data search service text } \\
\text { access information web } \\
\text { analysis methods content }\end{array}$ & $\begin{array}{l}\text { Search } \\
\text { Service, text } \\
\text { analysis }\end{array}$ & $\mathrm{N}$ & $\begin{array}{l}\text { Duplica } \\
\text { te } \\
\text { Topics }\end{array}$ & 0 \\
\hline 2 & $\begin{array}{l}\text { applications service access } \\
\text { data management services } \\
\text { platform integrate mobile } \\
\text { sms }\end{array}$ & $\begin{array}{l}\text { Mobile } \\
\text { Integratio, } \\
\text { platform } \\
\text { management } \\
\end{array}$ & $\mathrm{N}$ & $\begin{array}{l}>1 \\
\text { Theme }\end{array}$ & 5 \\
\hline 3 & $\begin{array}{l}\text { data information service } \\
\text { access location search } \mathrm{xml} \\
\text { methods json services }\end{array}$ & $\begin{array}{l}\text { Location } \\
\text { Services, JSON } \\
\text { data format } \\
\end{array}$ & $\mathrm{N}$ & & \\
\hline 4 & $\begin{array}{l}\text { access applications data } \\
\text { information content social } \\
\text { service site create integrate }\end{array}$ & $\begin{array}{l}\text { Social content } \\
\text { management, } \\
\text { data access }\end{array}$ & $\mathrm{N}$ & & \\
\hline
\end{tabular}

\begin{tabular}{|l|l|l|l|r|}
\hline \multicolumn{3}{|c|}{ 10-Topics } \\
\hline $\begin{array}{l}\text { Topic } \\
\text { ID }\end{array}$ & Words & General & N-New & \\
Interpretation & D-Duplicate & Delta 10-5 \\
\hline
\end{tabular}




\begin{tabular}{|c|c|c|c|c|c|}
\hline 0 & $\begin{array}{l}\text { applications access } \\
\text { integrate functionality } \\
\text { include information } \\
\text { methods retrieving } \\
\text { managing video }\end{array}$ & Integration & & $\begin{array}{l}\text { New } \\
\text { Topics }\end{array}$ & 5 \\
\hline 1 & $\begin{array}{l}\text { methods data support } \\
\text { service information access } \\
\text { database search records } \\
\text { resources }\end{array}$ & Database access & & $\begin{array}{l}\text { Duplicat } \\
\text { e Topics }\end{array}$ & 0 \\
\hline 2 & $\begin{array}{l}\text { text analysis search } \\
\text { content language data } \\
\text { web translation image } \\
\text { recognition }\end{array}$ & $\begin{array}{l}\text { Text Analysis, Image } \\
\text { Recognition }\end{array}$ & & $\begin{array}{l}>1 \\
\text { Theme }\end{array}$ & 3 \\
\hline 3 & $\begin{array}{l}\text { sms email messages } \\
\text { service send messaging } \\
\text { mobile services } \\
\text { applications phone }\end{array}$ & $\begin{array}{l}\text { SMS messaging, } \\
\text { email services, }\end{array}$ & $\mathrm{N}$ & & \\
\hline 4 & $\begin{array}{l}\text { json site data web } \\
\text { responses restful xml calls } \\
\text { service formatted }\end{array}$ & RESTful data format & $\mathrm{N}$ & & \\
\hline 5 & $\begin{array}{l}\text { data exchange bitcoin } \\
\text { market service } \\
\text { information calls json } \\
\text { trading account }\end{array}$ & Cryptocurrency & $\mathrm{N}$ & & \\
\hline 6 & $\begin{array}{l}\text { payment online services } \\
\text { service payments product } \\
\text { products access customers } \\
\text { information }\end{array}$ & Payment services & & & \\
\hline 7 & $\begin{array}{l}\text { data applications service } \\
\text { platform management } \\
\text { services cloud access web } \\
\text { json }\end{array}$ & $\begin{array}{l}\text { Cloud access, } \\
\text { Platform } \\
\text { management }\end{array}$ & $\mathrm{N}$ & & \\
\hline 8 & $\begin{array}{l}\text { service images travel } \\
\text { image files applications } \\
\text { information file search } \\
\text { integrate }\end{array}$ & File management & $\mathrm{N}$ & & \\
\hline 9 & $\begin{array}{l}\text { data information location } \\
\text { service access xml map } \\
\text { maps locations address }\end{array}$ & Location services & & & \\
\hline
\end{tabular}

\section{5-Topics}




\begin{tabular}{|c|c|c|c|c|c|}
\hline $\begin{array}{l}\text { Topic } \\
\text { ID }\end{array}$ & Words & General Interpretation & $\begin{array}{l}\text { N-New } \\
\text { D- } \\
\text { Duplicate }\end{array}$ & \multicolumn{2}{|c|}{ Delta $15-10$} \\
\hline 0 & $\begin{array}{l}\text { search information product } \\
\text { products travel access } \\
\text { services offers booking } \\
\text { online }\end{array}$ & Travel Service & $\mathrm{N}$ & $\begin{array}{l}\text { New } \\
\text { Topics }\end{array}$ & 6 \\
\hline 1 & $\begin{array}{l}\text { text analysis language } \\
\text { search content translation } \\
\text { web data processing } \\
\text { recognition }\end{array}$ & Text Analysis & & $\begin{array}{l}\text { Duplicate } \\
\text { Topics }\end{array}$ & 0 \\
\hline 2 & $\begin{array}{l}\text { json } \mathrm{xml} \text { responses data } \\
\text { calls restful formatted http } \\
\text { rest service }\end{array}$ & Rest data format & & $\begin{array}{l}>1 \\
\text { Theme }\end{array}$ & 4 \\
\hline 3 & $\begin{array}{l}\text { management data platform } \\
\text { service marketing } \\
\text { applications services } \\
\text { customer software tools }\end{array}$ & $\begin{array}{l}\text { Platform access, } \\
\text { marketing }\end{array}$ & $\mathrm{N}$ & & \\
\hline 4 & $\begin{array}{l}\text { data location information } \\
\text { service map maps weather } \\
\text { time locations access }\end{array}$ & Location, weather & $\mathrm{N}$ & & \\
\hline 5 & $\begin{array}{l}\text { information data access } \\
\text { website open public } \\
\text { government soap online } \\
\text { provided }\end{array}$ & $\begin{array}{l}\text { Open government } \\
\text { data }\end{array}$ & $\mathrm{N}$ & & \\
\hline 6 & $\begin{array}{l}\text { methods support service } \\
\text { data information access } \\
\text { search database } \\
\text { submission retrieval }\end{array}$ & Database access & & & \\
\hline 7 & $\begin{array}{l}\text { address service addresses } \\
\text { information email domain } \\
\text { services number shipping } \\
\text { data }\end{array}$ & $\begin{array}{l}\text { Address, email, } \\
\text { domain data, shipping } \\
\text { data }\end{array}$ & $\mathrm{N}$ & & \\
\hline 8 & $\begin{array}{l}\text { payment payments online } \\
\text { service card services credit } \\
\text { account processing } \\
\text { transactions }\end{array}$ & Payment services & & & \\
\hline 9 & $\begin{array}{l}\text { sms messages send } \\
\text { messaging service email } \\
\text { mobile services } \\
\text { applications phone }\end{array}$ & $\begin{array}{l}\text { SMS Messaging, Email } \\
\text { messaging }\end{array}$ & & & \\
\hline 10 & $\begin{array}{l}\text { cloud applications web } \\
\text { data access mobile }\end{array}$ & Cloud access APIs & & & \\
\hline
\end{tabular}




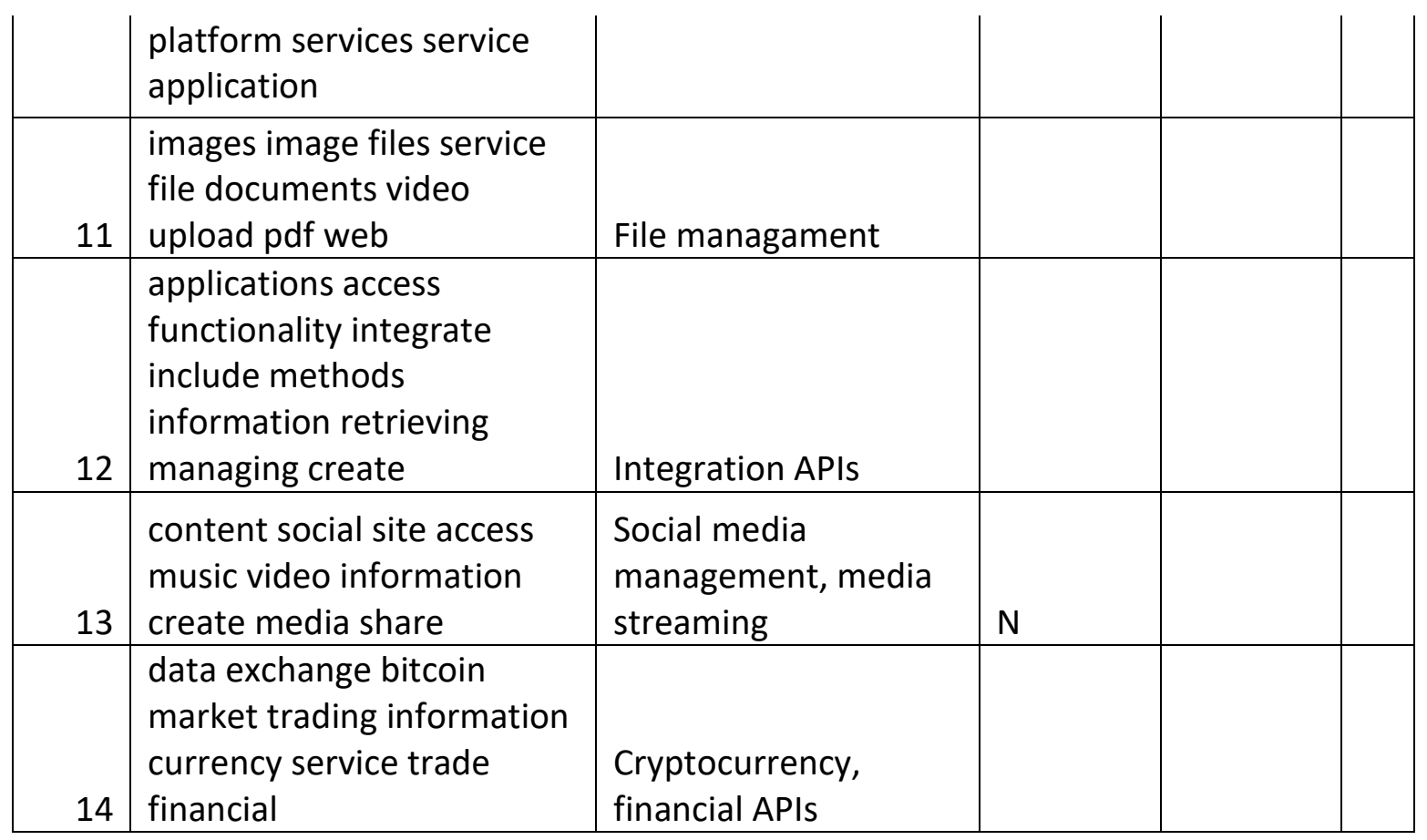

\begin{tabular}{|c|c|c|c|c|c|}
\hline \multicolumn{6}{|c|}{ 20-Topics } \\
\hline $\begin{array}{l}\text { Topic } \\
\text { ID }\end{array}$ & Words & General Interpretation & $\begin{array}{l}\text { N-New } \\
\text { D- } \\
\text { Duplicate }\end{array}$ & Delta 20- & \\
\hline 0 & $\begin{array}{l}\text { services address } \\
\text { information service website } \\
\text { domain email addresses } \\
\text { number soap }\end{array}$ & $\begin{array}{l}\text { Address and Domain } \\
\text { data }\end{array}$ & & $\begin{array}{l}\text { New } \\
\text { Topics }\end{array}$ & 4 \\
\hline 1 & $\begin{array}{l}\text { json } \mathrm{xml} \text { responses restful } \\
\text { formatted calls search data } \\
\text { service web }\end{array}$ & REST data format & & $\begin{array}{l}\text { Duplicate } \\
\text { Topics }\end{array}$ & 0 \\
\hline 2 & $\begin{array}{l}\text { data information access } \\
\text { database open search } \\
\text { research metadata public } \\
\text { library }\end{array}$ & Open data access & & $\begin{array}{l}>1 \\
\text { Theme }\end{array}$ & 1 \\
\hline 3 & $\begin{array}{l}\text { project management } \\
\text { projects job tasks access } \\
\text { time online learning system }\end{array}$ & $\begin{array}{l}\text { Project management } \\
\text { APIs }\end{array}$ & $\mathrm{N}$ & & \\
\hline 4 & $\begin{array}{l}\text { management email } \\
\text { marketing data customer } \\
\text { platform service services }\end{array}$ & $\begin{array}{l}\text { Marketing } \\
\text { management APIs }\end{array}$ & & & \\
\hline
\end{tabular}




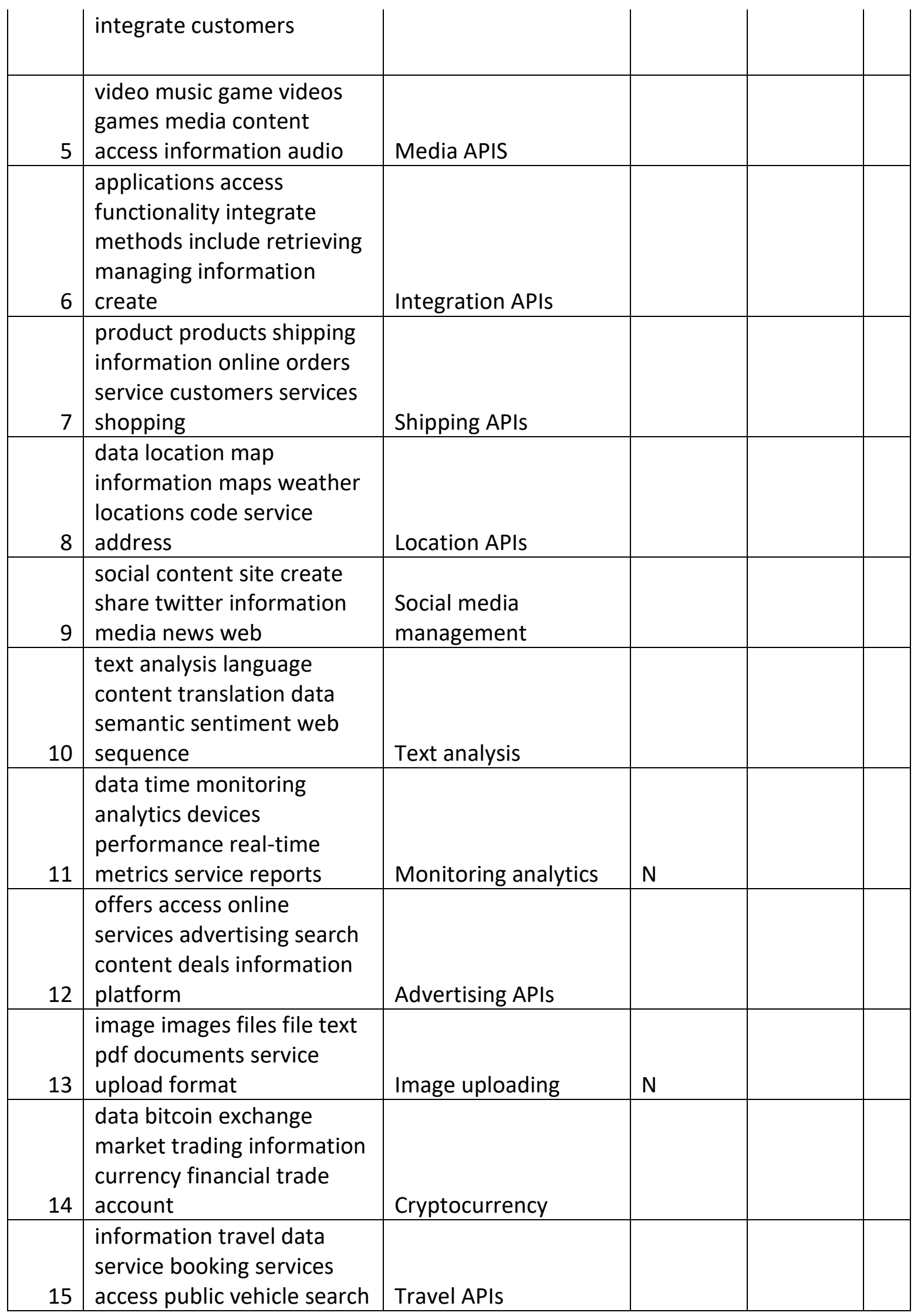




\begin{tabular}{|c|l|l|l|l|} 
& $\begin{array}{l}\text { applications web cloud } \\
\text { services service platform } \\
\text { access application mobile } \\
\text { apps }\end{array}$ & Cloud access & & \\
\hline 17 & $\begin{array}{l}\text { json authentication rest key } \\
\text { http data requests access } \\
\text { service account }\end{array}$ & Authentication APIs & $\mathrm{N}$ & \\
\hline 18 & $\begin{array}{l}\text { methods service support } \\
\text { information data } \\
\text { submission retrieval } \\
\text { functions specific including }\end{array}$ & Data access & & \\
\hline $\begin{array}{l}\text { sms payment messages } \\
\text { send service messaging } \\
\text { mobile payments services } \\
\text { text }\end{array}$ & Payment APIs, SMS & & \\
\hline
\end{tabular}

\begin{tabular}{|c|c|c|c|c|c|}
\hline \multicolumn{6}{|c|}{ 25-Topics } \\
\hline $\begin{array}{l}\text { Topic } \\
\text { ID }\end{array}$ & Words & General Interpretation & $\begin{array}{l}\text { N-New } \\
\text { D- } \\
\text { Duplicate }\end{array}$ & Delta $25-$ & \\
\hline 0 & $\begin{array}{l}\text { product products shipping } \\
\text { online information services } \\
\text { service customers orders } \\
\text { shopping }\end{array}$ & Shipping APIs & & $\begin{array}{l}\text { New } \\
\text { Topics }\end{array}$ & 6 \\
\hline 1 & $\begin{array}{l}\text { social create share events } \\
\text { site twitter information } \\
\text { people media access }\end{array}$ & $\begin{array}{l}\text { Social media } \\
\text { management }\end{array}$ & & $\begin{array}{l}\text { Duplicate } \\
\text { Topics }\end{array}$ & 0 \\
\hline 2 & $\begin{array}{l}\text { json } \mathrm{xml} \text { responses calls } \\
\text { restful formatted data http } \\
\text { rest service }\end{array}$ & REST data format & & $\begin{array}{l}>1 \\
\text { Theme }\end{array}$ & 4 \\
\hline 3 & $\begin{array}{l}\text { text analysis language } \\
\text { content translation } \\
\text { semantic sentiment } \\
\text { processing data speech }\end{array}$ & Text Processing & & & \\
\hline 4 & $\begin{array}{l}\text { location information data } \\
\text { service locations city code } \\
\text { address time weather }\end{array}$ & $\begin{array}{l}\text { Location APIs, } \\
\text { Weather data }\end{array}$ & & & \\
\hline 5 & $\begin{array}{l}\text { data exchange market } \\
\text { bitcoin trading information } \\
\text { currency trade financial } \\
\text { price }\end{array}$ & $\begin{array}{l}\text { Cryptocurrency, } \\
\text { financial data }\end{array}$ & & & \\
\hline
\end{tabular}




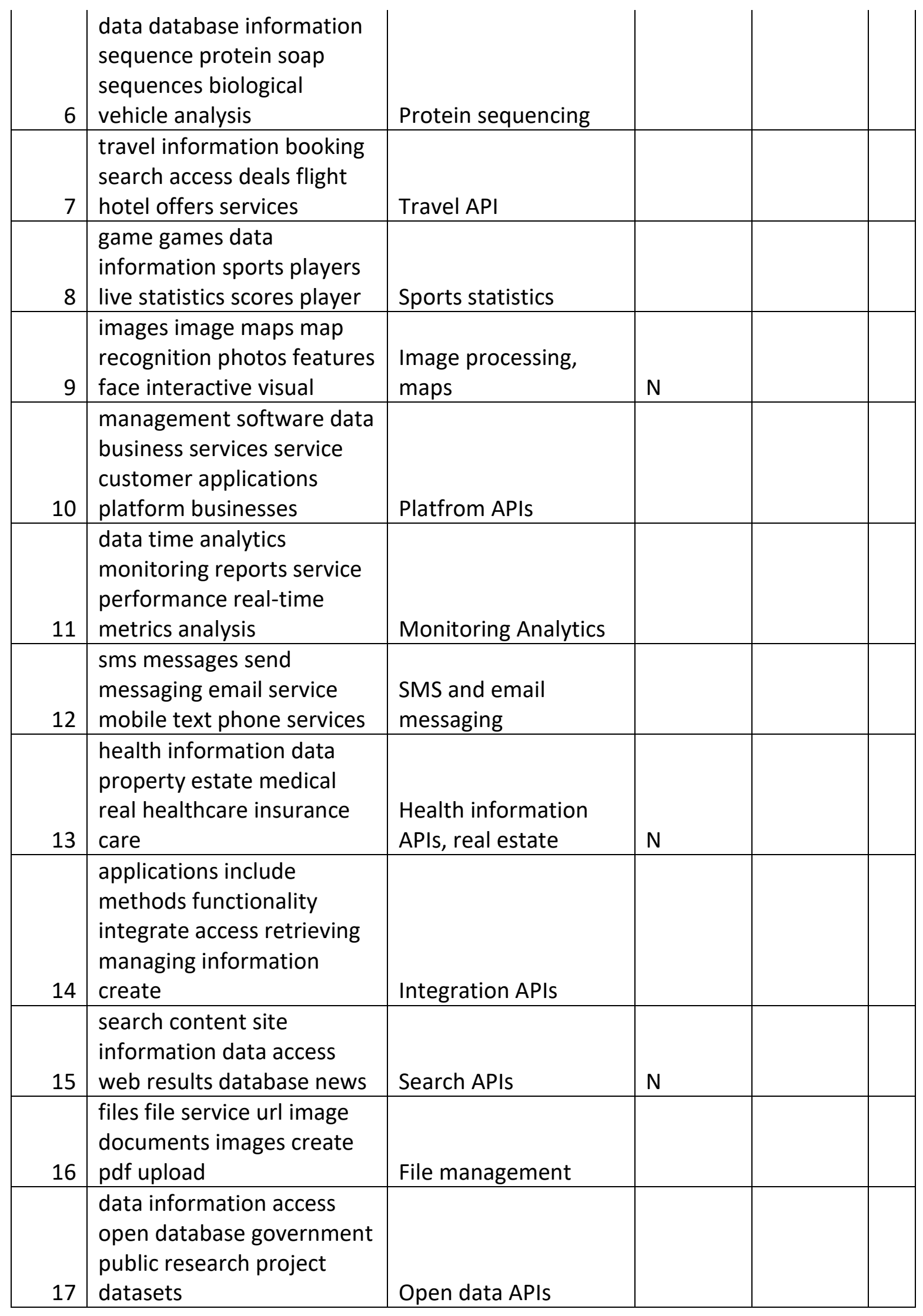




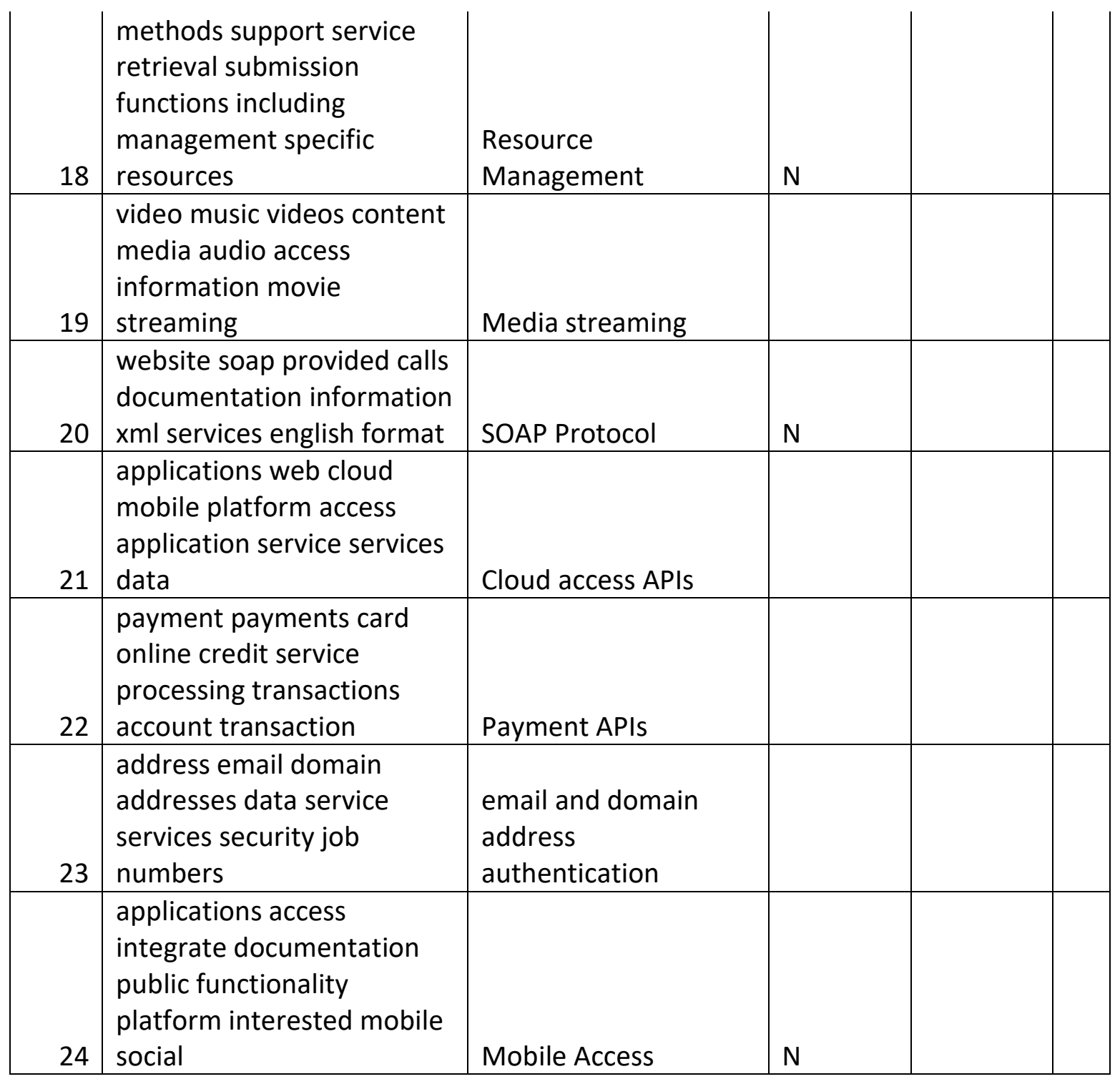

\begin{tabular}{|c|c|c|c|c|c|}
\hline \multicolumn{6}{|c|}{ 30-Topics } \\
\hline $\begin{array}{l}\text { Topic } \\
\text { ID }\end{array}$ & Words & General Interpretation & $\begin{array}{l}\text { N-New } \\
\text { D- } \\
\text { Duplicate }\end{array}$ & Delta 30- & \\
\hline 0 & $\begin{array}{l}\text { website information events } \\
\text { event soap provided calls } \\
\text { documentation english } \\
\text { retrieve }\end{array}$ & SOAP Protocol & & $\begin{array}{l}\text { New } \\
\text { Topics }\end{array}$ & 3 \\
\hline 1 & $\begin{array}{l}\text { location data information } \\
\text { map maps city service } \\
\text { locations code address }\end{array}$ & Location APIs & & $\begin{array}{l}\text { Duplicate } \\
\text { Topics }\end{array}$ & 0 \\
\hline
\end{tabular}




\begin{tabular}{|c|c|c|c|c|c|}
\hline 2 & $\begin{array}{l}\text { management services } \\
\text { platform applications } \\
\text { software service data } \\
\text { integrate systems business }\end{array}$ & Platfrom APIs & & $\begin{array}{l}>1 \\
\text { Theme }\end{array}$ & 2 \\
\hline 3 & $\begin{array}{l}\text { web site create website } \\
\text { code service application } \\
\text { javascript free google }\end{array}$ & Web APIs & $\mathrm{N}$ & & \\
\hline 4 & $\begin{array}{l}\text { payment payments online } \\
\text { card credit processing } \\
\text { transactions account } \\
\text { service transaction }\end{array}$ & Payment APIs & & & \\
\hline 5 & $\begin{array}{l}\text { sms messages send email } \\
\text { messaging service text } \\
\text { mobile message calls }\end{array}$ & $\begin{array}{l}\text { SMS and email } \\
\text { messaging }\end{array}$ & & & \\
\hline 6 & $\begin{array}{l}\text { image images files file pdf } \\
\text { documents upload text } \\
\text { service format }\end{array}$ & File management & & & \\
\hline 7 & $\begin{array}{l}\text { mobile devices app apps } \\
\text { applications device android } \\
\text { platform application ios }\end{array}$ & Mobile Access & & & \\
\hline 8 & $\begin{array}{l}\text { game games data } \\
\text { information sports players } \\
\text { scores live statistics player }\end{array}$ & Sports statistics & & & \\
\hline 9 & $\begin{array}{l}\text { xml json responses restful } \\
\text { formatted data calls web } \\
\text { service returns }\end{array}$ & REST data format & & & \\
\hline 10 & $\begin{array}{l}\text { data weather information } \\
\text { energy access conditions } \\
\text { location national solar } \\
\text { service }\end{array}$ & Weather & & & \\
\hline 11 & $\begin{array}{l}\text { bitcoin service account } \\
\text { exchange trading calls } \\
\text { currency rest trade } \\
\text { information }\end{array}$ & Cryptocurrency & & & \\
\hline 12 & $\begin{array}{l}\text { social content share media } \\
\text { twitter news create photos } \\
\text { access facebook }\end{array}$ & $\begin{array}{l}\text { Social media } \\
\text { management }\end{array}$ & & & \\
\hline 13 & $\begin{array}{l}\text { search access music } \\
\text { information database } \\
\text { metadata data library } \\
\text { books collection }\end{array}$ & Media search & $\mathrm{N}$ & & \\
\hline 14 & $\begin{array}{l}\text { data information access } \\
\text { open government public }\end{array}$ & Open data APIs & & & \\
\hline
\end{tabular}




\begin{tabular}{|c|c|c|c|}
\hline & $\begin{array}{l}\text { online learning state } \\
\text { education }\end{array}$ & & \\
\hline 15 & $\begin{array}{l}\text { search offers product } \\
\text { access services advertising } \\
\text { products online marketing } \\
\text { deals }\end{array}$ & Marketing & \\
\hline 16 & $\begin{array}{l}\text { json key authentication rest } \\
\text { http requests access data } \\
\text { format required }\end{array}$ & Authentication & \\
\hline 17 & $\begin{array}{l}\text { applications methods } \\
\text { include functionality access } \\
\text { integrate retrieving } \\
\text { managing information } \\
\text { create }\end{array}$ & Information Retrieval & \\
\hline 18 & $\begin{array}{l}\text { methods service support } \\
\text { submission functions } \\
\text { information retrieval } \\
\text { including specific access }\end{array}$ & Information Retrieval & \\
\hline 19 & $\begin{array}{l}\text { cloud storage service data } \\
\text { files access servers } \\
\text { management server } \\
\text { amazon }\end{array}$ & Cloud access APIs & \\
\hline 20 & $\begin{array}{l}\text { video content videos media } \\
\text { audio live chat streaming } \\
\text { service online }\end{array}$ & Media streaming & \\
\hline 21 & $\begin{array}{l}\text { text language content } \\
\text { analysis translation } \\
\text { recognition semantic } \\
\text { machine search sentiment }\end{array}$ & Text Processing & \\
\hline 22 & $\begin{array}{l}\text { data market financial stock } \\
\text { exchange access rates } \\
\text { historical quotes } \\
\text { information }\end{array}$ & Financial services API & \\
\hline 23 & $\begin{array}{l}\text { domain url github domains } \\
\text { links urls link service } \\
\text { services dns }\end{array}$ & Domain management & $\mathrm{N}$ \\
\hline 24 & $\begin{array}{l}\text { data health database } \\
\text { information analysis } \\
\text { sequence protein medical } \\
\text { sequences search }\end{array}$ & Health information & \\
\hline 25 & $\begin{array}{l}\text { address data email } \\
\text { addresses number numbers } \\
\text { phone information }\end{array}$ & $\begin{array}{l}\text { Email address } \\
\text { verification }\end{array}$ & \\
\hline
\end{tabular}




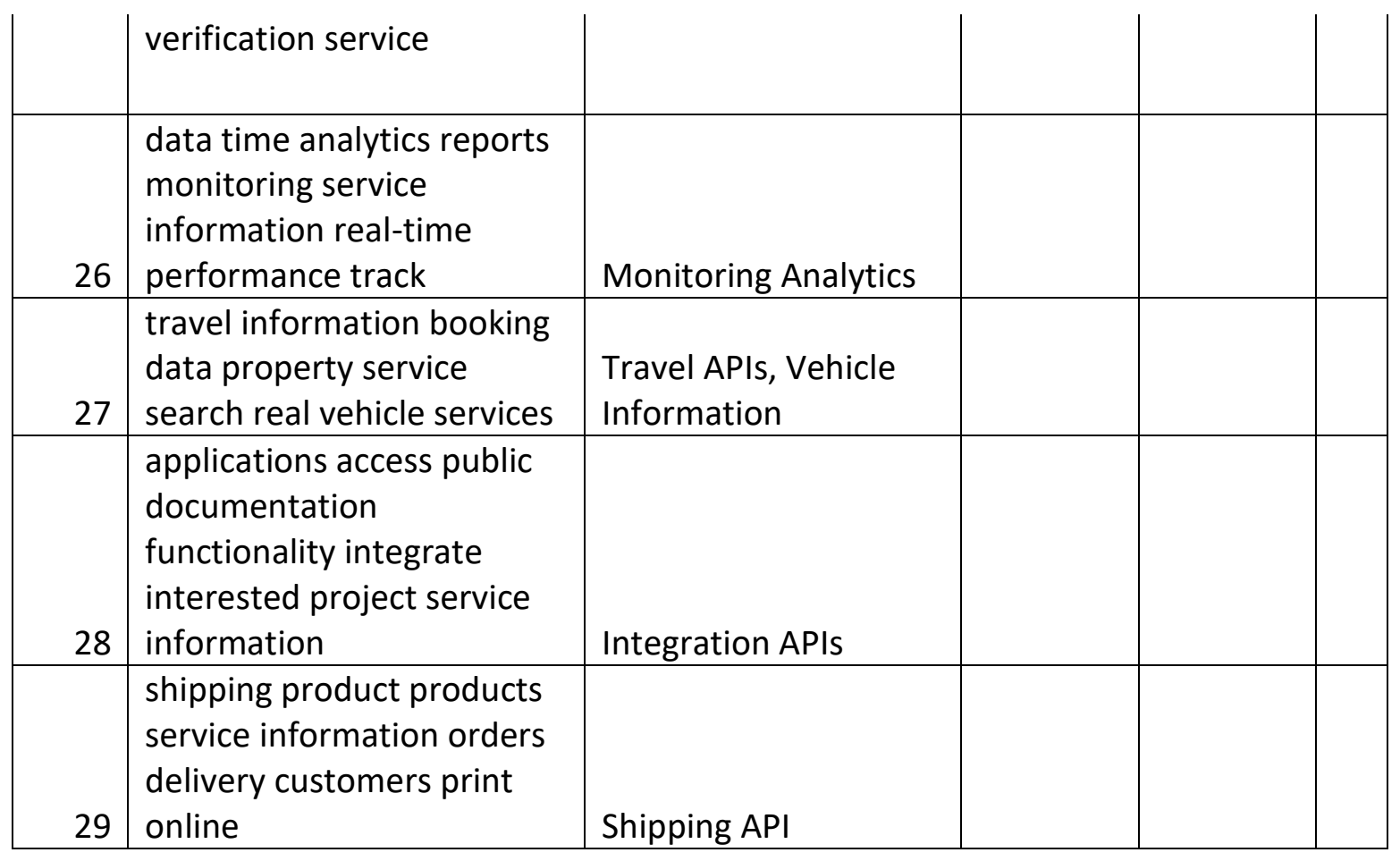

\begin{tabular}{|c|c|c|c|c|c|}
\hline \multicolumn{6}{|c|}{ 35-Topics } \\
\hline $\begin{array}{l}\text { Topic } \\
\text { ID }\end{array}$ & Words & General Interpretation & $\begin{array}{l}\text { N-New } \\
\text { D- } \\
\text { Duplicate }\end{array}$ & \multicolumn{2}{|c|}{ Delta 35-30 } \\
\hline 0 & $\begin{array}{l}\text { social site share twitter } \\
\text { create links service url } \\
\text { facebook people }\end{array}$ & $\begin{array}{l}\text { Social media } \\
\text { management }\end{array}$ & & $\begin{array}{l}\text { New } \\
\text { Topics }\end{array}$ & 2 \\
\hline 1 & $\begin{array}{l}\text { mobile devices app apps } \\
\text { device android application } \\
\text { applications access ios }\end{array}$ & Mobile Access & & $\begin{array}{l}\text { Duplicate } \\
\text { Topics }\end{array}$ & 3 \\
\hline 2 & $\begin{array}{l}\text { travel information booking } \\
\text { data service vehicle transit } \\
\text { access flight hotel }\end{array}$ & Travel APIs & & $\begin{array}{l}>1 \\
\text { Theme }\end{array}$ & 1 \\
\hline 3 & $\begin{array}{l}\text { methods service support } \\
\text { functions submission } \\
\text { including retrieval } \\
\text { information job include }\end{array}$ & Information Retrieval & & & \\
\hline 4 & $\begin{array}{l}\text { json rest key http } \\
\text { authentication requests } \\
\text { service access offers data }\end{array}$ & Authentication & & & \\
\hline 5 & $\begin{array}{l}\text { sms messages send } \\
\text { messaging text mobile }\end{array}$ & $\begin{array}{l}\text { SMS and email } \\
\text { messaging }\end{array}$ & & & \\
\hline
\end{tabular}




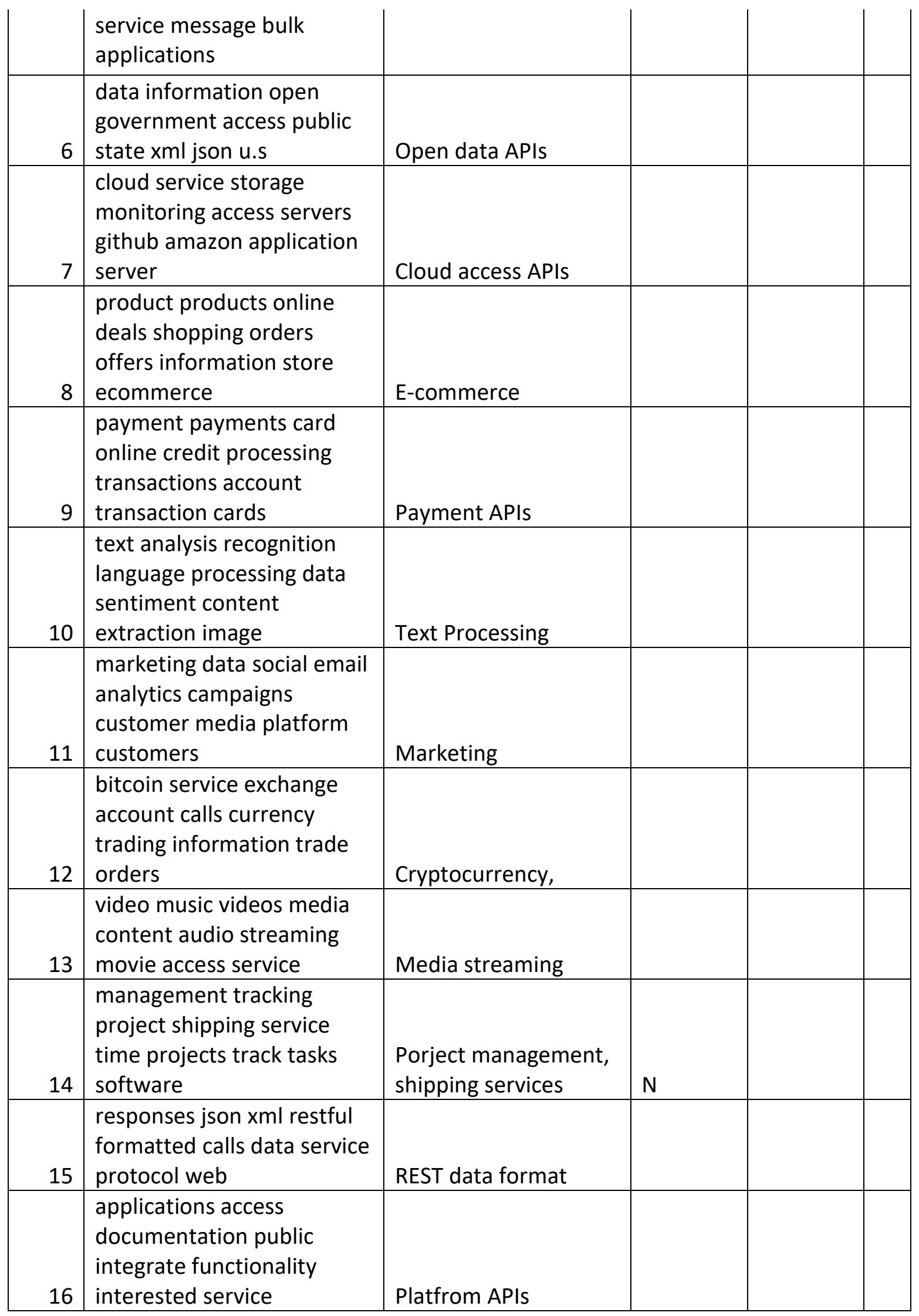




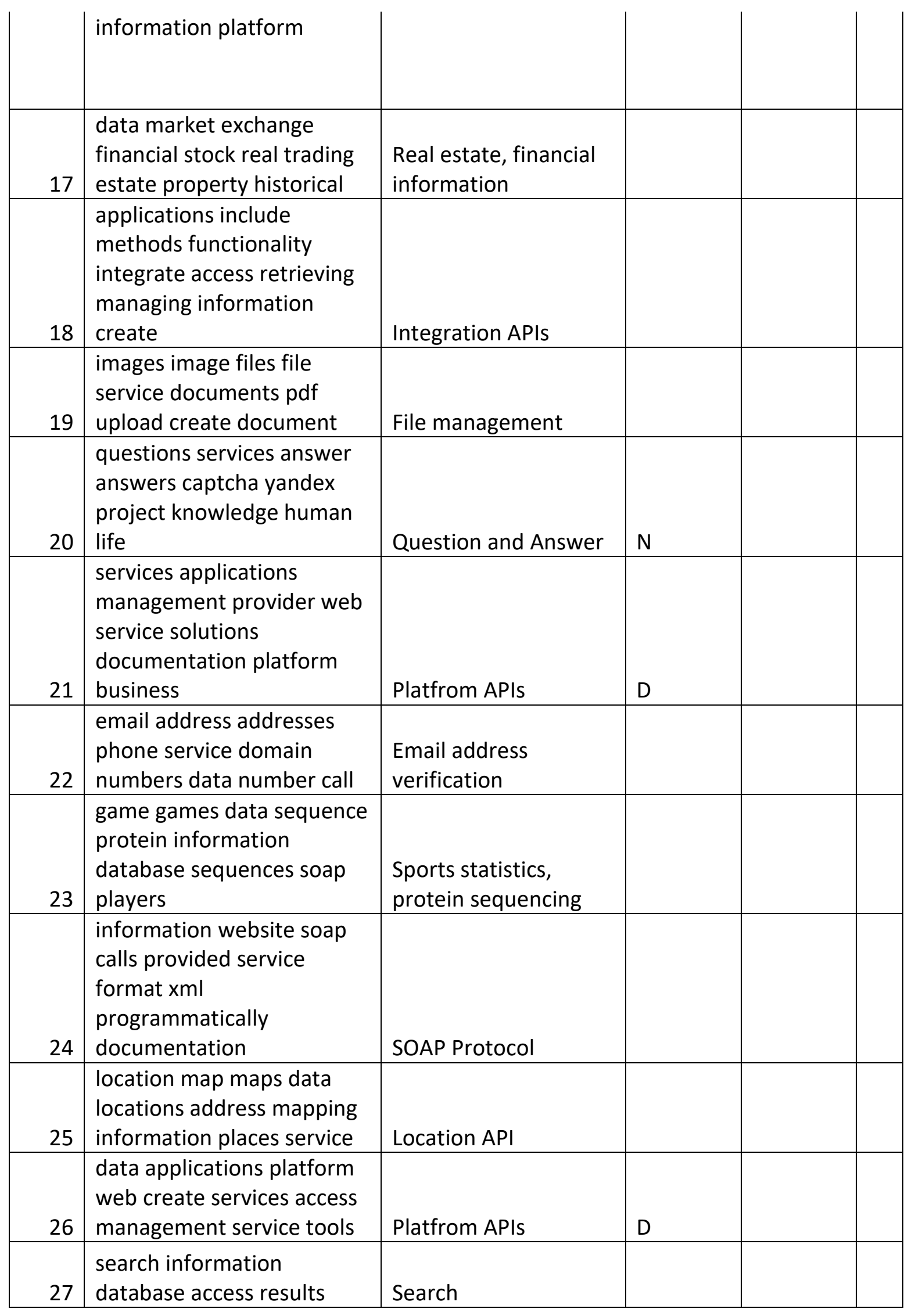




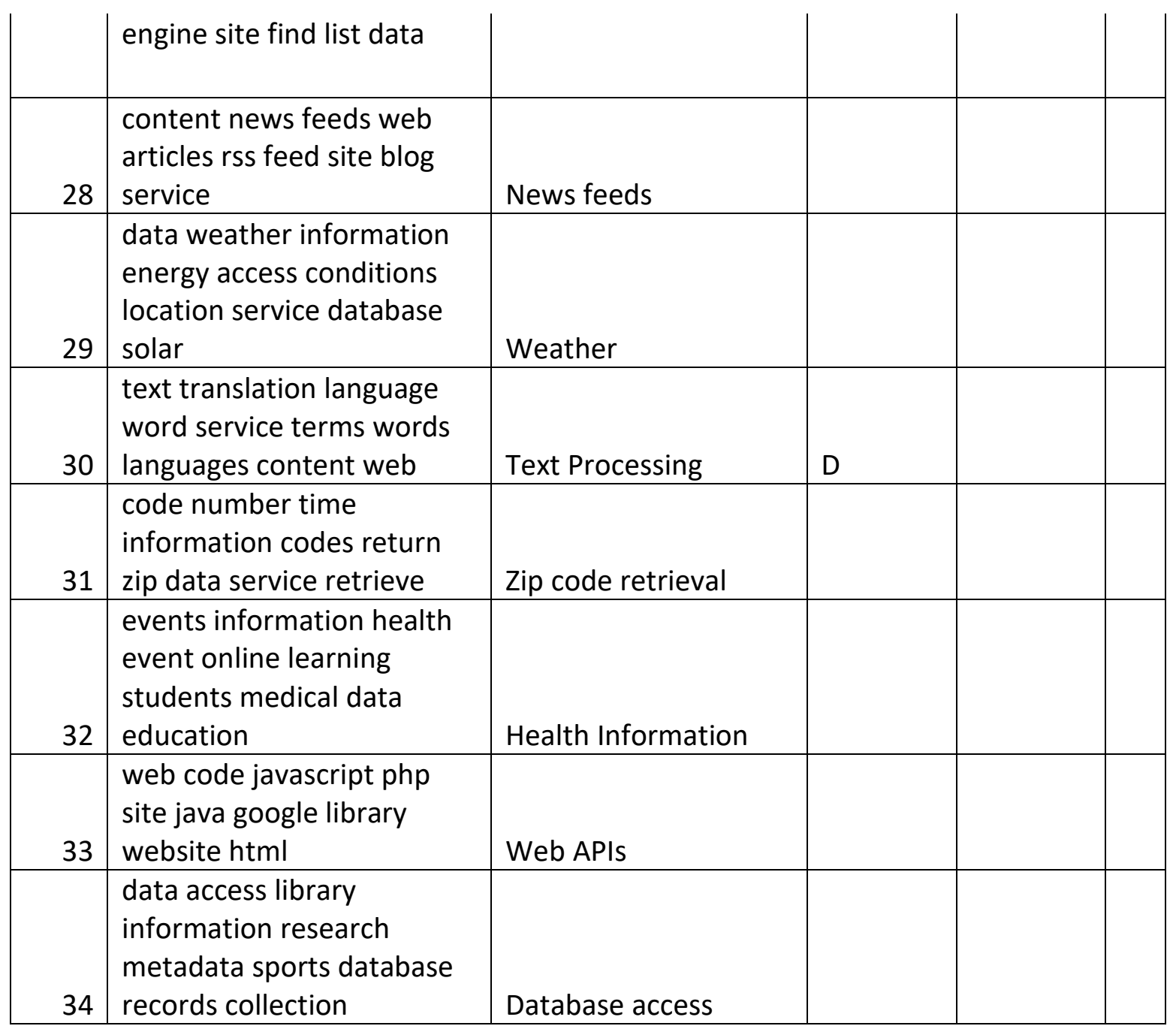

\begin{tabular}{|c|c|c|c|c|c|}
\hline \multicolumn{6}{|c|}{ 40-Topics } \\
\hline $\begin{array}{l}\text { Topic } \\
\text { ID }\end{array}$ & Words & General Interpretation & $\begin{array}{l}\text { N-New } \\
\text { D- } \\
\text { Duplicate }\end{array}$ & Delta 40 & \\
\hline 0 & $\begin{array}{l}\text { property real affiliate } \\
\text { estate search listings } \\
\text { properties rental website } \\
\text { program }\end{array}$ & Real Estate & & $\begin{array}{l}\text { New } \\
\text { Topics }\end{array}$ & 1 \\
\hline 1 & $\begin{array}{l}\text { social content twitter news } \\
\text { media share facebook } \\
\text { access data information }\end{array}$ & Social Media & & $\begin{array}{l}\text { Duplicate } \\
\text { Topics }\end{array}$ & 2 \\
\hline 2 & $\begin{array}{l}\text { domain shipping delivery } \\
\text { service services domains } \\
\text { tracking mail dns customers }\end{array}$ & $\begin{array}{l}\text { Shipping, Domain } \\
\text { services }\end{array}$ & & $\begin{array}{l}>1 \\
\text { Theme }\end{array}$ & 1 \\
\hline
\end{tabular}




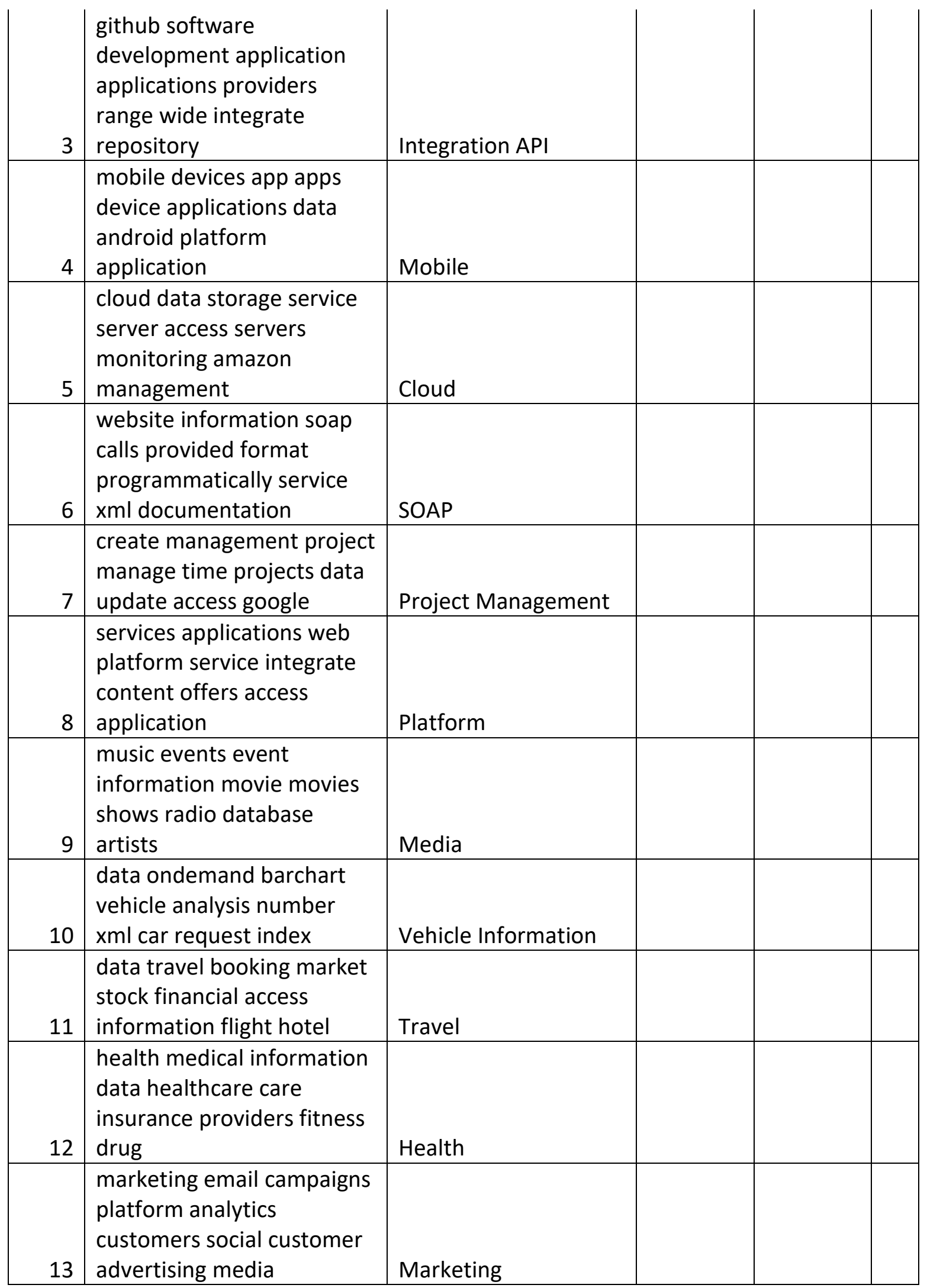




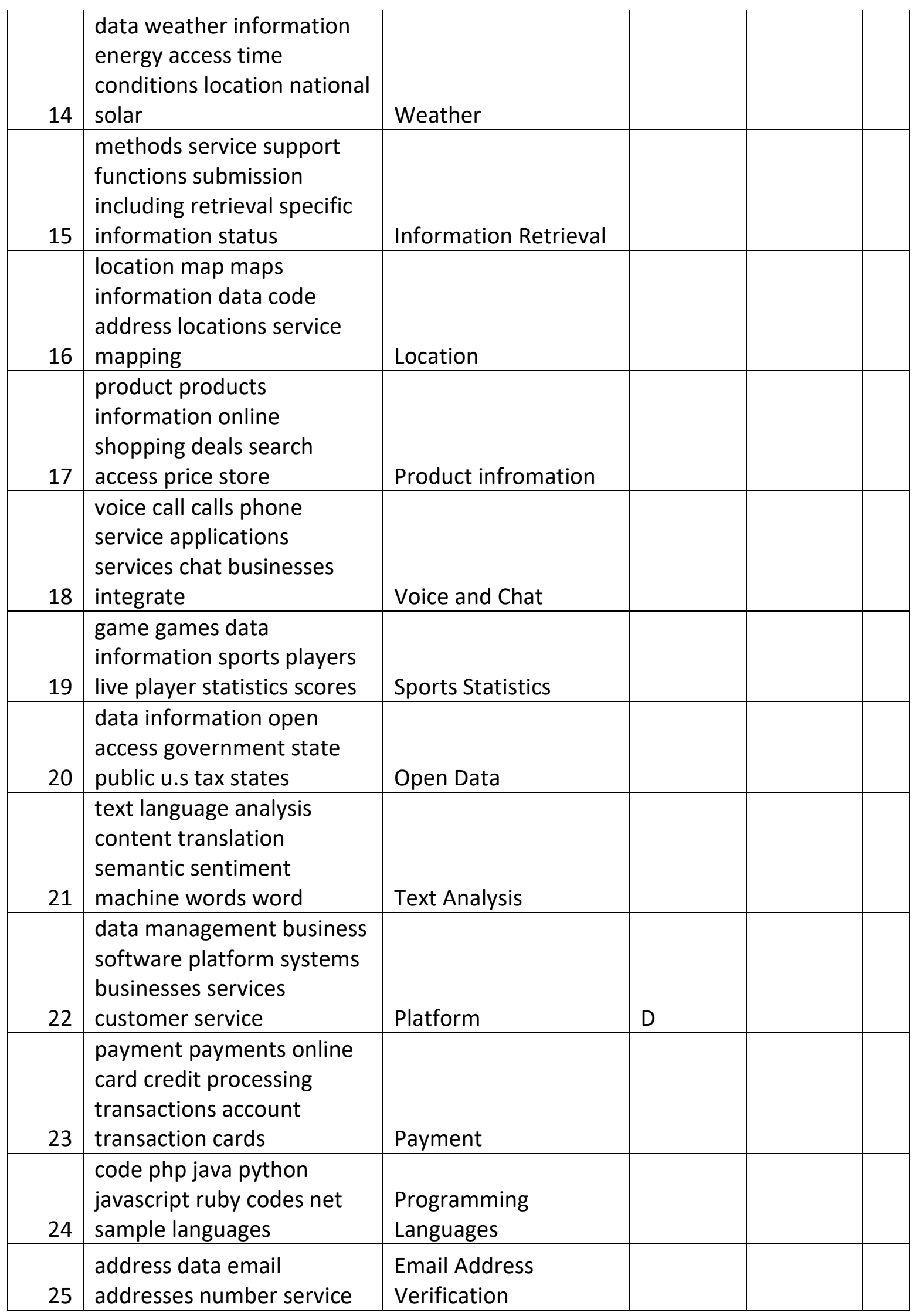




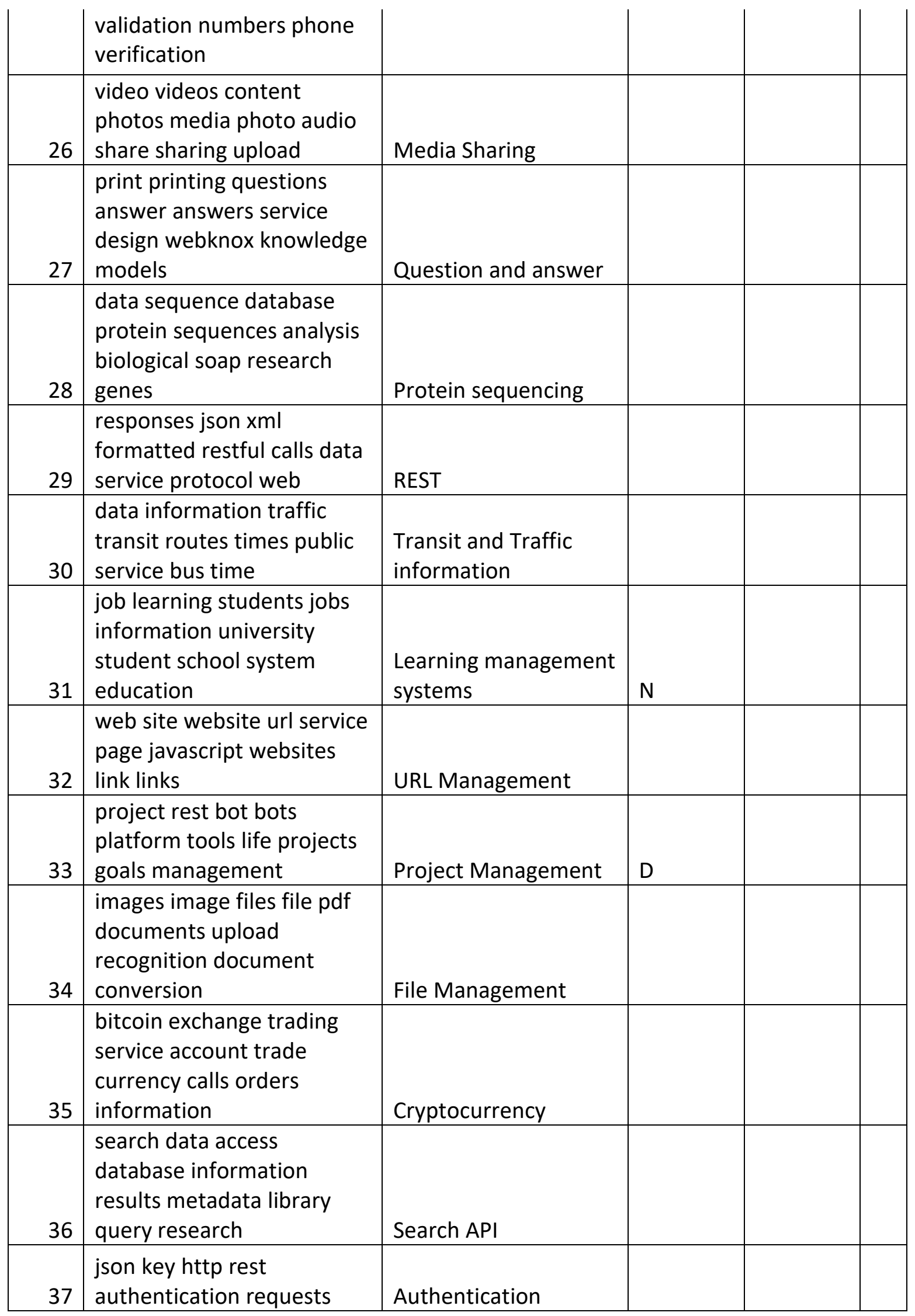




\begin{tabular}{|r|l|l|l|l|}
\hline service access data account & & & \\
\hline 38 & $\begin{array}{l}\text { sms messages send } \\
\text { messaging text mobile } \\
\text { message bulk sending } \\
\text { service }\end{array}$ & SMS messaging & & \\
\hline $\begin{array}{l}\text { applications access } \\
\text { functionality integrate } \\
\text { include methods } \\
\text { information retrieving } \\
\text { managing create }\end{array}$ & & & & \\
\hline 9
\end{tabular}

\begin{tabular}{|c|c|c|c|c|c|}
\hline \multicolumn{6}{|c|}{ 45-Topics } \\
\hline $\begin{array}{l}\text { Topic } \\
\text { ID }\end{array}$ & Words & General Interpretation & $\begin{array}{l}\text { N-New } \\
\text { D- } \\
\text { Duplicate }\end{array}$ & \multicolumn{2}{|c|}{ Delta $45-40$} \\
\hline 0 & $\begin{array}{l}\text { address domain email } \\
\text { addresses number data } \\
\text { numbers validation phone } \\
\text { verification }\end{array}$ & $\begin{array}{l}\text { Email address } \\
\text { Verification }\end{array}$ & & $\begin{array}{l}\text { New } \\
\text { Topics }\end{array}$ & 0 \\
\hline 1 & $\begin{array}{l}\text { applications include } \\
\text { methods integrate } \\
\text { functionality access } \\
\text { retrieving managing } \\
\text { information create }\end{array}$ & Integration API & & $\begin{array}{l}\text { Duplicate } \\
\text { Topics }\end{array}$ & 6 \\
\hline 2 & $\begin{array}{l}\text { share photos create social } \\
\text { service photo site sharing } \\
\text { twitter information }\end{array}$ & $\begin{array}{l}\text { Social Media } \\
\text { Management }\end{array}$ & & $\begin{array}{l}>1 \\
\text { Theme }\end{array}$ & 0 \\
\hline 3 & $\begin{array}{l}\text { access information data } \\
\text { library research learning } \\
\text { resources metadata online } \\
\text { university }\end{array}$ & Library access & & & \\
\hline 4 & $\begin{array}{l}\text { events event information } \\
\text { tickets calendar ticket } \\
\text { online family venues } \\
\text { listings }\end{array}$ & Events listings & & & \\
\hline 5 & $\begin{array}{l}\text { web site website javascript } \\
\text { google code create } \\
\text { applications application } \\
\text { websites }\end{array}$ & $\begin{array}{l}\text { Programming } \\
\text { languages }\end{array}$ & & & \\
\hline
\end{tabular}




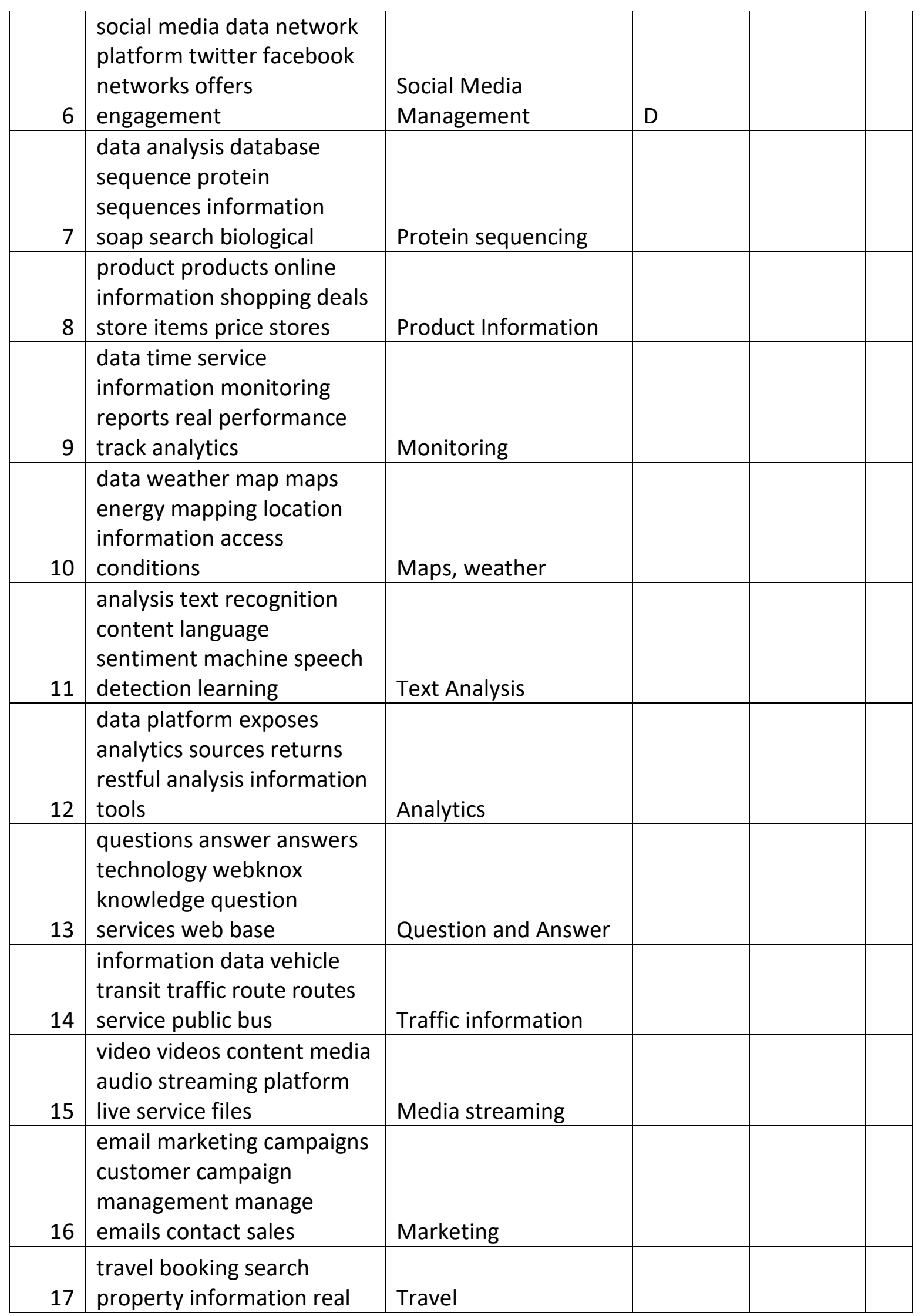




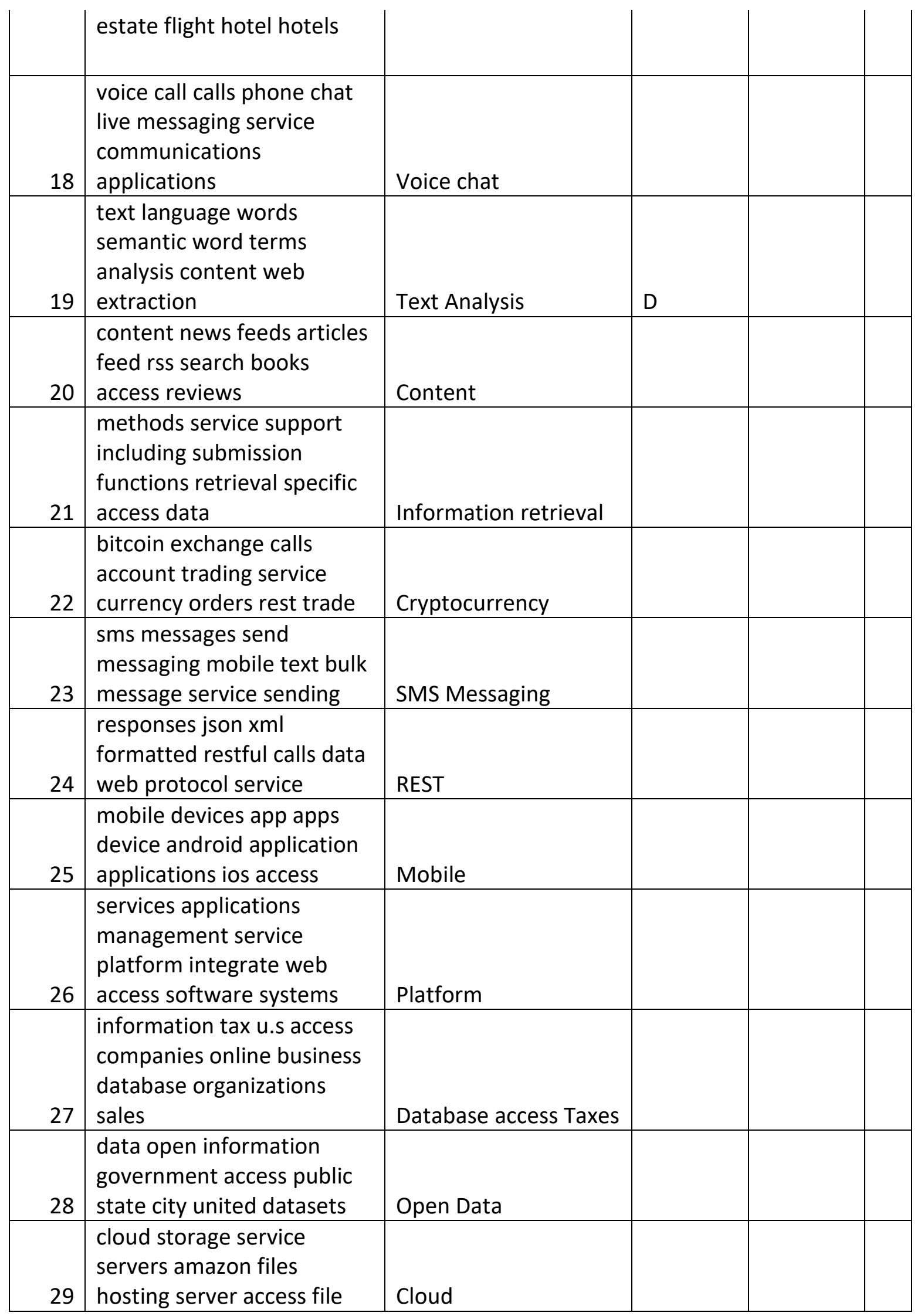




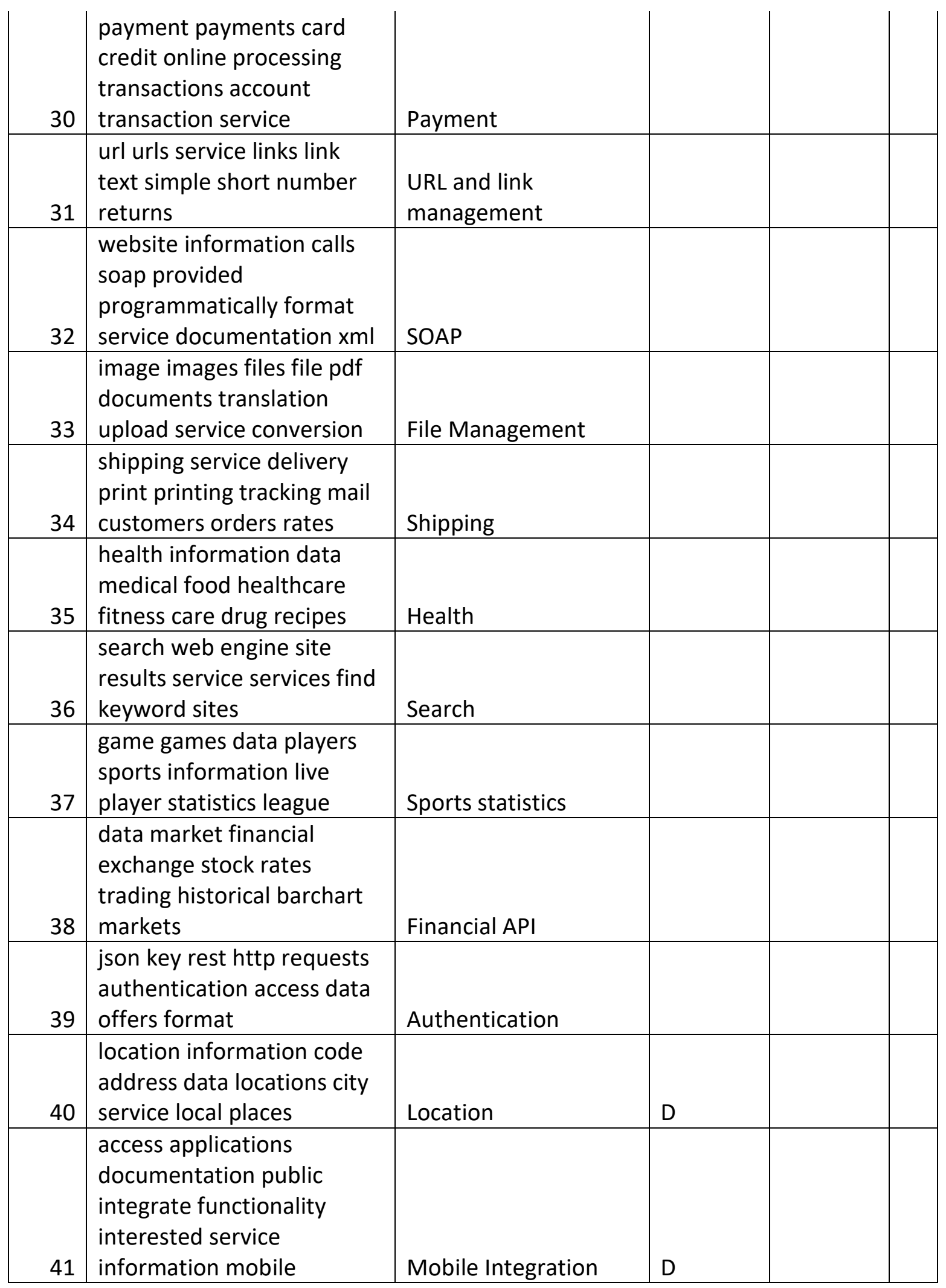




\begin{tabular}{|c|c|c|c|}
\hline 42 & $\begin{array}{l}\text { github application } \\
\text { authentication security } \\
\text { range software secure wide } \\
\text { development service }\end{array}$ & Github & $\mathrm{D}$ \\
\hline 43 & $\begin{array}{l}\text { music access movie movies } \\
\text { database radio artists } \\
\text { information search shows }\end{array}$ & Media information & D \\
\hline 44 & $\begin{array}{l}\text { project management } \\
\text { projects job tasks time jobs } \\
\text { tracking create team }\end{array}$ & Project Management & \\
\hline
\end{tabular}

\section{A.2 Topic Model 40-Topics Diagnostics}

\begin{tabular}{|c|c|c|c|c|c|}
\hline $\begin{array}{l}\text { Topic } \\
\text { ID }\end{array}$ & Label & tokens & $\begin{array}{l}\text { Document } \\
\text { Entropy }\end{array}$ & Coherence & $\begin{array}{l}\text { Rank } 1 \\
\text { Docs }\end{array}$ \\
\hline 0 & 1 & 4145 & 6.077 & -132.6077 & 0.2282 \\
\hline 1 & 2 & 15515 & 7.4201 & -98.1263 & 0.1802 \\
\hline 2 & 3 & 6349 & 6.2316 & -129.8569 & 0.264 \\
\hline 3 & 4 & 3637 & 5.9617 & -56.8569 & 0.2413 \\
\hline 4 & 5 & 12009 & 7.2243 & -99.9886 & 0.1683 \\
\hline 5 & 6 & 13614 & 7.1269 & -103.7207 & 0.1939 \\
\hline 6 & 7 & 9789 & 6.997 & -66.9379 & 0.1529 \\
\hline 7 & 8 & 15917 & 7.4878 & -101.0618 & 0.1481 \\
\hline 8 & 9 & 45475 & 8.5506 & -101.6913 & 0.1345 \\
\hline 9 & 10 & 7096 & 6.4416 & -142.3019 & 0.3019 \\
\hline 10 & 11 & 4534 & 5.5621 & -132.3278 & 0.2987 \\
\hline 11 & 12 & 11110 & 6.7242 & -145.894 & 0.2456 \\
\hline 12 & 13 & 4050 & 5.9291 & -129.3984 & 0.2393 \\
\hline 13 & 14 & 14725 & 7.2599 & -92.569 & 0.2101 \\
\hline 14 & 15 & 9529 & 6.4665 & -94.4813 & 0.2601 \\
\hline 15 & 16 & 22807 & 7.5628 & -91.5498 & 0.1111 \\
\hline 16 & 17 & 12392 & 6.9986 & -88.0853 & 0.21 \\
\hline 17 & 18 & 12214 & 7.0431 & -100.8506 & 0.2179 \\
\hline 18 & 19 & 7164 & 6.4441 & -83.9634 & 0.2729 \\
\hline 19 & 20 & 6782 & 6.1877 & -85.7157 & 0.3606 \\
\hline 20 & 21 & 13893 & 7.0489 & -104.9628 & 0.201 \\
\hline 21 & 22 & 12353 & 6.8748 & -106.6158 & 0.2149 \\
\hline 22 & 23 & 24303 & 7.8061 & -92.1162 & 0.1621 \\
\hline 23 & 24 & 11529 & 6.7254 & -70.2148 & 0.2724 \\
\hline
\end{tabular}




\begin{tabular}{|r|r|r|r|r|r|}
24 & 25 & 5854 & 6.5834 & -116.1633 & 0.1404 \\
\hline 25 & 26 & 10358 & 6.7873 & -81.3456 & 0.2013 \\
\hline 26 & 27 & 7606 & 6.6909 & -101.505 & 0.2127 \\
\hline 27 & 28 & 3858 & 5.8362 & -198.3161 & 0.1832 \\
\hline 28 & 29 & 6632 & 5.9591 & -86.3229 & 0.361 \\
\hline 29 & 30 & 21155 & 7.9959 & -72.0615 & 0.1013 \\
\hline 30 & 31 & 7268 & 6.4073 & -87.9058 & 0.2542 \\
\hline 31 & 32 & 5808 & 6.2887 & -137.9151 & 0.2266 \\
\hline 32 & 33 & 20978 & 7.9032 & -116.6143 & 0.1153 \\
\hline 33 & 34 & 4315 & 5.9665 & -133.9748 & 0.1672 \\
\hline 34 & 35 & 8816 & 6.8051 & -105.164 & 0.1836 \\
\hline 35 & 36 & 8603 & 6.2958 & -64.0209 & 0.3568 \\
\hline 36 & 37 & 21018 & 7.6867 & -111.524 & 0.1379 \\
\hline 37 & 38 & 29093 & 8.2032 & -83.9838 & 0.1231 \\
\hline 38 & 39 & 14366 & 6.8734 & -62.8485 & 0.2889 \\
\hline 39 & 40 & 23441 & 7.7624 & -44.2949 & 0.1924 \\
\hline
\end{tabular}

\section{A.3 Sample from output-doc-topic file for 40-topics}

Each line in the file contains the document number, the name of the document represented as a path to the file containing the document, and 3 pairs of topic-

distribution numbers separated by tabs. The name of the file containing the document is the API name, and the document in the file is the API description.

7110 file:/mallet/mallet-2.0.8RC3/../api_descriptions/Microsoft_Telephony.txt 24
$0.361021188908547 \quad 4$
0.32205510967179407
8

0.08939318113951183

7111 file:/mallet/mallet-2.0.8RC3/../api_descriptions/Microsoft_Translator.txt 32 $\begin{array}{lll}0.546736104106874321 & 0.23398216053413015 & 37\end{array}$ 0.08831377696044491 
7112 file:/mallet/mallet-2.0.8RC3/../api_descriptions/MIDAS.txt 6
0.29056900900133376
22
0.23956872837545545
8
0.1377578133880396

7113 file:/mallet/mallet-2.0.8RC3/../api_descriptions/Middlecoin.txt 35

$\begin{array}{llll}0.48548280027362317 & 13 & 0.18348776653375007 & 15\end{array}$

0.15419521295222544

7114 file:/mallet/mallet-2.0.8RC3/../api_descriptions/midíadía.txt 37

$\begin{array}{lllll}0.36484877851528835 & 17 & 0.27752345081644714 & 8\end{array}$

0.1964841978824068

7115 file:/mallet/mallet-2.0.8RC3/../api_descriptions/Mifos.txt 22

$0.682261182227287729 \quad 0.14667836669011772 \quad 5$

0.07329380253827886

7116 file:/mallet/mallet-2.0.8RC3/../api_descriptions/Mighty_Slider.txt 26

$\begin{array}{lll}0.300951785808144915 & 0.23627955550906288 & 37\end{array}$

0.13826818028384297

7117 file:/mallet/mallet-2.0.8RC3/../api_descriptions/MightyCast_NEX.txt 4

$0.608970865363629236 \quad 0.14614056954002344 \quad 22$

0.11084637484406136

7118 file:/mallet/mallet-2.0.8RC3/../api_descriptions/migme.txt 13

$\begin{array}{llll}0.31233354211121755 & 8 & 0.22743858718104373 & 1\end{array}$ 
0.22370888433032893

7119 file:/mallet/mallet-2.0.8RC3/../api_descriptions/miiCard.txt

23
0.383331736162607239
0.29689633941308178
0.2716090185941814

7120 file:/mallet/mallet-2.0.8RC3/../api_descriptions/MileSplit.txt

0.36889336424614916

1

0.15965639461454337

37

0.10915960634007972

7121 file:/mallet/mallet-2.0.8RC3/../api_descriptions/milkySMS.txt

38
0.91089760997696458
0.01067648269621506

\section{A.4 Example API description documents for each topic}

\begin{tabular}{|l|r|r|}
\hline API Name & \multicolumn{1}{l|}{$\begin{array}{l}\text { Topic } \\
\text { ID }\end{array}$} & \multicolumn{1}{l|}{$\begin{array}{l}\text { Topic } \\
\text { Distribution }\end{array}$} \\
\hline Quag & 2 & 0.802216987 \\
\hline Seesmic & 2 & 0.806650663 \\
\hline ShareThis_WebShare & 2 & 0.808596946 \\
\hline Bring_Easy_Return_Service & 3 & 0.806100468 \\
\hline Bring_Tracking & 3 & 0.818776009 \\
\hline USPS_Hold_for_Pickup & 3 & 0.889323571 \\
\hline USPS_International_Shipping_Labels & 3 & 0.860920462 \\
\hline USPS_Online_Express_Mail_Label & 3 & 0.878526048 \\
\hline USPS_Package_Pickup & 3 & 0.873083121 \\
\hline USPS_Signature_Confirmation_Label & 3 & 0.917073791 \\
\hline USPS_Track_\&_Confirm & 3 & 0.822896863 \\
\hline GitHub_Activity_Starring & 4 & 0.88052261 \\
\hline GitHub_Activity_Watching & 4 & 0.808196693 \\
\hline GitHub_Emojis & 4 & 0.900652583 \\
\hline GitHub_Gists_Comments & 4 & 0.844159055 \\
\hline GitHub_Git_Blobs & 4 & 0.833769893 \\
\hline GitHub_Git_Commits & 4 & 0.885117775 \\
\hline GitHub_Git_Trees & 4 & 0.931483823 \\
\hline GitHub_Issue_Comments & 4 & 0.833769893 \\
\hline
\end{tabular}




\begin{tabular}{|l|r|r|} 
GitHub_Issue_Milestones & 4 & 0.867102477 \\
\hline GitHub_Issues & 4 & 0.833769893 \\
\hline GitHub_Repository_Commits & 4 & 0.834060921 \\
\hline GitHub_Users & 4 & 0.813319411 \\
\hline AppLamp_Wifi_LED & 5 & 0.868366976 \\
\hline Erizo & 5 & 0.915742209 \\
\hline Prowl & 5 & 0.8156903 \\
\hline Atlantic & 6 & 0.820532841 \\
\hline Google_Cloud_Storage & 6 & 0.817150652 \\
\hline Google_Compute_Engine_Instance_Group_Manager & 6 & 0.834769803 \\
\hline HP_Cloud_Compute & 6 & 0.828335532 \\
\hline ilandcloud & 6 & 0.872635076 \\
\hline MuninMX & 6 & 0.801724506 \\
\hline Rackspace_Cloud_Big_Data & 6 & 0.809681916 \\
\hline Rackspace_Cloud_Metrics & 6 & 0.814116463 \\
\hline Rackspace_Cloud_Networks & 6 & 0.823275737 \\
\hline Rackspace_Cloud_Orchestration & 6 & 0.828335532 \\
\hline RhoConnect & 6 & 0.83505709 \\
\hline RightScale_Cloud_Analytics & 6 & 0.825050572 \\
\hline RightScale_Self-Service & 6 & 0.825050572 \\
\hline ShepHertz_App42_Cloud_NoSQL_Storage & 6 & 0.865985993 \\
\hline ShepHertz_App42_Cloud_Session_Management & 6 & 0.844826637 \\
\hline ShepHertz_App42_Cloud_User_Management & 6 & 0.870112604 \\
\hline Songsterr & 10 & 0.847826089 \\
\hline Ticketmaster_International_Discovery & 10 & 0.806160202 \\
\hline AgriCharts_getChart & 11 & 0.840414259 \\
\hline AgriCharts_getFuturesExpirations & 11 & 0.88946241 \\
\hline AgriCharts_getFuturesOptions & 11 & 0.895279972 \\
\hline AgriCharts_getFuturesOptionsExpirations & 11 & 0.88946241 \\
\hline AgriCharts_getInstrumentDefinition & 11 & 0.87910092 \\
\hline AgriCharts_getSignal & 11 & 0.821798894 \\
\hline AgriCharts_getSpecialOptions & 11 & 0.842650261 \\
\hline Australia_Car_Registration & 11 & 0.912067886 \\
\hline Car_Registrations_in_Portugal & 11 & 0.912067886 \\
\hline Dutch_Car_License_Plate_Lookup & 11 & 0.865144319 \\
\hline Finnish_Vehicle_Registration_Searches & 0.857438428 \\
\hline getChart & 0.919197387 \\
\hline getEquityOptions & 11 & 0.933676452 \\
\hline getFuturesExpirations & 1149 \\
\hline
\end{tabular}




\begin{tabular}{|c|c|c|}
\hline getFuturesOptionsExpirations & 11 & 0.933676452 \\
\hline getFuturesSpecifications & 11 & 0.886009306 \\
\hline getHighLows & 11 & 0.818496098 \\
\hline getIndexMembers & 11 & 0.92893917 \\
\hline getInstrumentDefintion & 11 & 0.915112895 \\
\hline getMomentum & 11 & 0.892170853 \\
\hline getQuoteEOD & 11 & 0.914580184 \\
\hline getRatings & 11 & 0.868693089 \\
\hline getScreener & 11 & 0.81109125 \\
\hline getSignal & 11 & 0.900257903 \\
\hline getSpecialOptions & 11 & 0.867011284 \\
\hline HPE_Haven_OnDemand_Connector_History & 11 & 0.838117784 \\
\hline HPE_Haven_OnDemand_Connector_Status & 11 & 0.921323734 \\
\hline HPE_Haven_OnDemand_Delete_Connector & 11 & 0.839043787 \\
\hline HPE_Haven_OnDemand_Delete_Text_Index & 11 & 0.824743281 \\
\hline HPE_Haven_OnDemand_List_Indexes & 11 & 0.811516527 \\
\hline HPE_Haven_OnDemand_Retrieve_Config & 11 & 0.860705646 \\
\hline HPE_Haven_OnDemand_Retrieve_Index_Fields & 11 & 0.95025706 \\
\hline HPE_Haven_OnDemand_Start_Connector & 11 & 0.829521069 \\
\hline HPE_Haven_OnDemand_Update_Connector & 11 & 0.868693089 \\
\hline Norwegian_Car_Registration_Lookup & 11 & 0.853245524 \\
\hline Search_French_License_Plates & 11 & 0.886009306 \\
\hline Swedish_Car_Registration_Search & 11 & 0.83362114 \\
\hline UK_\&_Irish_Car_Registration_Lookups & 11 & 0.943151062 \\
\hline Verifica_Targhe_Italiane & 11 & 0.889175655 \\
\hline Hotelbeds_Apitude_Content & 12 & 0.865130297 \\
\hline Mergent_Company_Fundamentals & 12 & 0.883319243 \\
\hline Xignite_Get_Real_Time_Rate & 12 & 0.828720383 \\
\hline Xignite_GetHistoricalRates & 12 & 0.940388357 \\
\hline Xignite_Global_Indices_Historical & 12 & 0.901094743 \\
\hline Xignite_GlobalHistoricalFile & 12 & 0.858316826 \\
\hline $\begin{array}{l}\text { Xignite_Initial_Public_Offering_Calendar_\&_Performance_ } \\
\text { Data }\end{array}$ & 12 & 0.834246871 \\
\hline Xignite_Realtime & 12 & 0.945355901 \\
\hline XigniteAnalysts & 12 & 0.912730425 \\
\hline XigniteBATSRealTime & 12 & 0.948231855 \\
\hline XigniteBondsRealTime & 12 & 0.848682895 \\
\hline XigniteEstimates & 12 & 0.905543792 \\
\hline XigniteFutures & 12 & 0.900821062 \\
\hline
\end{tabular}




\begin{tabular}{|c|c|c|}
\hline XigniteGlobalBondMaster & 12 & 0.877053656 \\
\hline XigniteGlobalExchanges & 12 & 0.834429575 \\
\hline XigniteGlobalMaster & 12 & 0.830070492 \\
\hline XigniteGlobalOptions & 12 & 0.829511159 \\
\hline XigniteGlobalQuotes & 12 & 0.913757255 \\
\hline XigniteGlobalRealTime & 12 & 0.917578643 \\
\hline XigniteGlobalRealTimeOptions & 12 & 0.901094743 \\
\hline XigniteMoneyMarkets & 12 & 0.84854082 \\
\hline AdRout & 14 & 0.816839597 \\
\hline TM_Forum_Customer_Management & 14 & 0.835155226 \\
\hline TM_Forum_Performance_Management & 14 & 0.858704026 \\
\hline TM_Forum_Quote & 14 & 0.829471055 \\
\hline TM_Forum_SLA_Management & 14 & 0.845457807 \\
\hline CDYNE_Weather & 15 & 0.847174725 \\
\hline CORDC_COAMPS_Winds_Model & 15 & 0.877658286 \\
\hline NASA's_Asterank & 15 & 0.822377128 \\
\hline NASA_Fireball_And_Bolide_Reports & 15 & 0.903085491 \\
\hline NCEP_Forecast & 15 & 0.845285244 \\
\hline NSIDC & 15 & 0.85777466 \\
\hline FraudLabs_ZIPCodeWorld_United_States & 17 & 0.932527253 \\
\hline Geobytes_Get_City_Details & 17 & 0.801239397 \\
\hline Geobytes_Get_Distance & 17 & 0.822977294 \\
\hline GeoBytes_Get_Nearby_Cities & 17 & 0.829081383 \\
\hline Map_Data_Services_QuickMap & 17 & 0.803989788 \\
\hline Macy's_Catalog_and_Store_Services & 18 & 0.818836926 \\
\hline Macy's_Shopping_Bag_Services & 18 & 0.820864715 \\
\hline Amadeus_Rail-Station_Autocomplete & 19 & 0.885475206 \\
\hline Nexmo_VoiceXML & 19 & 0.858208274 \\
\hline Plivo_Call & 19 & 0.8222285 \\
\hline Plivo_Call_Play & 19 & 0.834266246 \\
\hline Plivo_Call_Request & 19 & 0.851118926 \\
\hline Plivo_Call_Speak & 19 & 0.870537627 \\
\hline Plivo_Conference & 19 & 0.851118926 \\
\hline Halo_Profile & 20 & 0.824567089 \\
\hline Halo_Stats & 20 & 0.834312997 \\
\hline Italy_SerieA_League_Live_and_Historical_Results & 20 & 0.852504506 \\
\hline Live_Scoreboards & 20 & 0.852504506 \\
\hline Riot_Games & 20 & 0.83392114 \\
\hline Roanuz_Cricket & 20 & 0.906799533 \\
\hline
\end{tabular}




\begin{tabular}{|c|c|c|}
\hline Roanuz_Cricket_Authentication & 20 & 0.893485501 \\
\hline Roanuz_Cricket_Football_Match & 20 & 0.875733583 \\
\hline Roanuz_Cricket_ISL_Football & 20 & 0.870330854 \\
\hline Roanuz_Cricket_ISL_Football_Season & 20 & 0.857981808 \\
\hline Roanuz_Cricket_Match & 20 & 0.919393961 \\
\hline Roanuz_Cricket_Match_Over_Summary & 20 & 0.80044142 \\
\hline Roanuz_Cricket_News_Aggregation & 20 & 0.943358868 \\
\hline Roanuz_Cricket_Player_Stats & 20 & 0.909623732 \\
\hline Roanuz_Cricket_Recent_Matches & 20 & 0.895199812 \\
\hline Roanuz_Cricket_Recent_Seasons & 20 & 0.947830457 \\
\hline Roanuz_Cricket_Schedule & 20 & 0.875550191 \\
\hline Roanuz_Cricket_Season & 20 & 0.91478799 \\
\hline Roanuz_Cricket_Season_Points & 20 & 0.936050494 \\
\hline Roanuz_Cricket_Season_Team & 20 & 0.939926143 \\
\hline Sportradar_Cricket & 20 & 0.864436983 \\
\hline Sportradar_Golf & 20 & 0.871535769 \\
\hline Sportradar_MLB & 20 & 0.886217112 \\
\hline Sportradar_NBA & 20 & 0.941692986 \\
\hline Sportradar_NCAA_Football & 20 & 0.949168115 \\
\hline Sportradar_NCAA_Men's_Basketball & 20 & 0.923527532 \\
\hline Sportradar_NCAA_Women's_Basketball & 20 & 0.871535769 \\
\hline Sportradar_NFL & 20 & 0.857562339 \\
\hline Sportradar_NHL & 20 & 0.864436983 \\
\hline Sportradar_Odds & 20 & 0.886217112 \\
\hline Sportradar_Olympics & 20 & 0.867253724 \\
\hline Sportradar_Soccer & 20 & 0.84430085 \\
\hline Sportradar_WNBA & 20 & 0.944932204 \\
\hline World_Cup_in_JSON & 20 & 0.839278406 \\
\hline BusinessUSA_Events & 21 & 0.851454661 \\
\hline BusinessUSA_Programs & 21 & 0.884745505 \\
\hline CKAN_Czech_Republic & 21 & 0.830797367 \\
\hline FedSpending & 21 & 0.801357031 \\
\hline GuideStar_Detail & 21 & 0.834652046 \\
\hline International_Aid_Transparency_Initiative & 21 & 0.917654535 \\
\hline It's_Your_Parliament_EU_Data & 21 & 0.801899829 \\
\hline Larimer_County_Public_Records_Databases & 21 & 0.871628204 \\
\hline National_Crime_Victimization_Survey & 21 & 0.800863571 \\
\hline New_York_Times_Congress & 21 & 0.801899829 \\
\hline New_York_Times_NY_State_Legislature & 21 & 0.835970708 \\
\hline
\end{tabular}




\begin{tabular}{|c|c|c|}
\hline OffeneDaten & 21 & 0.860481688 \\
\hline Open_State_Project & 21 & 0.801357031 \\
\hline Open_States & 21 & 0.87648267 \\
\hline OpenColorado & 21 & 0.823124336 \\
\hline AlchemyAPI_Language_Detection & 22 & 0.847796585 \\
\hline AlchemyAPI_Concept_Tagging & 22 & 0.816021162 \\
\hline AlchemyAPI_Entity_Extraction & 22 & 0.840551453 \\
\hline AlchemyAPI_Keyword_Extraction & 22 & 0.849881544 \\
\hline Idilia_Language_Graph & 22 & 0.8583242 \\
\hline Proxem_Ontology-Based_Topic_Detection & 22 & 0.859111736 \\
\hline Allied_Wallet & 24 & 0.858712305 \\
\hline Bitcoin_Payment & 24 & 0.952021841 \\
\hline Darkcoin_Payment & 24 & 0.878852313 \\
\hline Dogecoin_Payment & 24 & 0.952021841 \\
\hline DoneCard & 24 & 0.853072674 \\
\hline Feathercoin_Payment & 24 & 0.927631998 \\
\hline Openpay & 24 & 0.814720653 \\
\hline Potcoin_Payment & 24 & 0.903242155 \\
\hline Reddcoin_Payment & 24 & 0.903242155 \\
\hline Speedcoin_Payment & 24 & 0.927631998 \\
\hline Vericoin_Payment & 24 & 0.952021841 \\
\hline Vertcoin_Payment & 24 & 0.952021841 \\
\hline BankVal_International & 26 & 0.912829418 \\
\hline Data8_Postcode_Lookup & 26 & 0.805762742 \\
\hline FraudLabs_MailBox_Validator & 26 & 0.828836444 \\
\hline FullContact_Disposable_Email & 26 & 0.801036446 \\
\hline WebKnox_Jokes & 28 & 0.846358101 \\
\hline WebKnox_Proxies & 28 & 0.861742556 \\
\hline WebKnox_Question-Answering & 28 & 0.909291426 \\
\hline WebKnox_Words & 28 & 0.800204733 \\
\hline Center_for_Biological_Sequence_Analysis & 29 & 0.863027226 \\
\hline ChromA & 29 & 0.840576147 \\
\hline CSC_PairsDB & 29 & 0.821943437 \\
\hline EBI_ClustalW2_Phylogeny & 29 & 0.912186923 \\
\hline EBI_Lalign & 29 & 0.893370288 \\
\hline EBI_NCBI_BLAST & 29 & 0.893370288 \\
\hline EBI_T-Coffee & 29 & 0.805229939 \\
\hline EMBOSS_Matcher & 29 & 0.879223564 \\
\hline EMBOSS_Needle & 29 & 0.917065336 \\
\hline
\end{tabular}




\begin{tabular}{|l|r|r|} 
EMBOSS_Stretcher & 29 & 0.944842593 \\
\hline EMBOSS_Water & 29 & 0.861510821 \\
\hline IBCP_gBIO & 29 & 0.865253703 \\
\hline MyHits & 29 & 0.906698721 \\
\hline Nuclear_Protein_Database & 29 & 0.846523068 \\
\hline Phylogenetic_Footprinting & 29 & 0.808247134 \\
\hline PlantTFDB & 29 & 0.822542574 \\
\hline Rose & 29 & 0.857554063 \\
\hline TheBus & 31 & 0.808559935 \\
\hline Trafiklab_SL_Real_Time_3 & 31 & 0.833959477 \\
\hline Trafiklab_SL_Trip_Planner_2 & 31 & 0.818865193 \\
\hline NAOqi_DCM & 32 & 0.815522556 \\
\hline Pemilu_FAQ_Presiden & 32 & 0.914829773 \\
\hline Atlassian_Stash_Audit_Rest & 34 & 0.825186823 \\
\hline Atlassian_Stash_Branch_Permissions_Rest & 34 & 0.916873388 \\
\hline Atlassian_Stash_Branch_Utilities_REST & 34 & 0.887533856 \\
\hline Atlassian_Stash_Build_Integration_Rest & 34 & 0.916873388 \\
\hline Atlassian_Stash_Comment_Likes_REST & 34 & 0.929786975 \\
\hline Atlassian_Stash_Core_Rest & 34 & 0.833524874 \\
\hline Atlassian_Stash_JIRA_Integration & 34 & 0.918012099 \\
\hline Atlassian_Stash_SSH_Rest & 34 & 0.897626884 \\
\hline Gupshup_HipChat_Bot & 34 & 0.889440832 \\
\hline Gupshup_InApp_Bot & 34 & 0.926476944 \\
\hline Gupshup_Slack_Bot & 34 & 0.926476944 \\
\hline Gupshup_Teamchat_Bot & 34 & 0.889440832 \\
\hline Gupshup_Twitter_Bot & 34 & 0.815368608 \\
\hline Gupshup_WeChat_Bot & 34 & 0.926476944 \\
\hline ConvertAPI_Email2Pdf & 35 & 0.811722496 \\
\hline ConvertAPI_Excel2Pdf & 35 & 0.923939914 \\
\hline ConvertAPI_Image2Pdf & 35 & 0.83426992 \\
\hline ConvertAPI_Jnt2Pdf & 35 & 0.917601692 \\
\hline ConvertAPI_Lotus2Pdf & 35 & 0.869307724 \\
\hline ConvertAPI_OpenOffice2Pdf & 35 & 0.942166011 \\
\hline ConvertAPI_Pdf2Image & 35 & 0.936569295 \\
\hline ConvertAPI_Pdf2PowerPoint & 0.936569295 \\
\hline ConvertAPI_PostScript2Pdf & 0.9152475 \\
\hline ConvertAPI_PowerPoint2Pdf & 35 & 0.886676622 \\
\hline ConvertAPI_Project2Pdf & \\
\hline ConvertAPI_Publisher2Pdf & 3543648 \\
\hline
\end{tabular}




\begin{tabular}{|c|c|c|}
\hline ConvertAPI_RichText2Pdf & 35 & 0.9152475 \\
\hline ConvertAPI_Snp2Pdf & 35 & 0.862047178 \\
\hline ConvertAPI_Text2Pdf & 35 & 0.886676622 \\
\hline ConvertAPI_Visio2Pdf & 35 & 0.943818378 \\
\hline 50BTC & 36 & 0.838397146 \\
\hline 796_Xchange & 36 & 0.850517155 \\
\hline Bitcurex & 36 & 0.861685519 \\
\hline BitKonan & 36 & 0.84041386 \\
\hline BitMarket & 36 & 0.906895256 \\
\hline bitNZ & 36 & 0.807119854 \\
\hline BTC_to_X & 36 & 0.862781998 \\
\hline Bter & 36 & 0.906895256 \\
\hline CaptchaCoin & 36 & 0.920825552 \\
\hline Coingaia_Trade & 36 & 0.814435129 \\
\hline CoinRelay & 36 & 0.84082771 \\
\hline Coins-E & 36 & 0.846949562 \\
\hline Comkort & 36 & 0.860946027 \\
\hline Cryptank & 36 & 0.854163018 \\
\hline Crypto-Trade & 36 & 0.886833221 \\
\hline Cryptonator & 36 & 0.819123063 \\
\hline emeBTC & 36 & 0.853549534 \\
\hline EtherScan_General_Stats & 36 & 0.875861213 \\
\hline EtherScan_Geth_Proxy & 36 & 0.819123063 \\
\hline Evergreen & 36 & 0.806131004 \\
\hline Feathercoin & 36 & 0.838397146 \\
\hline ICBIT_Trading & 36 & 0.805383333 \\
\hline itBit_Trading & 36 & 0.800517998 \\
\hline Litecoin-invest & 36 & 0.886304631 \\
\hline Poloniex & 36 & 0.870014632 \\
\hline Tagbond & 36 & 0.919476749 \\
\hline TheRockTrading & 36 & 0.870014632 \\
\hline Twenty15Coin & 36 & 0.810016989 \\
\hline Vicurex & 36 & 0.882960716 \\
\hline VirCurEx & 36 & 0.857635272 \\
\hline 247-BulkSMS & 39 & 0.819388156 \\
\hline $24 \times 7 S M S$ & 39 & 0.869467773 \\
\hline 5star_SMS & 39 & 0.9183226 \\
\hline AT\&T_SMS & 39 & 0.824700163 \\
\hline BulkSMSVilla & 39 & 0.936765483 \\
\hline
\end{tabular}




\begin{tabular}{|c|c|c|}
\hline Clickatell_Connect & 39 & 0.830939648 \\
\hline Clickatell_FTP & 39 & 0.893567127 \\
\hline Clickatell_SMTP & 39 & 0.815552069 \\
\hline Club080 & 39 & 0.834659961 \\
\hline ComposeSMS & 39 & 0.861390251 \\
\hline eStore_Bulk_SMS & 39 & 0.934657713 \\
\hline Everlanka_Advertising & 39 & 0.805849226 \\
\hline excelngSMS & 39 & 0.876657105 \\
\hline FDLINK_SMS & 39 & 0.894277094 \\
\hline Freesms & 39 & 0.93874152 \\
\hline GenesisBulkSMS & 39 & 0.890361529 \\
\hline GiftedSMS & 39 & 0.881590687 \\
\hline GlobalBulkSMS & 39 & 0.807736032 \\
\hline GSMA_OneAPI_MMS & 39 & 0.812071964 \\
\hline Intelli_Messaging & 39 & 0.850994696 \\
\hline LinkmySMS & 39 & 0.872250758 \\
\hline Mayorfirst_SMS & 39 & 0.801327377 \\
\hline MessageBird_Voice_Messaging & 39 & 0.801327377 \\
\hline milkySMS & 39 & 0.91089761 \\
\hline MireZone_SMS & 39 & 0.837087222 \\
\hline Mobyt_SMS & 39 & 0.942344889 \\
\hline MyGateSMS & 39 & 0.9405978 \\
\hline NetBulkSMS & 39 & 0.886144774 \\
\hline OneAPI4SMS & 39 & 0.828958713 \\
\hline OVERTURES_SMS & 39 & 0.8418135 \\
\hline Pearl_SMS & 39 & 0.828958713 \\
\hline QUICK_SMS & 39 & 0.849690567 \\
\hline Recharge_Blast & 39 & 0.858563668 \\
\hline RedSMS & 39 & 0.869467773 \\
\hline SFW_SMS & 39 & 0.934657713 \\
\hline Skycore & 39 & 0.854111345 \\
\hline SMSBump & 39 & 0.886144774 \\
\hline SmsDial & 39 & 0.915421268 \\
\hline SMSWebGh & 39 & 0.889993376 \\
\hline Softnet_SMS & 39 & 0.816289305 \\
\hline SplendidSMS & 39 & 0.93874152 \\
\hline SurfBulkSMS & 39 & 0.841591767 \\
\hline Telstra_SMS & 39 & 0.897922627 \\
\hline TripleClick_SMS & 39 & 0.897922627 \\
\hline
\end{tabular}




\begin{tabular}{|l|r|r|} 
Universal_SMS_Advertising & 39 & 0.8418135 \\
\hline Utexta_Bulk_SMS & 39 & 0.801592846 \\
\hline Vectramind & 39 & 0.813744155 \\
\hline Vizz_Media & 39 & 0.801137756 \\
\hline Vodacom_Bulk_SMS_Messaging & 39 & 0.897922627 \\
\hline way2easy & 39 & 0.844993496 \\
\hline
\end{tabular}

\section{A.5 Model interpretation and analysis}

Topic1: \{property real affiliate estate search listings properties rental website program\}

The topic contains words that describe real estate, properties, listings and searching. Example APIs descriptions with this topic are Tripping, Rio Branco Real Estate, and Zillow Home Valuations. Tripping is a vacation rental search utility that allows users to search for short-term vacation rental homes in multiple locations at once. The Tripping API gives developers a programmatic interface to the same utility allowing them to search for properties, or retrieve information about a given listing. Rio Branco Real Estate is a Brazilian Real Estate company. Its API gives users the ability to search the site for available properties. Zillow Home Valuations is a real estate network where member sites can each be a real estate portal. The API offers developers the ability to search for home valuation results, charts, comparable houses, market trend charts, property level information, city and neighborhood market statistics, and mortgage rates and monthly payment estimates.

The three APIs allow developers to create applications that can access real estate data without actually collecting it themselves. However, Zillow Home take it a step further by allowing developers to become real estate portals themselves. This makes the purpose 
of APIs described by topic 1 is to search for Real Estate Information. The benefits to developers is access to data and information they previously could not have access to, and that is expensive to get.

Topic 2: \{social content twitter news media share facebook access data information\}

The topic contains words that describe access to social media data and information as well as sharing of content. Examples of API descriptions mainly composed from this topic include Seesmic and ShareThis Webshare.

Seesmic is social media management tool that was acquired by Hootsuite in $2012^{5}$. The description of the Seesmic API says that it allows its consumers to view who a user follows, and get information about the content the user posts. ShareThis is a tool that allows users to share to multiple social media sites at once. Its WebShare API allows developers to integrate ShareThis's functionality into their apps so that they are able to create applications that can connect to multiple social media sites at the same time.

The main purpose of APIs described by these documents is provide developers with the ability to share content on multiple social media sites at the same time. The main benefits to the developers is they do not have to go through the trouble of implementing integrations to multiple social media sites at the same time. This reduces their implementation cost and increases their connectivity.

Topic 3: \{domain shipping delivery service services domains tracking mail dns

${ }^{5}$ https://www.crunchbase.com/organization/seesmic\#/entity 
customers\}

Topic 3 descibes shipping and delivery tracking services. The topic also contains the word "domain" and "dns", but the main theme of the topic is shipping services. This is evident by the API descriptions that are mostly composed of topic 3 which include Bring Easy Return Service, Bring Tracking, and 6 USPS APIs.

Bring Cargo is a Norwegian logistics and transportation services company. Their API allows developers to integrate into their applications Bring's services. Thereby enabling the developers' customers to get shipping information directly. USPS is also a major US postal services company. Their suite of APIs can be used by developers to integrate into their applications the ability to track packages, get information about packages, perform scheduling tasks, and more.

APIs described by this topic allow developers to integrate shipping and delivery services provided by major logistics and postal services companies into their applications. The benefit these APIs gives to developers is the ability to provide shipping and delivery services without being a shipping and delivery company.

Topic 4: \{github software development application applications providers range wide integrate repository\}

This topic is very specific and describes GitHub APIs and APIs that are similar to Github. The APIs allow developers to integrate software repository management functionality into their applications. It also allows the programmatic management of software repositories for the purposes of automation. The main benefit to API consumers is to 
use software repository management functionality without building infrastructure.

Topic 5: \{mobile devices app apps device applications data android platform application\}

Topic 5 is centered around mobile applications and platforms. Three API description examples give more insight into the topic: AppLamp Wifi LED, Erizo, and Prowl.

AppLamp Wifi LED API allows customers of the AppLamp to write their own applications to control the Wifi LED lamp. Erizo API allows developers to integrate their own scripts and applications to use the videoconferencing technology provided by Lynckia's Licode WebRTC platform. Prowl API allows users to write scripts for Growl's iPhone client application.

The examples show that the main purpose of APIs described by this topic is to integrate mobile applications with the main platform provided by the service provider. The main benefit to developers is extending existing applications or building their own allowing them to personalize and customize the use of the products.

Topic 6: \{cloud data storage service server access servers monitoring amazon management

Topic 6 describes access to, monitoring and management of cloud services. Example APIs for this topic include Google Cloud Storage, IlandCloud, and Rackspace Cloud Orchestration. The main purpose of the APIs as described in the example documents is to allow programmatic access to the cloud infrastructure services provided by the service provider. The benefit to developers is allowing them to access cloud resources without acquiring the infrastructure in house. 
Topic 10: \{music events event information movie movies shows radio database artists\}

This topic describes databases for media information such as music, movie, events, artists, and radio shows. Two API description examples for this topic are Songsterr, and Ticketmaster International Discovery. Songsterr allows developers to search for songs in their database. Ticketmaster API allows developers to programmatically access Ticketmaster's database of tickets, concerts, sporting events, plays, fairs, and more.

The main purpose of APIs described by this topic is to give programmatic access and searching capability to databases owned by companies such an online ticket retailer. The benefits to developers is gaining access to information they could not get access to previously.

Topic 11: \{data ondemand barchart vehicle analysis number $\mathrm{xml}$ car request index\}

This topic focus on access of vehicle information. Examples in this topic include Australia Car Registration API, Car Registration in Portugal, and Finnish Vehicle Registration Authority. The main purpose of APIs described by these APIs is to provide developers access to car registration information from multiple countries. The main benefit to developers is having access to data they could not get access to before as well as querying multiple sources of data at once.

Topic 12: data travel booking market stock financial access information flight hotel\}

Topic 12 is the topic that has two themes. The two themes in this topic are travel and financial information. From the words in the topic, the travel theme revolves around 
booking and specifies flights and hotels as entities. The financial theme focuses on market, stock, and access.

Examples of travel API descriptions in this topic include the suite of Hotelbeds Aptitude APIs. Examples of the financial APIs include Mergent Company Fundamentals, and Xignite suite of APIs.

Hotelbeds Aptitude API provides developers with access to Hotelbeds's database of hotels. The database is Hotelbeds's main product provided to B2B partners. The value to API consumers in this case is getting access to data that is hard to collect and that they do not have access to before.

Mergent Company Fundamental APIs and Xignite's suite of APIs provide financial information such as historical financial statements of publicaly traded companies, information on executives, currency conversion rates, and current economic events. Mergent's APIs focuses on crude data collected over history, while Xignite's APIs provide access to processed data such as market statistics and trends. Xignite's APIs also provide access to real-time financial data.

Both financial APIs have the purpose of giving developers access to financial data gathered, aggregated, and analyzed by the provider. The main benefit to the developers is having access to hard to collect data.

Topic 13: \{health medical information data healthcare care insurance providers fitness drug\} 
Topic 13 describes the general field of health care data. Examples of APIs in this topic are Rx Aggregation API, Doctoralia, and GETHealth API. Rx Aggregation API and Doctoralia API allows developers to access the providers aggregated and collected databases of prescriptions and healthcare professionals. GETHealth API allows developers to integrate their Applications with the myriad of wearable devices such as Fitbit, Jawbone and Lifefitness. The main benefit from both types of APIs is allowing developers to access multiple resources at once such as aggregated data, or multivendor wearable devices.

Topic 14: \{marketing email campaigns platform analytics customers social customer advertising media\}

Topic 14 describes marketing and advertising analytics. Examples of API descriptions in this topic are AdRout and TM Forum APIs. AdRout API gives developers access to traffic quality scoring and attribution metrics of ads provided by AdRout. The main service allows users to optimize and improve their marketing budget, and the API allows users to retrieve continuous reports on their campaigns. The TM Forum suite of APIs give developers access to the TM Forum's platform. TM Forum provides its members the ability to co-create, prototype, deliver, and monetize digital services for their customers. Their APIs provide developers the ability to manage SLA lifecycle, manage customers, and manage performance over standardized interfaces. The value to developers using these types of APIs is getting access to functionality that is costly to develop in terms of infrastructure and know how. 
Topic 15: data weather information energy access time conditions location national solar\}

This topic describes weather and energy related information. Examples of API descriptions in this topic include CDYNE Weather API, NCEP Forecast API, and NSIDC API. The three APIs provide developers with access to weather related data such as Earth's cryosphere, frozen areas like the polar ice caps, current and forecasted weather information, wind speed and direction, barometric pressure, and relative humidity. The main benefit to developers is getting access to hard to collect data that requires large infrastructure investments to gather and aggregate.

Topic 17: \{location map maps information data code address locations service mapping\} This topic is describing mapping and location based information and services. Examples of API descriptions in this topic are Geobytes Get City Details and Map Data Services QuickMap API. Geobytes Get City Details API provides developers with the ability to query city attributes for a location given as n IP address or latitude/longitude coordinates. The main benefit for developers using this API is the ability to locate IP Addresses. Map Data Services QuickMap APIs on the other hand provide mapping functionality such as directions between locations and definition of lines and polygons within mapped regions. The main benefit to developers is reducing their development cost by providing them with functionality that is hard to develop in terms of know-how

Topic 18: \{product products information online shopping deals search access price 
store\}

This topic describes shopping and product related information such as pricing and deals. An example API description for this topic is Macy's Catalog and Store Services API. The API allows developers to access different types of content provided by Macy's. Developers can get access to product catalogs, store events, promotions and user profiles. The main benefit provided by this API is allowing developers access to data that is costly to gather in an automated way. While developers can get access to most of this information by things like scraping and web crawling, the API standardizes the task and makes it easier for developers. Another example of an API in this topic is Macy's Shopping Bag Services. This API gives developers access to Macy's shopping bag and the services the shopping bag provides such as adding items, deleting items, or updating item quantities. The benefit this API gives to developers is the ability to build applications based on Macy's retail services. Applications will only allow the end users to access services provided by Macy's making the developers a part of Macy's service system acting as affiliates or resellers.

Topic 19: \{voice call calls phone service applications services chat businesses integrate\}

This topic describes the integration of voice calls and chat services into applications. Examples of API descriptions in this topic include Nexmo VoiceXML and Plivo call. These APIs give developers the ability to integrate functionality such as calling, text to speech conversion, conference calling, call tracking, and call recording. The main benefit to developers is the ability to integrate functionality that is hard to develop because of the 
lack of know-how or the time needed for development.

Topic 20: \{game games data information sports players live player statistics scores\}

This topic describes access to game and sports statistics and information. Example API descriptions in this topic include Halo Profile API, Roanuz Cricket API, and SportRadar NHL API. The Halo Profile API gives developers access to player profile information for the game Halo. Both Roanuz Cricket API and SportRadar NHL API give developers access to real-time game stats and metrics for the respective sports intended to be used for betting applications. The main benefit to developers is getting access to hard to collect and aggregate sports data.

Topic 21: \{data information open access government state public u.s tax states\}

This topic focuses on open data and specifically government data. Some of the example API descriptions in this topic are CKAN API, It's Your Parliament EU Data, and Open State Project API. The main purpose of these APIs is to provide modeling and search capabilities to open data initiatives. The CKAN suite of API allows service providers to model their data and allow developers to search for the data. While It's Your Parliament EU Data API, and Open State Project API give developers the ability to query government data such as parliament records and state legislative information. The benefits of these types of APIs are twofold: they allow data providers to model and open their data in a standardized and consistent way, and they allow developers to access hard to collect and aggregate data. 
Topic 22: \{text language analysis content translation semantic sentiment machine words word\}

This topic describes Natural Language Processing web services such as text analysis, translation, and sentiment analysis. Example API descriptions for this topic include the suite of Alchemy APIs, Idilia Language Graph API, and Proxem Ontology Based Topic Detection API. The purpose of these APIs is to give access to a range of Natural Language Processing functionality such as keyword extraction, predict language sentiment, and extract relevant topics from text based on relevant categories. The benefits these APIs provide to developers is the ability to do complicated NLP tasks without the need to develop the algorithms or invest in the infrastructure themselves.

Topic 24: \{payment payments online card credit processing transactions account transaction cards\}

This topic describes payment transactions processing. Examples of API descriptions in this topic include Allied Wallet API, Bitcoin Payment, and Openpay. These purpose of these APIs is to provide payment processing functionality for digital and real currencies. The benefit to developers using this API is getting the ability to process payments without having to deal with banking systems, compliance, fraud, and security.

Topic 26: \{address data email addresses number service validation numbers phone verification\}

This topic describes email address and phone number validation services. Example API descriptions in this topic include BankVal International API, Data8 Postcode Lookup API, 
and FraudLabs MailBox Validator. These APIs allow developers to validate email addresses, validate routing numbers, and validate postcodes. The main benefits to developers is having access to functionality that is hard to implement due to the high cost of gathering the necessary data and the lack of know-how.

Topic 27: \{video videos content photos media photo audio share sharing upload\}

This topic describes content sharing and uploading services, and specifically video, photos, and audio. Examples of API descriptions in this topic include SlideShare Player API, Joomeo API, and Zenfolio API. These APIs allow developers to build applications that use functionality such as photo uploading, slide player, and photo editing. The main benefit to developers is the ability to integrate functionality that is hard to develop into their applications.

Topic 29: \{data sequence database protein sequences analysis biological soap research genes\}

This topic describes protein sequencing and genetic analysis functionality. API descriptions in this topic include Center for Biological Sequence Analysis API, ChromA API, and European Bioinformatics Institute API. The purpose of these APIs is to provide a programmatic interface to functionality such as protein sequencing, protein sequence analysis, alignment of mass spectrometry images for comparison, and DNA sequencing. The main benefit to developers is having access to very complex machine learning algorithms that are hard to develop due to lack of know-how and the high cost of needed infrastructure. 
Topic 31: \{data information traffic transit routes times public service bus time\}

This topic describes access to transit routes and traffic information. API descriptions in this topic include TheBus API and Trafiklab suite of APIs. The purpose of these APIs is to provide access to real-time bus, subway, and train information such as location and schedule. These APIs also provide travel planning functionality. The benefit for developers using these APIs is having access to hard to gather information that only a city can provide.

Topic 32: \{job learning students jobs information university student school system education\}

Topic 32 describes access to information related to jobs, learning, and education. However, top examples of API descriptions for topic 32 are NAOqi DCM and Pemilu FAQ Presiden. Both are not related to the words in the topic. The first example is of a robotics API, while the second example is of open government elections data API for Indonesia. Other examples do include school information and data, as well as open data initiatives from school districts. Due to the inconsistency among examples this topic was excluded.

Topic 34: \{project rest bot bots platform tools life projects goals management

This topic describes functionality of project management tools and bots. Examples of APIs in this topic include the suite of Atlassian APIs and the suite of Gupshup APIs. Atlassian products provide a wide array of project management and collaboration functionality. Their APIs provide programmatic access to their functionality. While 
Gupshup suite of APIs provide access to Gupshup bots for chatting and sms. Both providers focus on workplace tools and applications such as project management, collaboration and chatting. The main purpose of the APIs is to enable the users of the products to customize, and integrate the products with other applications. The main benefit these APIs provide is interoperability and personalization of the main service provided by the vendors.

Topic 35: \{images image files file pdf documents upload recognition document conversion\}

This topic describes file conversion functionality. The top example of an API description for this topic is ConvertAPI. ConvertAPI allows developers to perform file format conversions between multiple file formats. The main benefits to the developers is access to hard to develop functionality in terms of know-how and time required.

Topic 36: \{bitcoin exchange trading service account trade currency calls orders information\}

This topic describes cryptocurrency information and functionality. Example API descriptions in this topic include 50BTC API, BitMarket API, and Bitcurex API. These APIs allow developers to perform cryptocurrency related tasks such as mining bitcoin, query exchange rate information and market statistics, and perform trading transactions like purchasing, holding, and selling bitcoins. The main benefit to developers is the ability to have access to hard to gather data and hard to develop functionality.

Topic 39: \{sms messages send messaging text mobile message bulk sending service $\}$ 
This topic describes sms messaging functionality. Examples of API descriptions in this topic include 24X7SMS, 5Star SMS, and BulkSMSVilla. These APIs provide developers the ability to send single or bulk sms messages to multiple countries and mobile providers around the world. The main benefit to developers is having connectivity to multiple mobile network operators at once, reducing the cost of connectivity and integration. 